\title{
The nature of ultraviolet spectra of AG Pegasi and other symbiotic stars: locations, origins, and excitation mechanisms of emission lines ${ }^{\star}$
}

\author{
M. Eriksson ${ }^{1,2}$, S. Johansson ${ }^{2}$, and G. M. Wahlgren ${ }^{2}$ \\ 1 University College of Kalmar, 39182 Kalmar, Sweden \\ 2 Atomic Astrophysics, Lund Observatory, Lund University, Box 43, 22100 Lund, Sweden
}

Received 10 May 2005 / Accepted 4 December 2005

\section{ABSTRACT}

\begin{abstract}
A detailed study of ultraviolet spectra of the symbiotic star AG Peg has been undertaken to derive the atomic excitation mechanisms and origin of formation for the lines common in symbiotic systems. More than 600 emission lines are observed in spectra from IUE, HST and FUSE of which 585 are identified. Population mechanisms and origin of formation are given for a majority of those lines. Based on the understanding of the AG Peg spectra IUE data of 19 additional symbiotic stars are investigated and differences and similarities of their spectra are discussed. Fe II fluorescence lines pumped by strong emission lines between 1000 and $2000 \AA$ are observed in 13 of these systems. Some of the symbiotic systems belonging to the subclass symbiotic novae have more than $100 \mathrm{Fe}$ II fluorescence lines in the ultraviolet wavelength region. Forbidden lines are detected for 13 of the stars, mostly from highly-ionized spectra such as $\mathrm{Ar} \mathrm{V,} \mathrm{Ne} \mathrm{V} \mathrm{and} \mathrm{Mg} \mathrm{V}$. Further, [Mg VI] and [Mg VII] lines are observed in a symbiotic star (AG Dra) for the first time. Five of the symbiotic stars have broad white-dwarf wind profiles $\left(F W H M>400 \mathrm{~km} \mathrm{~s}^{-1}\right)$ for a few lines in their spectra. The stars with no such broad lines can be divided into two similarly sized groups, one where all lines have $F W H M$ less than $70 \mathrm{~km} \mathrm{~s}^{-1}$ and the other where one, a few or all of the broad $\left(F W H M>400 \mathrm{~km} \mathrm{~s}^{-1}\right)$ lines of AG Peg have an enhanced broad wing $\left(110-140 \mathrm{~km} \mathrm{~s}^{-1}\right)$.
\end{abstract}

Key words. atomic processes - line: formation - stars: binaries: symbiotic - ultraviolet: stars

\section{Introduction}

From numerous recordings with the IUE satellite during 1978 to 1995 symbiotic stars are today known to be interacting binaries consisting of a white dwarf and a red giant with orbital periods of typically a few years. Symbiotic stars have composite spectra, an M-star continuum dominating at red and infrared wavelengths, a nebula continuum at ultraviolet and optical wavelengths, a rising continuum toward the far ultraviolet from the presence of a hot component and numerous strong emission lines throughout the spectrum indicating large plasma regions within the systems.

AG Peg is a symbiotic system consisting of a white dwarf and a red giant orbiting each other with a period of $812.3 \pm 6.3$ days (Kenyon et al. 1993). The luminosity of the white dwarf decreased by a factor of $\sim 4$ during 1984-1997 (Kenyon et al. 2001). This decline can be understood as a decrease of its radius by a factor of $\sim 2$ under constant temperature (Altamore \& Cassatella 1997; Mürset \& Nussbaumer 1994) or as an increase in the temperature of the white dwarf Schmutz 1996, which would imply a even larger decrease of its radius.

* Full Table 13 and Tables $14-16$ are only available in electronic form at http://www. edpsciences.org
Between the two stars there is a region where the fast wind $\left(v=\sim 900 \mathrm{~km} \mathrm{~s}^{-1}\right)$ (Nussbaumer et al. 1995) from the white dwarf collides with the slow wind $\left(v=\sim 60 \mathrm{~km} \mathrm{~s}^{-1}\right)$ (Eriksson et al. 2004) from the red giant (Mürset et al. 1995). More recent and detailed ideas are discussed with respect to the wind structure concerning shock fronts from the wind collision region (Contini 2003) and the possibility of bipolar outflow (Yoo et al. 2002).

AG Peg belongs to a small subclass of symbiotic stars called symbiotic novae that have undergone nova events when the luminosity has increased by three to four magnitudes. Ultraviolet region line lists are available for two symbiotic novae, RR Tel (Penston et al. 1983) and V1016 Cyg (Nussbaumer \& Schild 1981). Both of these systems have spectra dominated by allowed transitions from one to three times ionized elements, but also forbidden lines from more highly ionized elements have an impact on the spectrum. V1016 Cyg erupted in 1964 and RR Tel in 1944, while AG Peg erupted at least 150 years ago. An interesting open question is whether the decline of the UV flux in AG Peg during the 1980 s is a natural evolutionary stage of symbiotic novae and whether, subsequently, RR Tel and V1016 Cyg will undergo a similar spectrum evolution in the future. A time analysis of the AG Peg spectrum can therefore give insights into what happens at the end of nova eruptions in symbiotic stars. 
During the last 25 years the emission lines in AG Peg have been used for various diagnostics to measure parameters such as electron density (Keyes \& Plavec 1980; Penston \& Allen 1985) and temperature (Kenyon \& Webbink 1984; Altamore \& Cassatella 1997). By careful analysis of the spectra it is possible to categorize the emission lines in terms of population processes and line profiles. It is important to understand the origins of the emission lines as well as the processes that populate the corresponding upper levels when using them in any analysis. Here we explain the appearance of most of the emission lines formed at UV wavelengths in AG Peg. The main goal is to obtain an enhanced understanding of the emission lines, which would be helpful for anyone who wants to use emission lines as a diagnostic tool for symbiotic stars or related novae-like environments. Furthermore, the spectral investigation gives insight into how the UV spectum has evolved during the period 1978-1995.

Symbiotic stars are categorized in terms of stellar (S) and dusty (D) types based on their appearence at IR wavelengths (Allen 1982). The S-types have typical orbital periods of a few years and the cooler component consists of a solar-mass star on the red giant branch, while the D-types have orbital periods mostly in excess of 20 years and the cool component in those systems is typically a Mira. The small subset of $\mathrm{D}^{\prime}$ type symbiotic stars has a cool star of spectral type G or K rather than M (Belczynski et al. 2000). The hot components are dominantly white dwarfs in both the S and D type systems. However, a few exceptions have the hot component as an accreation disk around a main sequence star (Kenyon \& Garcia 1986).

Beyond the shared basic properties defining the group, the characteristics of symbiotic stars differ significantly. Besides the nova-like outbursts exhibited by the symbiotic novae, other phenomena observed in symbiotic stars are white-dwarf winds (Nussbaumer et al. 1995), recurrentnovae eruptions (Belczynski \& Mikalojewska 1998), jets (Burgarella et al. 1992) and wind collision regions (Mürset et al. 1997).

By applying the understanding of the AG Peg spectrum at UV wavelengths to a set of 19 symbiotic stars we aim to detect differences and similarities among them. A detailed study of the lines showing broad white-dwarf wind lines in AG Peg is done to see how common such winds are in symbiotic systems. Fe II lines caused by photo-exitation by accidental resonance (PAR) are investigated to see whether this phenomenon is unique to a few symbiotic stars (Eriksson et al. 2003; Hartman \& Johansson 2000) or more common among such systems. Also, forbidden lines of highly-ionized ions are analyzed to compare the ionization degree of low-density regions in symbiotic stars.

\section{Data}

The present study utilizes ultraviolet spectral data obtained from three different satellite observatories, spanning over nearly 25 years. The data were extracted from the Multimission Archive at STScI (MAST) in reduced format and are listed in Table 1. The extensive temporal coverage (1978-1995) of the International Ultraviolet Explorer IUE data for AG Peg allows
Table 1. Spectra used for AG Peg.

\begin{tabular}{|c|c|c|}
\hline Instrument & Coverage $(\AA)$ & Spectum identification \\
\hline \multirow[t]{2}{*}{$I U E$ (LWR) } & $1900-3350$ & $02591,06389,07504$ \\
\hline & & $09672,09310,10579$ \\
\hline \multirow[t]{4}{*}{ IUE (LWP) } & $1900-3350$ & 09698, 16684, 19235 \\
\hline & & $21635,24149,24285$ \\
\hline & & $25565,25995,28122$ \\
\hline & & 30936 \\
\hline \multirow[t]{7}{*}{ IUE (SWP) } & 1150-1980 & $02326,02334,06335$ \\
\hline & & 06809, 08760, 10454 \\
\hline & & $13957,15651,29862$ \\
\hline & & $29863,37420,37477$ \\
\hline & & $40149,43006,43007$ \\
\hline & & $46149,47715,50707$ \\
\hline & & 54749,55055 \\
\hline \multirow[t]{7}{*}{$H S T$ (GHRS) } & $1222-1258$ & $\mathrm{z} 27 \mathrm{e} 0206 \mathrm{t}$ \\
\hline & 1354-1389 & $\mathrm{z} 27 \mathrm{e} 0207 \mathrm{n}$ \\
\hline & $1383-1418$ & $\mathrm{z} 27 \mathrm{e} 0208 \mathrm{t}$ \\
\hline & $1468-1503$ & $\mathrm{z} 27 \mathrm{e} 0209 \mathrm{t}$ \\
\hline & $1532-1567$ & z27e020at \\
\hline & $1623-1657$ & $\mathrm{z} 27 \mathrm{e} 020 \mathrm{bn}$ \\
\hline & $1696-1737$ & $\mathrm{z} 27 \mathrm{e} 020 \mathrm{dt}$ \\
\hline FUS E (LWRS) & $920-1190$ & Q1110101 \\
\hline FUS E (MDRS) & $920-1190$ & Q1110103 \\
\hline
\end{tabular}

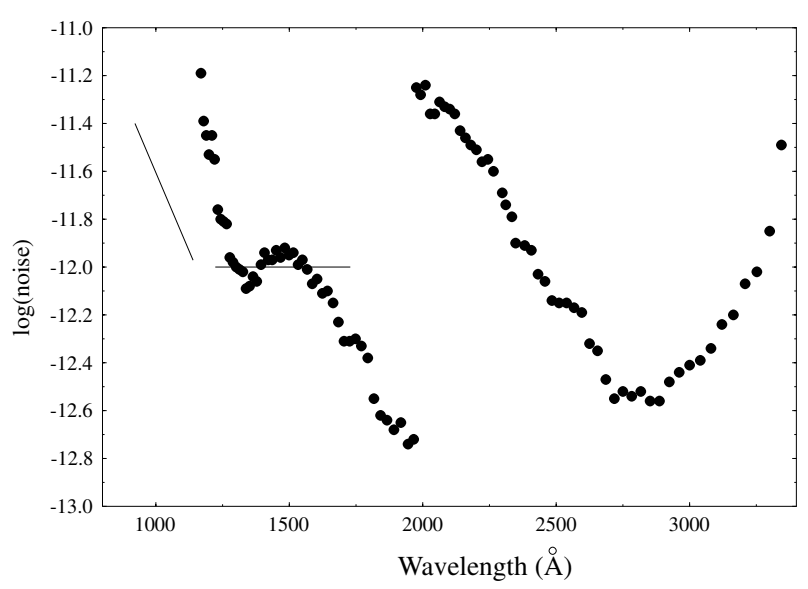

Fig. 1. The dots represent the noise level for each of the different orders in the longest exposed IUE spectra, LWP25995 and SWP47715. The lines represent the noise level in the HST and FUSE spectra used in this work. The $y$-axis gives the value of the logarithm of the noise level measured in erg cm${ }^{-2} \mathrm{~s}^{-1} \AA^{-1}$. The noise level is defined as twice the standard deviation of the pixel intensity from the mean intensity, measured in wavelength regions not affected by spectral lines.

us to follow spectrum developments during these years. The same data were exploited by Eriksson et al. (2004) to study wind affected line profiles for this star. Figure 1 prestents the noise levels for each spectral order for the longest exposures of the IUE high resolution observations. The figure thus provides a guide to the weakest detectable features and possible explanation for the relative strength of observed features. The resolution of IUE spectra depends on several parameters, such as the 
dispersion angle, the reduction routine used and the wavelength being considered. No instrumental profile is deconvolved from the $F W H M$ given in tables in this paper. Imhoff 1984 measured widths of platinum lines, with the $F W H M$ being between 16 and $30 \mathrm{~km} \mathrm{~s}^{-1}$. Therefore, the widths of lines narrower than $40 \mathrm{~km} \mathrm{~s}^{-1}$ in our tables should be treated with caution.

The data recorded by the Goddard High Resolution Spectrograph (GHRS) onboard the Hubble Space Telescope (HST) during 1994 overlap in wavelength with the IUE data but were recorded at a later epoch and for only limited wavelength intervals. The greater sensitivity of the GHRS detectors makes it possible to measure intensities to a greater accuracy than can be done from the $I U E$ spectra.

Two spectra of AG Peg have been recorded by the Far Ultraviolet Spectroscopic Explorer (FUSE) satellite, one in July 2001 and one in June 2003. The inclusion of FUSE spectra in our analysis increases the wavelength range for the detection of emission lines. However, since those spectra were obtained several years after the $I U E$ and $H S T$ data we must be careful when incorporating these data sets into the analysis. The spectrum of AG Peg underwent obvious changes during the lifetime of the IUE (Eriksson et al. 2004) and we might expect that its development would continue in the sense that certain spectral lines would increase or decrease in intensity and width. Without contemporaneous observations in other wavelength regions, emission line intensities from the FUSE data cannot be rigorously correlated with the line intensities at longer wavelengths.

For the symbiotic stars other than AG Peg presented in this analysis only IUE data are used. Since some of the Fe II lines as well as some of the forbidden lines are quite weak, one SWP and one LWP spectrum, observed with large aperture and with long exposure time, were selected for each system. The emission lines associated with the white-dwarf wind in AG Peg were easily saturated in the $I U E$ spectrum, which is why an extra SWP spectrum was retrieved from the MAST archive for some of the symbiotic systems. Table 2 lists the data used for the selected objects.

\section{Excitation and origin of AG Peg emission lines}

The spectral lines can be divided into different categories depending upon their widths and profiles. However, lines that look similar in one spectrum can show a different appearance in later spectra. This means that the time history of a spectral line is also important. Some narrow lines are selectively populated by radiative line excitation and they are classified as fluorescence lines, whereas others originate from excited levels populated by collisions or recombination. We have categorized the spectral lines by their overall appearance in the following way:

1. Broad emission lines $\left(F W H M>500 \mathrm{~km} \mathrm{~s}^{-1}\right)$ in spectra until 1981 that later evolve into narrower $(F W H M<$ $80 \mathrm{~km} \mathrm{~s}^{-1}$ ) emission lines.

2. Emission lines caused by fluorescence.

3. Narrow emission lines from levels excited by collisions.

4. Narrow emission lines from levels populated by recombination.
Table 2. IUE spectra used for the selected symbiotic stars.

\begin{tabular}{llll}
\hline \hline Object & LWP/LWR $^{a}$ & SWP $^{a}$ & SWP $^{b}$ \\
\hline Z And & LWP06225 & 26177 & 26938 \\
EG And & LWP25855 & 56021 & 46879 \\
R Aqr & LWP21998 & 31102 & 40265 \\
T CrB & LWP01536 & 28490 & \\
BF Cyg & LWP15253 & 35843 & 58386 \\
CH Cyg & LWP08631 & 28011 & \\
CI Cyg & LWR10427 & 18602 & 50760 \\
AG Dra & LWP24400 & 15656 & 55373 \\
RW Hya & LWR10227 & 13601 & \\
SY Mus & LWR10829 & 14236 & 16383 \\
AX Per & LWP19332 & 21443 & 06807 \\
RX Pup & LWR10831 & 31285 & 16597 \\
HM Sge & LWP12921 & 40081 & \\
RR Tel & LWR16187 & 20246 & 18371 \\
KX Tra & LWP17871 & 38742 & \\
PU Vul & LWP26780 & 37190 & 49265 \\
V1016 Cyg & LWP04961 & 29830 & 24657 \\
V1329 Cyg & LWP13121 & 24663 & 05615 \\
HBV475 & LWP08277 & 30853 & \\
\hline
\end{tabular}

${ }^{a}$ Spectrum with long exposure times used to detect weak Fe II fluorescence lines and forbidden lines.

${ }^{b}$ Spectrum with short exposure times used when allowed lines are saturated in longer exposed spectra.

5. Narrow emission lines from levels with an uncertain population mechanism.

6. Interstellar absorption lines

7. Stellar absorption lines.

The lines showing a broad structure originate from ions of higher ionization stages, and they are partially or completely formed in the wind of the white dwarf before 1980 (Eriksson et al. 2004). During 1980-1985 the broad contribution from the white-dwarf wind to these lines vanished as a result of the reduced bolometric luminosity (a factor of 2-3) of the white dwarf. Narrow "nebular" lines replaced these broad wind lines in later spectra. Unfortunately, no IUE spectra of AG Peg were recorded during the years 1982 to 1985 , when most of the line profiles must have undergone a rapid change. The narrow lines are most probably formed at further distance from the white dwarf, like in the extended parts of the red giant, such as its wind or upper atmosphere, or in the surrounding nebula. These lines involve mostly permitted lines and intercombination lines, but there are also a few forbidden lines originating from metastable states with lifetimes on the order of seconds. Most of the absorption lines are believed to be formed in the outer parts of the surrounding nebula (Penston \& Allen 1985). In Table 3 we present for each element the number of identified lines observed in the UV spectrum of AG Peg.

\subsection{Broad wind lines}

In $I U E$ spectra recorded before 1986 there are 22 emission lines with a $F W H M$ larger than $600 \mathrm{~km} \mathrm{~s}^{-1}$ (Table 4). These lines originate from abundant elements in higher ionization stages than for the narrow lines, and they are presumably 
Table 3. The distribution of emission lines for AG Peg, according to population processes.

\begin{tabular}{|c|c|c|c|c|c|c|c|c|c|c|c|}
\hline \multirow[t]{2}{*}{ Spec. } & \multicolumn{4}{|c|}{ Process $^{a}$} & \multirow[t]{2}{*}{ Tot } & \multirow[t]{2}{*}{ Spec. } & \multicolumn{4}{|c|}{ Process $^{a}$} & \multirow[t]{2}{*}{ 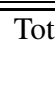 } \\
\hline & fl. & rec. & col. & unk & & & fl. & rec. & col. & unk & \\
\hline H I & & 1 & & & 1 & {$[\mathrm{Ne} \mathrm{V}]$} & & & 3 & & 3 \\
\hline $\mathrm{He} \mathrm{I}$ & & 8 & & & 8 & Mg II & & & 2 & 7 & 9 \\
\hline He II & & 14 & & & 14 & $\mathrm{Mg}$ IV & & 7 & & & 7 \\
\hline C II & & & 5 & 3 & 8 & {$[\mathrm{Mg} \mathrm{V}]$} & & & 3 & & 3 \\
\hline C III & & 8 & & 3 & 11 & $\mathrm{Al} \mathrm{II}]$ & & & 1 & & 1 \\
\hline C III] & & & 2 & & 2 & Al III & & & 2 & & 2 \\
\hline C IV & & & 2 & & 2 & $\mathrm{Si} \mathrm{I}$ & & & & 5 & 5 \\
\hline N I & 1 & & & 4 & 5 & Si II & & & 3 & 5 & 8 \\
\hline $\mathrm{N} \mathrm{I}]$ & & & 4 & & 4 & $\mathrm{Si}$ II] & & & 2 & & 2 \\
\hline N III & & 5 & & 4 & 9 & Si III & & & & 4 & 4 \\
\hline N III] & & & 5 & & 5 & $\mathrm{Si} \mathrm{III}]$ & & & 1 & & 1 \\
\hline N IV & & 1 & & & 1 & Si IV & & & 2 & 5 & 7 \\
\hline N IV] & & & 2 & & 2 & P II & & & 3 & 1 & 4 \\
\hline $\mathrm{N} \mathrm{V}$ & & & 2 & & 2 & P II] & & & 1 & & 1 \\
\hline O I & & & 2 & & 2 & P III & & & 2 & & 2 \\
\hline $\mathrm{O} \mathrm{I}]$ & & & & 2 & 2 & P IV & & & & 1 & 1 \\
\hline O III & 16 & 6 & & & 22 & P IV] & & & 1 & & 1 \\
\hline O III] & 1 & 1 & 3 & 2 & 7 & S I & 1 & & 5 & & 6 \\
\hline [O III] & & & 1 & & 1 & S I] & & & 1 & & 1 \\
\hline O IV & & 3 & & 2 & 5 & S II] & & & 1 & & 1 \\
\hline O IV] & & 5 & & & 5 & S IV] & & & 5 & & 5 \\
\hline $\mathrm{OV}$ & & 3 & & 1 & 4 & S V & & & & 1 & 1 \\
\hline $\mathrm{O}$ V] & & & & 1 & 1 & S V] & & & & 1 & 1 \\
\hline O VI & & & 2 & & 2 & {$[\mathrm{Ar} \mathrm{V}]$} & & & 1 & & 1 \\
\hline $\mathrm{Ne}$ III & & 8 & & & 8 & $\mathrm{Fe} \mathrm{II}^{*}$ & 226 & 3 & 85 & 32 & 346 \\
\hline Ne III] & & 2 & & & 2 & $\mathrm{Fe}$ III & 3 & & & 11 & 14 \\
\hline [Ne III] & & & 1 & & 1 & $\mathrm{Fe} \mathrm{V}$ & & 4 & & & 4 \\
\hline [Ne IV] & & & 4 & & 4 & {$[\mathrm{Fe} \mathrm{VI}]$} & & & 2 & & 2 \\
\hline $\mathrm{Ne}$ V] & & & 2 & & 2 & Co II* & 5 & & & 6 & 11 \\
\hline
\end{tabular}

${ }^{*}$ Spin-forbidden transitions are also included.

${ }^{a} \mathrm{fl}=$ fluorescence; rec $=$ recombination; col = collision; unk = unknown.

formed in the hot white-dwarf wind. An analysis of some of these lines has yielded that the terminal velocity of the whitedwarf wind is $\sim 900 \mathrm{~km} \mathrm{~s}^{-1}$ (Vogel \& Nussbaumer 1994). A few of the lines are ground-state transitions (resonance lines) and show P Cygni structure while others are LS-allowed transitions having an excited lower level. In a few cases the transitions are spin-forbidden (intercombination lines). After 1986, when the broad wind lines were replaced by narrow emission (Fig. 2), it is notable that the six lines with highest peak intensity in the IUE spectra (He II $\lambda 1640$, C IV $\lambda \lambda 1548,1550, \mathrm{~N}$ IV] $\lambda 1486, \mathrm{~N} V \lambda \lambda 1238,1242$ ) had broad line profiles in earlier spectra.

$\mathrm{He}^{+}$has a low ionization energy compared to the other emitting ions detected in the white-dwarf wind, which is why the He II lines can be considered as recombination lines. The He II lines with wavelengths in the range of IUE are Balmer $\alpha$, Balmer $\beta$, and the whole Paschen series except $\mathrm{Pa} \alpha$. He II Balmer $\beta$ is close in wavelength to $\mathrm{H} \mathrm{Ly} \alpha$ and therefore totally absorbed. The He II lines detected in IUE spectra of AG Peg are He II Balmer $\alpha$ and 13 consecutive Pashen lines starting with $\mathrm{Pa} \beta$ and reaching upper levels with quantum numbers $n=5-17$. Only the second to the sixth lines can be detected from the noise before 1986 when the lines were broad.

For a few of the white-dwarf lines (C IV $\lambda \lambda 1548,1558$, N IV]1486, Si IV $\lambda 1402$, Si IV 21393 ) the development into narrow "nebular" lines had already started in 1978, and the structure in the line profile, as shown in Fig. 3, is caused by the narrow line superimposed on the broad line. That the contribution of narrow emission lines occurred earlier for the ions of lower ionisation potential gives an idea into why the emission lines changed origin. As the white dwarf emerged at the end of the nova-like outburst the wind became less dense and more transparent for UV photons. The line intensities from the white-dwarf wind would then decrease at the same time that the material in the extended part of the red-giant atmosphere facing the white dwarf would be subjected to more of the white-dwarf UV radiation. The heated part of the red giant atmosphere became hotter and more ionised, resulting in the strong, narrowemission lines. In recent FUSE observations of AG Peg it is clear that the O VI resonance doublet still has contributions from the white-dwarf wind (Fig. 8). Since the ionisation energy of $\mathrm{O} \mathrm{VI}$ is $114 \mathrm{eV}$ its presence would be expected with a temperature increase in the white-dwarf wind, contrary to what 
Table 4. The broad emission lines in AG Peg spectra.

\begin{tabular}{|c|c|c|c|c|c|}
\hline \multirow[b]{2}{*}{ Line } & \multirow[b]{2}{*}{$\mathrm{IP}^{a}$} & \multicolumn{2}{|c|}{ Before 1986} & \multicolumn{2}{|c|}{ After 1986} \\
\hline & & $F W H M^{b}$ & $\mathrm{Int}^{c}$ & $F W H M^{b}$ & $\operatorname{Int}^{c}$ \\
\hline He II $\lambda 3203$ & 24.6 & 800 & $394^{A}$ & 40 & $550^{B}$ \\
\hline He II $\lambda 2733$ & & 770 & $235^{A}$ & 61 & $326^{B}$ \\
\hline He II $\lambda 2511$ & & 790 & $215^{A}$ & 40 & $243^{B}$ \\
\hline He II $\lambda 2385$ & & 800 & $207^{A}$ & 48 & $300^{C}$ \\
\hline He II $\lambda 2307$ & & 740 & $143^{A}$ & 40 & $235^{C}$ \\
\hline He II $\lambda 1640$ & & 770 & $7370^{D}$ & 66 & $22040^{E}$ \\
\hline C IV $\lambda 1550$ & 47.9 & tcp & tcp & 45 & $24420^{E}$ \\
\hline C IV $\lambda 1548$ & & tcp & tcp & 37 & $44470^{E}$ \\
\hline N IV $\lambda 1718$ & 47.5 & 680 & $1443^{D}$ & $<145$ & $214^{F}$ \\
\hline N IV] $\lambda 1486$ & & tcp & tcp & 32 & $14200^{E}$ \\
\hline N V $\lambda 1242$ & 77.5 & 800 & $4168^{D}$ & 56 & $12570^{E}$ \\
\hline N V $\lambda 1238$ & & 430 & $3529^{D}$ & 70 & $19560^{E}$ \\
\hline O V $\lambda 2781$ & 77.4 & 820 & $54^{A}$ & 38 & $29^{C}$ \\
\hline O V $\lambda 1371$ & & 860 & $424^{G}$ & $<83$ & $473^{F}$ \\
\hline Ne III $\lambda 2678$ & 41.0 & 480 & $128^{A}$ & 37 & $28^{C}$ \\
\hline Si IV $\lambda 1402$ & 33.5 & tcp & tcp & 36 & $2439^{E}$ \\
\hline Si IV $\lambda 1393$ & & tcp & tcp & 37 & $3796^{E}$ \\
\hline S V $\lambda 1502$ & 45.1 & 820 & $358^{G}$ & & \\
\hline S V] $\lambda 1199$ & & 770 & $480^{G}$ & 40 & $1066^{C}$ \\
\hline unid $\lambda 1266$ & & 550 & $858^{G}$ & & \\
\hline unid $\lambda 1260$ & & 700 & $1556^{G}$ & & \\
\hline unid $\lambda 1253$ & & 790 & $1469^{G}$ & & \\
\hline
\end{tabular}

${ }^{a}$ The ionization potential in $\mathrm{eV}$ of the next lower ion. ${ }^{b}$ Given in $\mathrm{km} \mathrm{s}^{-1}$. ${ }^{c}$ Peak intensity in units of $10^{-14} \mathrm{erg} \mathrm{cm}^{-2} \mathrm{~s}^{-1} \AA^{-1}$. The indices on the measured intensities stand for: ${ }^{A}$ As measured in LWR05596, ${ }^{B}$ LWP28122, ${ }^{C}$ LWP25995, ${ }^{D}$ SWP02326, ${ }^{E}$ SWP55055, ${ }^{F}$ SWP47715, ${ }^{G}$ SWP02334. tcp = Two component profile as the spectral line has a narrow emission component superimposed on the broad white dwarf wind profile.
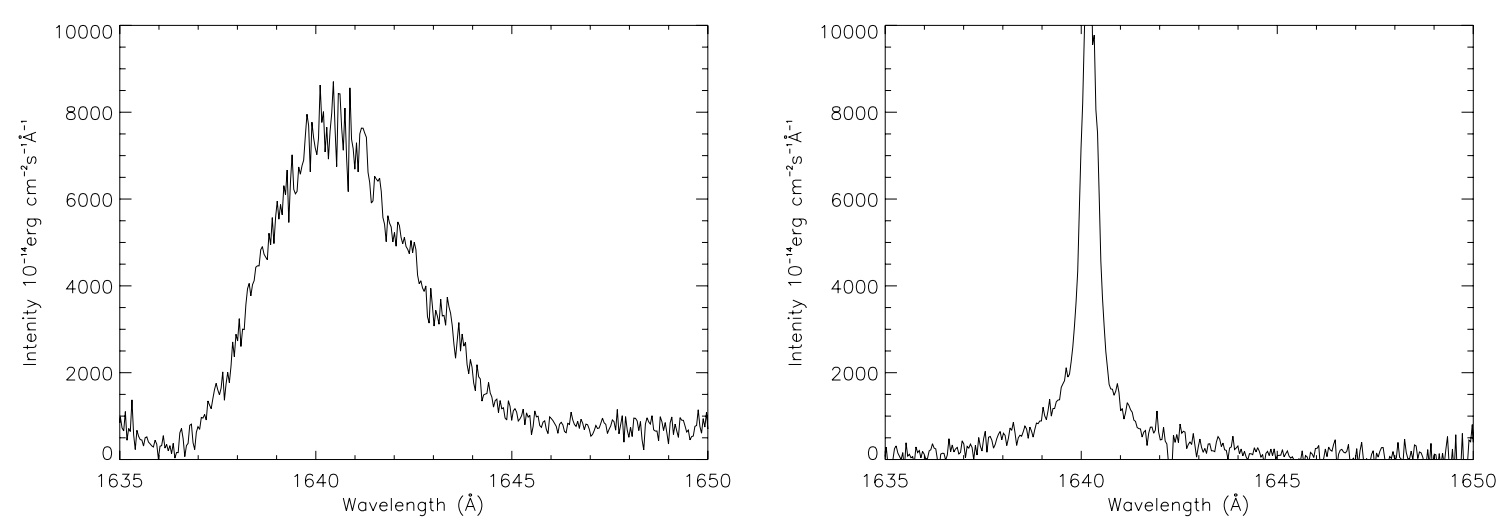

Fig. 2. The development of He II Balmer $\alpha$. The spectrum to the left (SWP02326) was recorded in 1978 and the spectrum to the right (SWP40148) was recorded in 1990. The large change in profile width is related to the change in origin for He II emission between those dates. In 1978 most of the He II emission originated from the white-dwarf wind while in 1990 the emission instead came from the heated part of the extended red-giant atmosphere.

is given by Zanstra determinations (Altamore \& Cassatella 1997).

The O III Bowen lines were also broader than the nebular lines in early IUE spectra. Like the white-dwarf lines discussed earlier the O III Bowen lines also evolved into narrower lines during the 1980s. The reason that they are not included in Table 4 is that they have less than half of the FWHM of the other broad line profiles and are formed in a different way (fluorescence). The Bowen lines are discussed in Sect. 3.3. 

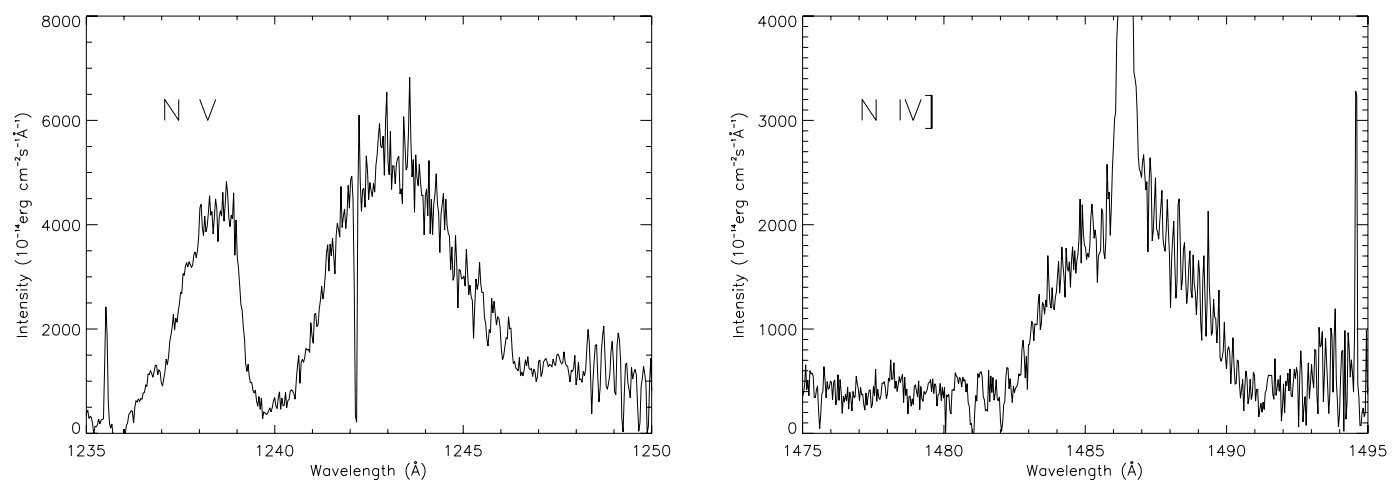

Fig. 3. The IUE spectrum (SWP02334) of AG Peg, recorded in 1978, illustrates the difference in the profiles between lines from ions of ionisation energy near $40 \mathrm{eV}$ and those of higher ionisation energy (around $70 \mathrm{eV}$ ). The N IV] $\lambda 1486$ had a contribution from a "nebular line" already in 1978 while all flux in the N V resonance doublet came from the white-dwarf wind.

\subsection{The "nebular" lines}

A majority of the emission lines observed in $I U E$ spectra of AG Peg have a FWHM between 10 and $50 \mathrm{~km} \mathrm{~s}^{-1}$ and have had the same line profile although changed in intensity between 1978 and 1995. There is a wide range in ionisation energy for the narrow lines, from singly-ionised elements to more highlyionised species such as Mg V, S IV and Fe V. Most of the emission lines correspond to LS-allowed transitions or intercombination lines but there are also a few parity-forbidden lines such as $[\mathrm{Mg} \mathrm{V}] \lambda 2928$.

\subsubsection{Narrow fluorescence lines}

The process of photo-excitation by accidental resonance (PAR) can account for as many as 218 of the 585 identified lines in IUE spectra of AG Peg. The Fe II levels $\mathrm{y}^{4} \mathrm{H}_{11 / 2}$ and $\mathrm{w}^{2} \mathrm{D}_{3 / 2}$ are known to be pumped by C IV $\lambda 1548$ in at least eight symbiotic systems (Johansson 1983; Eriksson et al. 2001). The levels $\left({ }^{5} \mathrm{D}\right) 5 \mathrm{p} \quad{ }^{6} \mathrm{~F}_{9 / 2}$ and $\left({ }^{3} \mathrm{~F}\right) 4 \mathrm{p}{ }^{4} \mathrm{G}_{9 / 2}$ are known to be pumped by $\mathrm{H}$ Ly $\alpha$ in the symbiotic star RR Tel (Johansson \& Jordan 1984; Hartman \& Johansson 2000) and they are involved in laser action in gas condensations of $\eta$ Car (Johansson \& Letokhov 2004). In an analysis of AG Peg (Eriksson et al. 2003) 29 Fe II levels were shown to be populated by the PAR mechanism, and in the present work 11 newly identified pumped channels lead to a total of 40 presumably pumped Fe II levels, of which 22 are confirmed by three or more fluorescence lines (Table 5).

Most of the spectral lines that pump (selectively excite) Fe II are formed in the white-dwarf wind. Since the profiles of those lines change as their origin evolves from being dominated by the white-dwarf wind to the heated part of the redgiant atmosphere (or wind) the emission from the pumped Fe II levels also changes after 1986. Fe II channels that are separated by more than $40 \mathrm{~km} \mathrm{~s}^{-1}$ from their pumping line cannot be pumped by the narrow emission lines and therefore those lines disappeared after 1986 (Fig. 4). However, the Fe II fluorescence lines excited in channels that are close in wavelength to their pumping lines can be pumped by the narrow "nebular" emission lines and they do appear in the spectrum throughout
Table 5. Pumped Fe II channels confirmed by 3 or more fluorescence lines.

\begin{tabular}{lcrr}
\hline \hline Pumping Line & Fe II channel & $\delta \lambda^{a}(\AA)$ & No. $^{b}$ \\
\hline Si III $] \lambda 1892.03$ & $a^{4} \mathrm{P}_{3 / 2}-x^{4} \mathrm{~F}_{5 / 2}$ & 0.15 & 6 \\
Si III] $\lambda 1892.03$ & $a^{4} \mathrm{D}_{7 / 2}-z^{4} \mathrm{G}_{9 / 2}$ & 0.05 & 14 \\
N IV $\lambda 1718.55$ & $a^{6} \mathrm{D}_{3 / 2}-z^{4} \mathrm{G}_{5 / 2}$ & -0.45 & 6 \\
O III] $\lambda 1666.15$ & $a^{6} \mathrm{D}_{7 / 2}-y^{4} \mathrm{P}_{5 / 2}$ & 0.03 & 4 \\
O III] $\lambda 1660.81$ & $a^{4} \mathrm{~F}_{9 / 2}-z^{2} \mathrm{G}_{9 / 2}$ & 0.03 & 5 \\
He II $\lambda 1640.07$ & $a^{4} \mathrm{~F}_{3 / 2}-y^{4} \mathrm{G}_{5 / 2}$ & 0.08 & 4 \\
C IV $\lambda 1548.19$ & $a^{4} \mathrm{~F}_{9 / 2}-y^{4} \mathrm{H}_{11 / 2}$ & 0.01 & 13 \\
C IV $\lambda 1548.19$ & $a^{4} \mathrm{~F}_{7 / 2}-y^{2} \mathrm{D}_{5 / 2}$ & 0.51 & 7 \\
C IV $\lambda 1548.19$ & $a^{4} \mathrm{P}_{1 / 2}-w^{2} \mathrm{D}_{3 / 2}$ & 0.22 & 13 \\
N IV] $\lambda 1486.50$ & $a^{4} \mathrm{G}_{5 / 2}-u^{4} \mathrm{~F}_{3 / 2}$ & -0.03 & 7 \\
O IV] $\lambda 1401.16$ & $a^{6} \mathrm{D}_{5 / 2}-\left({ }^{3} \mathrm{D}\right) 4 \mathrm{p}^{4} \mathrm{P}_{3 / 2}$ & -0.12 & 4 \\
N V $\lambda 1242.78$ & $a^{4} \mathrm{~F}_{5 / 2}-v^{2} \mathrm{G}_{7 / 2}$ & -0.04 & 3 \\
N V $\lambda 1238.80$ & $a^{4} \mathrm{P}_{5 / 2}-\left({ }^{4} \mathrm{P}\right) 4 s 4 \mathrm{p}^{4} \mathrm{P}_{5 / 2}$ & -0.22 & 5 \\
H I $\lambda 1215.67$ & $a^{4} \mathrm{D}_{5 / 2}-\left(b^{3} \mathrm{P}\right) 4 \mathrm{p}^{4} \mathrm{~S}_{3 / 2}$ & 0.31 & 4 \\
H I $\lambda 1215.67$ & $a^{4} \mathrm{D}_{5 / 2}-\left({ }^{5} \mathrm{D}\right) 5 \mathrm{p}^{4} \mathrm{D}_{5 / 2}$ & 0.18 & 6 \\
H I $\lambda 1215.67$ & $a^{4} \mathrm{D}_{1 / 2}-\left({ }^{5} \mathrm{D}\right) 5 \mathrm{p}^{4} \mathrm{D}_{3 / 2}$ & 0.85 & 5 \\
He II $\lambda 1084.94$ & $a^{6} \mathrm{D}_{9 / 2}-x^{4} \mathrm{H}_{7 / 2}$ & 0.96 & 4 \\
He II $\lambda 1084.94$ & $a^{6} \mathrm{D}_{9 / 2}-x^{4} \mathrm{H}_{9 / 2}$ & 0.64 & 3 \\
He II $\lambda 1084.94$ & $a^{6} \mathrm{D}_{9 / 2}-x^{4} \mathrm{H}_{11 / 2}$ & 0.05 & 3 \\
He II $\lambda 1084.94$ & $a^{6} \mathrm{D}_{9 / 2}-u^{2} \mathrm{G}_{9 / 2}$ & -0.01 & 3 \\
He II $\lambda 1025.27$ & $a^{4} \mathrm{D}_{1 / 2}-\left({ }^{4} \mathrm{~F}\right) 4 s 4 \mathrm{p}^{6} \mathrm{~F}_{3 / 2}$ & -0.17 & 5 \\
He II $\lambda 933.45$ & $a^{4} \mathrm{~F}_{5 / 2}-\left({ }^{3} \mathrm{H}\right) 5 \mathrm{p}{ }^{4} \mathrm{G}_{7 / 2}$ & -0.07 & 6 \\
\hline
\end{tabular}

a $\lambda_{\text {lab }}$ (pumped Fe II channel) $-\lambda_{\text {lab }}$ (pumping line).

${ }^{b}$ Number of observed Fe II fluorescence lines from the pumped level.

the lifetime of IUE. There are four lines from highly- ionised elements (Si III] $\lambda 1892$, O III] $\lambda \lambda 1660,1666$ and O IV] $\lambda 1401$ ), which are not white-dwarf wind lines but still responsible for PAR processes in Fe II. These lines have in common that they are narrower than the other pumping lines, even compared to the FWHM after 1986, and that they, along with the corresponding fluorescence lines, did not change during the years 1978-1995.

In AG Peg $\mathrm{H}$ Ly $\alpha$ activates numerous Fe II channels resulting in fluorescence lines from both primary and secondary decays of the pumped levels. Lines from the $\left({ }^{5} \mathrm{D}\right) 5 \mathrm{~s}$ levels 


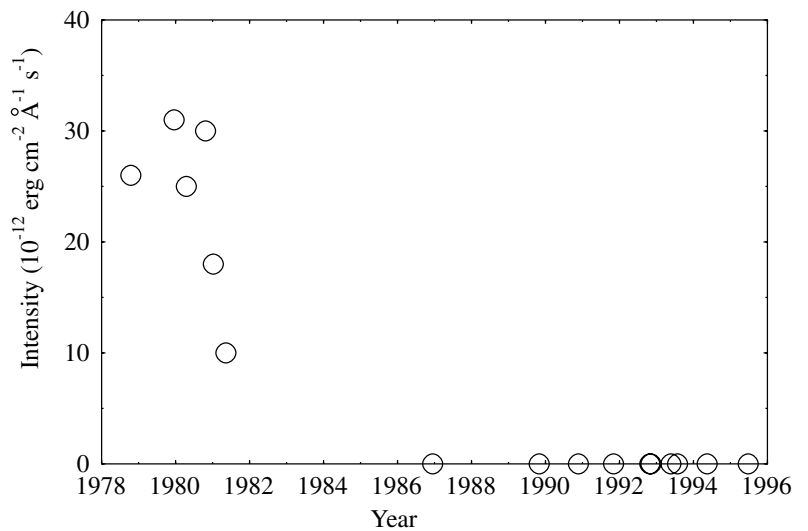

Fig. 4. The total intensity of all Fe II lines from the upper level $\mathrm{y}^{2} \mathrm{D}_{5 / 2}$, which is pumped by the C IV $\lambda 1548.187$ line through the channel $a^{4} \mathrm{~F}_{7 / 2}-y^{2} \mathrm{D}_{5 / 2}$ at $1548.697 \AA$. When the broad foot of the C IV resonance lines vanished the activity in this channel stopped.

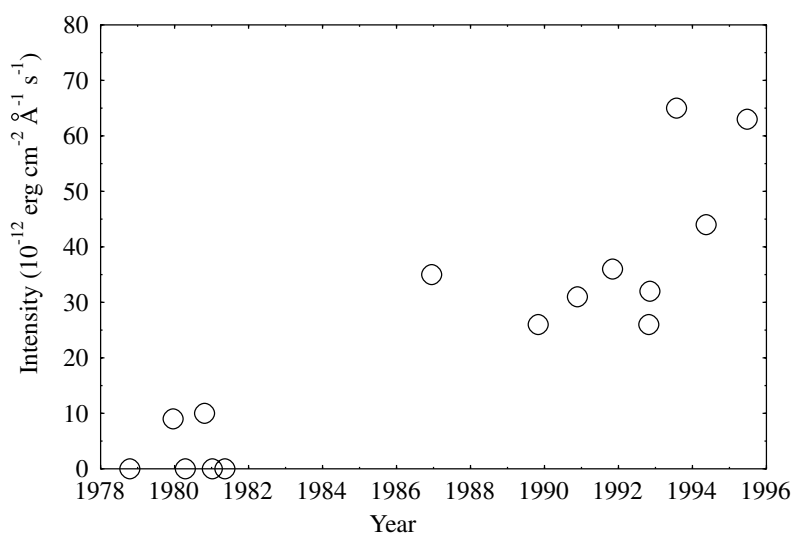

Fig. 5. The strength of the $\lambda 2508.34$ Fe II line representing the channel $a^{4} \mathrm{D}_{7 / 2}-\left(b^{3} \mathrm{~F}\right) 4 \mathrm{p}^{4} \mathrm{G}_{9 / 2}$ pumped by H Ly $\alpha$. As the temperature increased the $\mathrm{H}$ II region around the white dwarf became larger, which allowed more $\mathrm{H} \operatorname{Ly} \alpha$ to reach the Fe II regions.

(i.e. the $e^{6} \mathrm{D}$ and $\mathrm{e}^{4} \mathrm{D}$ terms) are seen in the AG Peg spectrum. Those lines are also seen in RR Tel, where they are explained as secondary decay from H Ly $\alpha$ pumped $\left({ }^{5} \mathrm{D}\right) 5 \mathrm{p}$ levels (Hartman \& Johansson 2000), and we conclude that the same explanation is valid for AG Peg. A consequence of the density decrease in the white-dwarf wind is that it becomes less dominant (less extended in the binary system) as well as less opaque so that the $\mathrm{H}$ II region can grow and more $\mathrm{H} \operatorname{Ly} \alpha$ radiation can reach the $\mathrm{Fe}^{+}$ions. This leads to an increase of the intensity of the $\mathrm{H} \mathrm{Ly} \alpha$ pumped Fe II fluorescence lines (Fig. 5). It is interesting to note that the velocity shift is the same for the Fe II fluorescence lines but differs from the velocity shift of the lines from collisionally excited Fe II levels.

We observe lines from Fe II levels that are not selectively photo-excited by strong lines. The population of these levels can in general be explained by collisional or recombination excitation (see later sections). However, we also observe emission lines from $21 \mathrm{Fe}$ II levels of medium excitation energy $(E P \approx 7-8 \mathrm{eV})$, for which neither of the excitation mechanisms mentioned above is plausible. Absorption lines of Fe II at short wavelengths are observed, and they give an explanation

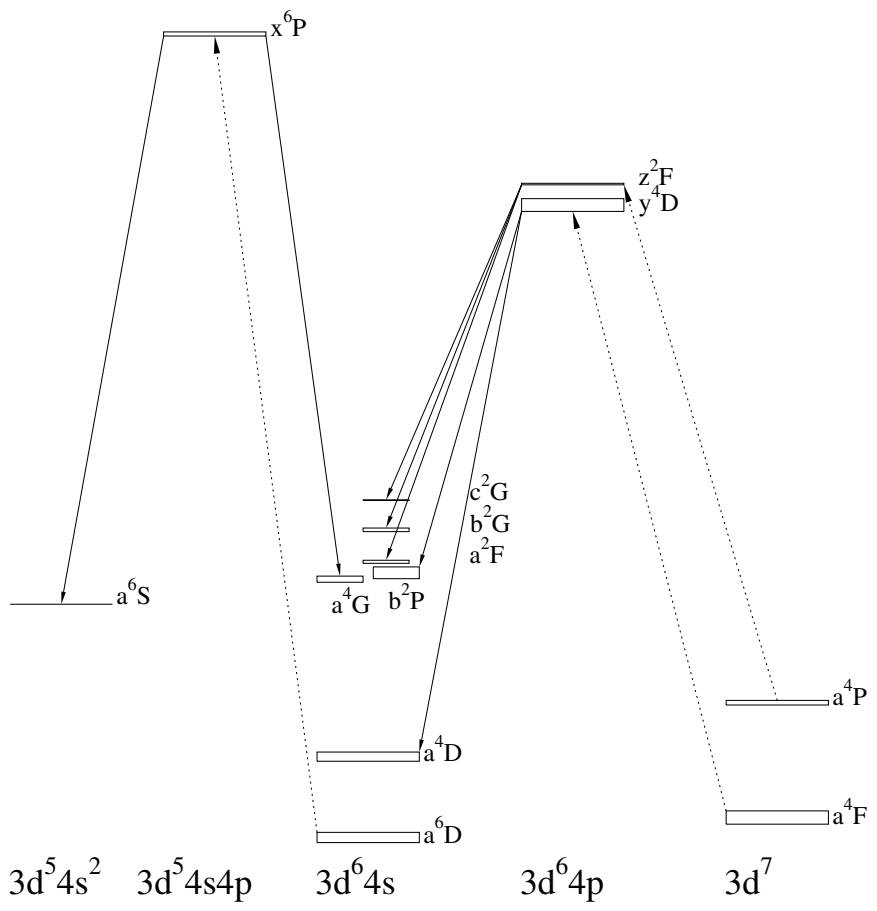

Fig. 6. Grotrian diagram of Fe II showing the levels involved in continuum fluorescence. The dotted lines are the pumped channels while the solid lines represent decay channels observed in AG Peg.

Table 6. Pumped channels in ions other than Fe II.

\begin{tabular}{llcr}
\hline \hline Pumping line & Pumped element & Pumped transition & $\lambda^{a}(\AA)$ \\
\hline O IV] $\lambda 1401.16$ S I & $3 \mathrm{p}^{4}{ }^{3} \mathrm{P}_{2}-\left({ }^{4} \mathrm{~S}\right) 5 \mathrm{~s}{ }^{3} \mathrm{~S}_{1}$ & 1401.51 \\
N V $\lambda 1242.78$ & N I & $2 \mathrm{p}^{3}{ }^{2} \mathrm{D}_{5 / 2}-\left({ }^{1} \mathrm{D}\right) 3 \mathrm{~s}{ }^{2} \mathrm{D}_{5 / 2}$ & 1243.18 \\
N V $\lambda 1242.78$ & Co II & $4 \mathrm{~s} \mathrm{a} \mathrm{F}_{3}-4 \mathrm{~s} 4 \mathrm{p} y^{5} \mathrm{P}_{3}$ & 1242.49 \\
H I $\lambda 1215.67$ & Co II & $3 \mathrm{~d}^{8} \mathrm{a}^{3} \mathrm{P}_{2}-\left({ }^{4} \mathrm{~F}\right) 5 \mathrm{p}{ }^{5} \mathrm{D}_{3}$ & 1213.26 \\
H I $\lambda 1215.67$ & Fe III & $3 \mathrm{~d}^{6}{ }^{5} \mathrm{D}_{4}-\left({ }^{6} \mathrm{~S}\right) 4 \mathrm{p}^{7} \mathrm{P}_{3}$ & 1214.57 \\
H I $\lambda 1215.67$ & Fe III & $3 \mathrm{~d}^{6}{ }^{5} \mathrm{D}_{4}-\left({ }^{6} \mathrm{~S}\right) 4 \mathrm{p}^{7} \mathrm{P}_{4}$ & 1213.45 \\
continuum & Co II & $3 \mathrm{~d}^{8}{ }^{3} \mathrm{~F}_{4}-4 \mathrm{p} v^{3} \mathrm{D}_{3}$ & 1187.42 \\
\hline
\end{tabular}

${ }^{a}$ Wavelength of the pumped channel.

${ }^{b}$ Absorption at $1187 \AA$ is observed, which explains the presence of emission from the Co II $v^{3} \mathrm{D}_{3}$ level.

to the population of seven of those 21 levels (Fig. 6). These are levels belonging to the LS terms $y^{4} \mathrm{D}, z^{2} \mathrm{~F}$ and $x^{6} \mathrm{P}$ (except for $y^{4} \mathrm{D}_{1 / 2}$ and $x^{6} \mathrm{P}_{3 / 2}$ ), and they are photo-excited by continuum radiation from the white dwarf through the channels $a^{4} \mathrm{~F}-y^{4} \mathrm{D}$, $a^{4} \mathrm{P}-z^{2} \mathrm{~F}$ and $a^{6} \mathrm{D}-x^{6} \mathrm{P}$. Only the strongest transitions between these terms are observed as absorption lines in AG Peg, probably due to the low continuum level.

The strong emission line $\lambda 1411.94$ in AG Peg is identified as the $2 \mathrm{p}^{3}{ }^{2} \mathrm{P}_{3 / 2}-2 \mathrm{p}^{2} 3 \mathrm{~s}{ }^{2} \mathrm{D}_{5 / 2}$ transition of N I but no emission is detected from the $2 \mathrm{p}^{2} 3 \mathrm{~s}^{2} \mathrm{D}_{3 / 2}$ level. We suggest that the level $2 \mathrm{p}^{2} 3 \mathrm{~s}^{2} \mathrm{D}_{5 / 2}$ is selectively populated by being pumped by $\mathrm{N} V \lambda 1242$ in the absorption channel $2 \mathrm{p}^{3}{ }^{2} \mathrm{D}_{5 / 2}-2 \mathrm{p}^{2} 3 \mathrm{~s}^{2} \mathrm{D}_{5 / 2}$. A similar case is $\lambda 1409.34$, which is identified as a transition from the $\mathrm{S}$ I level $\left({ }^{4} \mathrm{~S}\right) 5 \mathrm{~s}{ }^{3} \mathrm{~S}_{1}$ having a high excitation energy $(8.85 \mathrm{eV})$. We suggest the $\mathrm{S}$ I level is pumped by O IV] $\lambda 1401$. Furthermore, two pumped channels in Co II and two in Fe III have been detected in the IUE spectrum of AG Peg (Table 8). 
Table 7. Parity forbidden lines observed in AG Peg.

\begin{tabular}{lccccccc}
\hline \hline Spectrum & $\begin{array}{c}\text { Ionization } \\
(\mathrm{eV})\end{array}$ & $\begin{array}{c}\lambda_{\text {lab }}(\mathrm{vac}) . \\
(\AA)\end{array}$ & $\begin{array}{c}\text { Shift }^{a} \\
\left(\mathrm{~km} \mathrm{~s}^{-1}\right)\end{array}$ & $\begin{array}{c}\text { Width } \\
\left(\mathrm{km} \mathrm{s}^{-1}\right)\end{array}$ & Transition & $\begin{array}{c}\mathrm{A}_{i j} \\
\left(\mathrm{~s}^{-1}\right)\end{array}$ & Note $^{b}$ \\
\hline$[\mathrm{Fe} \mathrm{VI}]$ & 75.01 & 1957.28 & $\mathrm{bl}$ & $\mathrm{bl}$ & $3 \mathrm{~d}^{3}{ }^{2} \mathrm{G}_{7 / 2}-3 \mathrm{~d}^{3}{ }^{2} \mathrm{D} 1_{5 / 2}$ & 0.91 & $\uparrow$ \\
& & 1944.30 & 17 & 20 & $3 \mathrm{~d}^{3}{ }^{2} \mathrm{G}_{7 / 2}-3 \mathrm{~d}^{3}{ }^{2} \mathrm{D} 1_{3 / 2}$ & 12 & $\uparrow$ \\
{$[\mathrm{Mg} \mathrm{V}]$} & 109.25 & 2928.0 & $\mathrm{bl}$ & $\mathrm{bl}$ & $2 \mathrm{p}^{4}{ }^{3} \mathrm{P}_{1}-2 \mathrm{p}^{4}{ }^{1} \mathrm{D}_{2}$ & 0.55 & $\uparrow$ \\
& & 2783.50 & $\mathrm{bl}$ & $\mathrm{bl}$ & $2 \mathrm{p}^{4}{ }^{3} \mathrm{P}_{2}-2 \mathrm{p}^{4}{ }^{1} \mathrm{D}_{2}$ & 1.90 & $\uparrow$ \\
& & 1324.45 & 45 & 20 & $2 \mathrm{p}^{4}{ }^{3} \mathrm{P}_{1}-2 \mathrm{p}^{4}{ }^{1} \mathrm{~S}_{0}$ & 23 & $\uparrow$ \\
{$[\mathrm{Ne} \mathrm{V}]$} & 97.08 & 2975.66 & 152 & 51 & $2 \mathrm{p}^{2}{ }^{1} \mathrm{D}_{2}-2 \mathrm{p}^{2}{ }^{1} \mathrm{~S}_{0}$ & 2.60 & $\uparrow$ \\
& & 1575.18 & 124 & 84 & $2 \mathrm{p}^{2}{ }^{3} \mathrm{P}_{1}-2 \mathrm{p}^{2}{ }^{1} \mathrm{~S}_{0}$ & 4.20 & $\uparrow$ \\
{$[\mathrm{Ar} \mathrm{V}]$} & 59.81 & 2692.02 & 41 & 40 & $3 \mathrm{p}^{2}{ }^{3} \mathrm{P}_{1}-3 \mathrm{p}^{2}{ }^{1} \mathrm{~S}_{0}$ & 6.80 & $\uparrow$ \\
{$[\mathrm{Ne}$ IV] } & 63.46 & 2425.23 & -6 & 18 & $2 \mathrm{p}^{3}{ }^{4} \mathrm{~S}_{3 / 2}-2 \mathrm{p}^{3}{ }^{2} \mathrm{D}_{5 / 2}$ & 0.00018 & $\leftrightarrow$ \\
& & 2422.60 & -7 & 17 & $2 \mathrm{p}^{3}{ }^{4} \mathrm{~S}_{3 / 2}-2 \mathrm{p}^{3}{ }^{2} \mathrm{D}_{3 / 2}$ & 0.0053 & $\leftrightarrow$ \\
& & 1601.67 & $\mathrm{bl}$ & $\mathrm{bl}$ & $2 \mathrm{p}^{3}{ }^{4} \mathrm{~S}_{3 / 2}-2 \mathrm{p}^{3}{ }^{2} \mathrm{P}_{1 / 2}$ & 0.53 & $\leftrightarrow$ \\
{$[\mathrm{Ne}$ III $]$} & 40.96 & 1814.63 & 21 & 40 & $2 \mathrm{p}^{4} \mathrm{P}_{1}-2 \mathrm{p}^{4}{ }^{1} \mathrm{~S}_{0}$ & 2.20 & $\leftrightarrow$ \\
{$[\mathrm{O}$ III] } & 35.12 & 2321.66 & 49 & 25 & $2 \mathrm{p}^{2} \mathrm{P}_{1}-2 \mathrm{p}^{2}{ }^{1} \mathrm{~S}_{0}$ & 0.22 & $\downarrow$ \\
\hline
\end{tabular}

$a \frac{\lambda_{\text {lab }}-\lambda_{\mathrm{obs}}}{\lambda_{\mathrm{lab}}} \cdot 3 \times 10^{5} ;{ }^{b} \downarrow=$ Only observed before $1986, \leftrightarrow=$ observed throughout 1978 to $1995, \uparrow=$ only observed after 1986, $\mathrm{bl}=\mathrm{blend}$.

\subsubsection{Parity forbidden lines}

Radiative transitions between levels of the same parity must be formed by magnetic dipole (M1) or electric quadrupole (E2) interaction, which means many orders of magnitude smaller transition probabilities than electric dipole (E1) transitions including a parity change. Observations of M1 and E2 radiation from an astrophysical plasma require that the density of the plasma is low enough so the radiative lifetime of the metastable state is smaller than the time scale for deexcitation by collisional quenching. Hence, the lines from the parity forbidden transitions originate from low density regions, such as from a nebula surrounding the system. In the $I U E$ spectra of AG Peg, 14 parity-forbidden emission lines have been identified, originating from highly-ionised elements such as $\mathrm{Ne} \mathrm{V}$ and Fe VI (Table 7). The ionisation energies are very high for the ions emitting M1 and E2 radiation, which implies that all parityforbidden radiation originates from a thin plasma, heated and ionized by the UV radiation from the white dwarf. There is a difference among the forbidden lines in $I U E$ spectra before and after 1986 . Before 1986 only six of the 14 observed parityforbidden lines were present, and they originated from the ions $\mathrm{O}^{2+}, \mathrm{Ne}^{2+}$ and $\mathrm{Ne}^{3+}$. No forbidden lines from higher ionisation stages were observed. After 1986 the forbidden emission from $\mathrm{O}^{2+}$ ([O III] 22321.66 ) vanished and the emission from $\mathrm{Ne}^{2+}$ ([Ne III] 21814.63 ) became weaker, while eight new emission lines from $\mathrm{Ar}^{4+}, \mathrm{Ne}^{4+}, \mathrm{Mg}^{4+}$ and $\mathrm{Fe}^{5+}$ appeared in the $I U E$ spectrum.

\subsubsection{Population by recombination or collisions}

Emission lines from a particular ion can originate from different regions in the symbiotic system. Still, after discarding the emission lines that originated from the white-dwarf wind before 1986 as well as all fluorescence lines and parity-forbidden lines, the remaining emission lines from a specific ion have about the same velocity shifts. The widths of these remaining emission lines did not change during 1978-1995, but the relative shift between different ions was variable. In Table 3 all ions observed in AG Peg are listed with the number of corresponding emission lines that are formed by collision or recombination, excluding the white-dwarf wind emission lines. We will now give suggestions for how and where some of those lines are formed.

\section{A) The helium $2 s^{3} S_{1}-n p^{3} P_{2}$ series}

Four emission lines from the He I $2 \mathrm{~s}{ }^{3} \mathrm{~S}_{1}-n p{ }^{3} \mathrm{P}_{2}$ series $(n=5-8)$ are identified in the $\mathrm{RR}$ Tel spectrum Penston et al. 1983. In the IUE spectra of AG Peg recorded before 1986 there are no traces of He I emission. The broad He II emission lines from the white-dwarf wind before 1986 are presumably formed by recombination. Because of the high temperature and strong UV flux in the white-dwarf wind there is no neutral helium there. However, after 1986 seven He I emission lines of the series $2 \mathrm{~s}{ }^{3} \mathrm{~S}_{1}-n p{ }^{3} \mathrm{P}_{2}(5 \leq n \leq 11)$ are present in the spectrum as "nebular" lines with a mean $F W H M$ of $35 \mathrm{~km} \mathrm{~s}^{-1}$. The explanation of the He I emission is probably linked to the change of the He II lines from broad wind profiles to "narrow" lines having an average $F W H M$ of $49 \mathrm{~km} \mathrm{~s}^{-1}$ (see Sect. 3.1). Kenyon et al. (1993) suggest that the presence of $\mathrm{He} \mathrm{I}$ is caused by heating of the red-giant atmosphere by radiation from $\mathrm{He}^{+}$ions in a region around the white dwarf. If He II in the white-dwarf wind is responsible for He I emission from the red-giant atmosphere, then the absence of He I lines before 1986 is a problem. Another suggestion is that when the whitedwarf wind became less dense during the transition period it was not able to produce broad He II emission enough to be observed by $I U E$, but at the same time more continuum radiation 


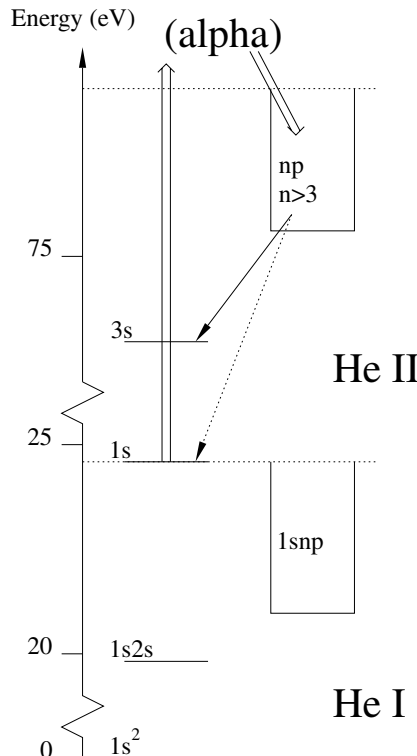

White dwarf wind before 1986

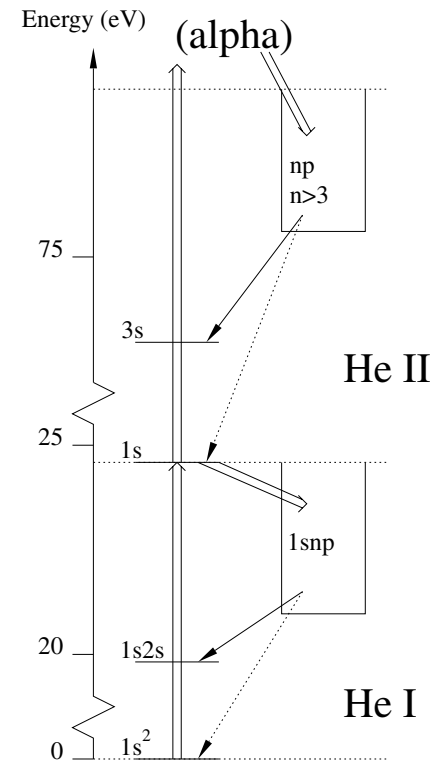

Red giant atmosphere after 1986

Fig. 7. Suggestion of the origin of broad He emission (left) and narrow He emission (right) before and after 1986 (see text).

from the white dwarf reached the red-giant atmosphere, ionising helium to both $\mathrm{He}^{+}$and $\mathrm{He}^{2+}$ (Fig. 7). This implies that after 1986 both the He I and He II emission lines are formed in the red-giant atmosphere facing the white dwarf.

\section{B) The $n s^{2} \mathrm{~S}-n p^{2} \mathrm{P}$ transitions in alkali-like spectra}

It is only possible to detect the $2 \mathrm{~s}^{2} \mathrm{~S}-2 \mathrm{p}{ }^{2} \mathrm{P}$ doublet transition for three species, $\mathrm{C} \mathrm{IV}, \mathrm{N} \mathrm{V}$, and O VI, within the wavelength regions covered by $I U E$ and FUSE. Atomic lithium and the ions $\mathrm{Be}^{+}$and $\mathrm{B}^{2+}$ are too rare to be observed and for the three-electron systems heavier than oxygen the $2 \mathrm{~s}-2 \mathrm{p}$ transition lies shortward of $900 \AA$. Two of the three observable doublets, C IV $\lambda \lambda 1548.19,1550.77$ and N V $\lambda \lambda 1238.80,1242.78$ are observed as broad $\left(\sim 800 \mathrm{~km} \mathrm{~s}^{-1}\right)$ emission lines that evolve into narrow emission $\left(\sim 40 \mathrm{~km} \mathrm{~s}^{-1}\right)$ during the 1980 s as discussed in Sect. 3.1. The O VI $11031.92,1037.614$ resonance doublet is outside the range of IUE, but is observed with FUSE (Fig. 8). Since FUSE was launched in 1999 there have been no data on the O VI resonance doublet in AG Peg prior to the dramatic change of profile of the N V and C IV resonance doublets. However, at the base of the O VI resonance lines there are wings $\left(F W H M \sim 800 \mathrm{~km} \mathrm{~s}^{-1}\right.$, based on Gaussian fit of the line wings in the Q1110101 spectra) indicating that the O VI doublet evolved in the same way as the C IV and $\mathrm{N}$ V doublets. The peak intensity of the nebular components appears to have increased from 2001 (Q1110101) to the 2003 FUS E observation (Q1110103) while the intensity of the broad underlying wind-profile decreased slightly. This could mean that the same transfer of origin of the C IV resonance doublet at the end of 1970s to the beginning of the 1980s and the N V resonance doublet during the 1980s and beginning of 1990s (Eriksson et al. 2004) is now taking place for the O VI resonance doublet.

For the iso-electronic sequence of spectra involving 11 electrons the $3 \mathrm{~s}{ }^{2} \mathrm{~S}-3 \mathrm{p}{ }^{2} \mathrm{P}$ doublets are reachable with IUE for three different elements (Mg II $\lambda \lambda 2796.35,2803.53$, Al III $\lambda \lambda 1854.72,1862.79$ and Si IV $\lambda \lambda 1393.76,1402.77)$, and one with FUSE (P V $\lambda \lambda 1117.98,1128.01)$. The P V resonance doublet is not detected in the FUSE data probably because of a low abundance of phosphorus in the red-giant atmosphere. Energetically it would be possible since the O VI resonance doublet is observed, and the ionisation potential of $\mathrm{O}$ V $(113.9 \mathrm{eV})$ is higher than for P IV $(51.4 \mathrm{eV})$. The Si IV resonance lines evolved in the same manner as the $\mathrm{C}$ IV and $\mathrm{N}$ V resonance lines and are discussed in Sect. 3.1. The Mg II resonance doublet (Fig. 8) is known to be common in the chromospheres of red-giant stars (Kondo et al. 1976) and is probably emitted all around the red giant atmosphere. Both the Mg II and Al III resonance doublets consist of narrow emission lines throughout 1978 to 1995 and have probably never been formed in the white-dwarf wind because of the low ionisation temperature required.

\section{C) The $n s^{2}{ }^{1} \mathrm{~S}-n s n p^{3} \mathrm{P}$ transitions in alkaline-earth-like spectra}

The spin-forbidden $n s^{2}{ }^{1} \mathrm{~S}-n s n p^{3} \mathrm{P}$ transition includes two possible intercombination lines: ${ }^{1} \mathrm{~S}_{0}-{ }^{3} \mathrm{P}_{1}$, which is often strong in emission in hot nebular spectra, and ${ }^{1} \mathrm{~S}_{0}-{ }^{3} \mathrm{P}_{2}$. Since $\Delta J=2$ for the latter line, it can only occur via a magnetic quadrupole transition, which has a very small transition probability. Similar to the observational restrictions for the $2 \mathrm{~s}^{2} \mathrm{~S}-2 \mathrm{p}{ }^{2} \mathrm{P}$ transitions discussed in the previous subsection, the $2 \mathrm{~s}^{2}{ }^{1} \mathrm{~S}-2 \mathrm{p}{ }^{3} \mathrm{P}$ transitions can only be observed for C III], N IV] and O V]. The C III] $\lambda 1908.73\left({ }^{1} \mathrm{~S}_{0}-{ }^{3} \mathrm{P}_{1}\right)$ emission line is observed as strong $\left(I \sim 3.5 \times 10^{-11} \mathrm{erg} \mathrm{cm}^{-2} \mathrm{~s}^{-1} \AA^{-1}\right)$ and narrow $(F W H M \sim$ $35 \mathrm{~km} \mathrm{~s}^{-1}$ ) in all of the $I U E$ observations. This is probably due to the ionization energy of C III, which is too low for $\mathrm{C}^{2+}$ ions to survive in the white-dwarf wind, but the ionisation potential of C II is not too high for $\mathrm{C}^{2+}$ to be produced in the heated part of the red-giant atmosphere. At the detection limit in the longest exposed spectra at $1906.67 \AA$ there is a weak feature $\left(I \sim 30 \times 10^{-13} \mathrm{erg} \mathrm{cm}^{-2} \mathrm{~s}^{-1} \AA^{-1}\right)$, which can possibly be identified as the E2 $\left({ }^{1} \mathrm{~S}_{0}-{ }^{3} \mathrm{P}_{2}\right)$ transition of $\mathrm{C}$ III] blended with Mg IV.

The $\mathrm{N}$ IV] $\lambda 1486.50\left({ }^{1} \mathrm{~S}_{0}-{ }^{3} \mathrm{P}_{1}\right)$ emission line is a broad wind line before 1986 and is observed as a narrow emission line after 1986 as discussed in Sect. 3.1. Interestingly, the [N IV] M2 transition at $1483.32 \AA$ is present throughout the IUE observations but has a $F W H M$ around $150 \mathrm{~km} \mathrm{~s}^{-1}$, which is very different from the $F W H M$ of N IV] $\lambda 1486.50$ both before and after 1986. Since O V has a higher ionisation energy than N IV one would also expect the O V] $\lambda 1218.34$ emission line to have evolved from a broad wind profile to a narrow nebular line. However, its relative closeness to H Ly $\alpha$ at $1215.67 \AA$ causes absorption by the neutral hydrogen in the surrounding nebula and the O V] $\lambda 1218.34$ line is absent before 1986. When the temperature of the white dwarf increased the H II region expanded further out into the surrounding nebula, making it more 

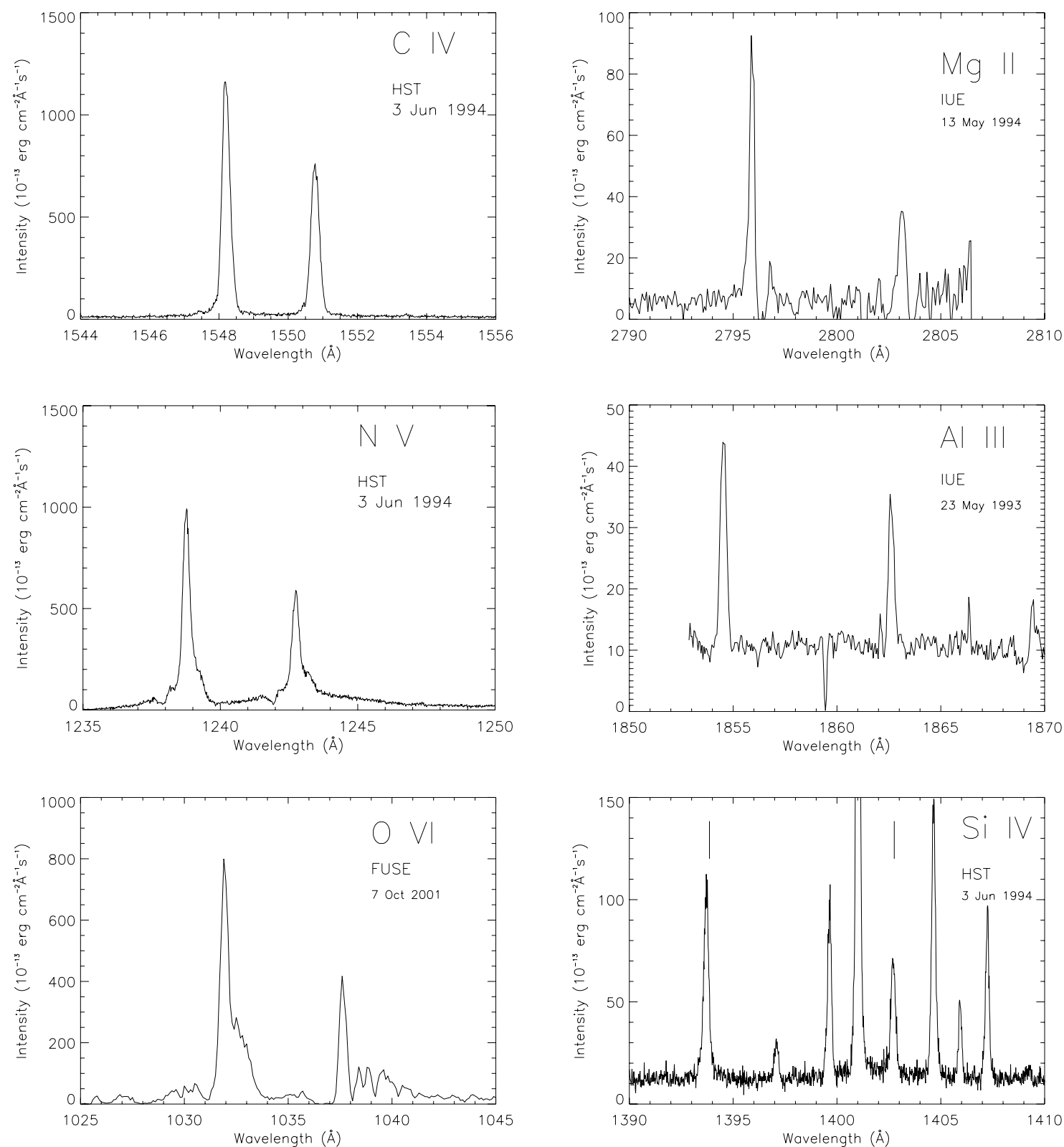

Fig. 8. The $n{ }^{2} \mathrm{~S}-\mathrm{np}{ }^{2} \mathrm{P}$ doublets observed in AG Peg. The figures represent the profile of the resonance doublets after the transition period in the middle of the 1980s. The resonance doublets corresponding to $n=3$ ( $\mathrm{Si} \mathrm{IV,} \mathrm{Al} \mathrm{III,} \mathrm{Mg} \mathrm{II)} \mathrm{and} \mathrm{C} \mathrm{IV} \mathrm{almost} \mathrm{completely} \mathrm{consist} \mathrm{of} \mathrm{narrow}$ components, while the $\mathrm{N} \mathrm{V}$ and $\mathrm{O}$ VI resonance doublets still have detectable contributions from the broad white-dwarf wind profile.

transparent for the $\mathrm{O}$ V] $\lambda 1218.34$ emission, which after 1986 is observed as a strong emission line.

In the $\mathrm{Mg} \mathrm{I}$ iso-electronic sequence of 12-electron ions the transition $3 s^{2}{ }^{1} \mathrm{~S}_{0}-3 \mathrm{~s} 3 \mathrm{p}^{3} \mathrm{P}_{1}$ is observed in four elements (Al II], Si III], P IV] and S V]). The S V] $\lambda 1199.04$ feature evolved from a broad wind profile to a narrow nebular line during the 1980s, while Al II] $\lambda 2669.95, \mathrm{Si}$ III] $\lambda 1892.03$, and P IV] $\lambda 1467.43$ are observed as narrow $\left(F W H M \sim 30 \mathrm{~km} \mathrm{~s}^{-1}\right)$ throughout the time interval 1978 to 1995 . The intensity ratio $\mathrm{I}\left({ }^{1} \mathrm{~S}_{0}-{ }^{3} \mathrm{P}_{1}\right) / \mathrm{I}\left({ }^{1} \mathrm{~S}_{0}-{ }^{3} \mathrm{P}_{2}\right)$ has been used in $\mathrm{C}$ III and $\mathrm{N}$ IV as a diagnostic tool to obtain electron densities in AG Peg Nussbaumer \& Schild 1979, Nussbaumer \& Schild 1981. The same transitions can be used for O V, Al II, Si III, P IV and $\mathrm{S} \mathrm{V}$ to derive complementary information about the plasma. Understanding the origin of the ${ }^{1} \mathrm{~S}-{ }^{3} \mathrm{P}$ lines is therefore of great importance.

\section{D) The excited $(\mathrm{sp})^{k} 2<k<8$ configurations}

The more ionised an element is the more sensitive the average energy of a configuration is to the principal quantum number, $n$. Excited states in highly-ionized spectra, for which all electrons have the same $\mathrm{n}$ as the ground configuration, are therefore at relatively low excitation energies. As an example the LS term 

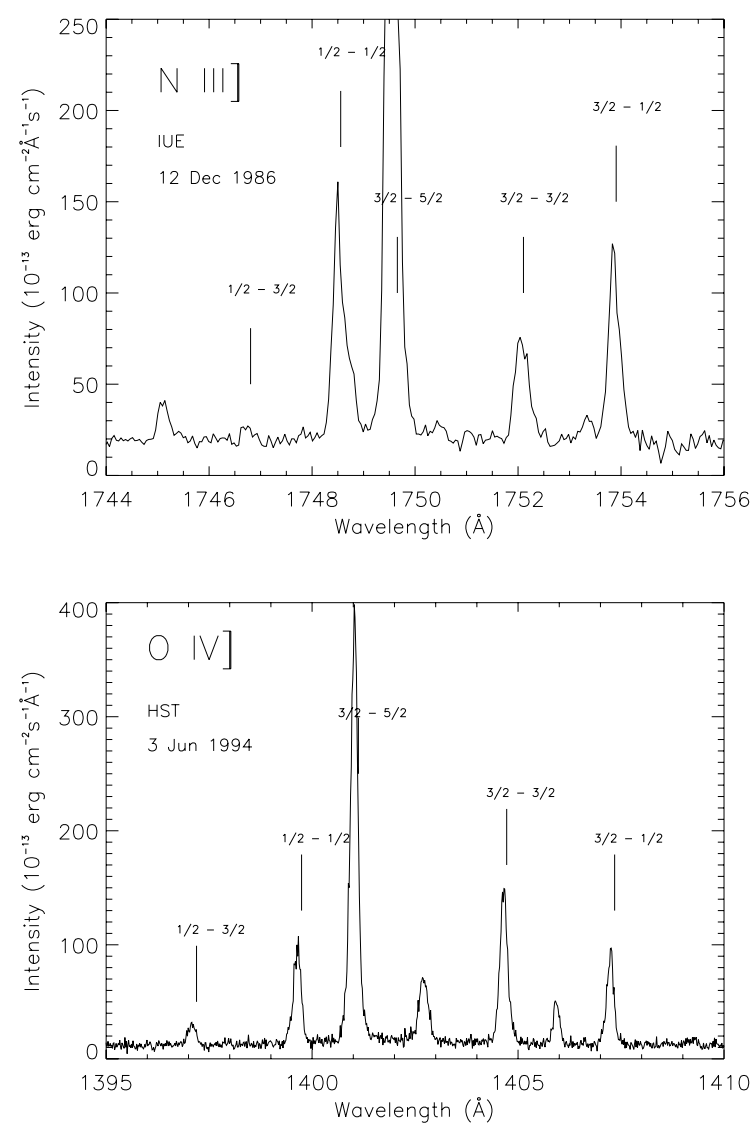

Fig. 9. The intercombination multiplet $2 s^{2} 2 p^{2} \mathrm{P}-2 \mathrm{~s} 2 \mathrm{p}^{2}{ }^{4} \mathrm{P}$ in N III] and $\mathrm{O}$ IV] spectra. The fine-structure component $3 / 2-5 / 2$ is over-exposed in the N III] plot. The region of the N III] multiplet has not been observed by $H S T$ (GHRS) at high resolution. The dynamic range of IUE was not sufficient to record spectra where the weakest $\mathrm{N}$ III] components are observable at the same time that $\mathrm{N} \mathrm{III]} 3 / 2-5 / 2$ is not overexposed.

$2 \mathrm{~s} 2 \mathrm{p}^{2}{ }^{4} \mathrm{P}$ of $\mathrm{C}$ II is at $\sim 5.3 \mathrm{eV}$, while the $\mathrm{LS}$ term $2 \mathrm{~s} 2 \mathrm{p} 3 \mathrm{p}{ }^{4} \mathrm{P}$ is at an energy of $(\sim 23.1 \mathrm{eV})$, i.e. more than a factor of four higher. Because of the low energy required for exciting the $(\mathrm{sp})^{k}$ configurations they can be populated through collisions. Allowed emission lines from $(s p)^{k}, 2<k<8$, dominate the contribution from C II, N III, O IV, Si II, P II, P III, S II and S IV and they are also present in C III, N IV and O V. An intercombination transition, $n s^{2} n p^{2} \mathrm{P}-n s n p^{2}{ }^{4} \mathrm{P}$, is specially strong in N III, O IV and S IV (Fig. 9), and is also present in the Si II spectrum. The metastable $n s n p^{2}{ }^{4} \mathrm{P}$ is the lowest excited term in systems with five and 13 electrons and it can therefore only decay to the ground state, which explains why the corresponding multiplets are so strong. Those multiplets can be used for electron density diagnostics (Nussbaumer \& Storey 1982; Nussbaumer \& Storey 1979).

\section{E) Emission lines from neutral atoms heavier than helium}

Emission lines from NI, OI and SI are observed in the ultraviolet spectrum of AG Peg. Most of the emission lines from

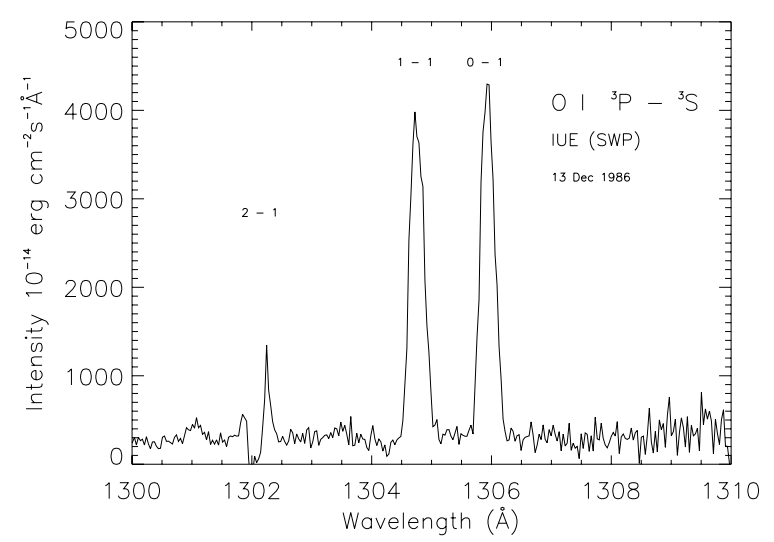

Fig. 10. The O I multiplet $2 \mathrm{p}^{4}{ }^{3} \mathrm{P}-2 \mathrm{p}^{3}\left({ }^{4} \mathrm{~S}\right) 3 \mathrm{~s}{ }^{3} \mathrm{~S}$. The component ${ }^{3} \mathrm{P}_{2}-$ ${ }^{3} S_{1}$ to the ground level is in absorption while the other two finestructure components are in emission.

neutral elements are from allowed transitions to levels within the ground configuration, except for the ground state (Fig. 9). That the emitting gas is optically thick for transitions to the ground state indicates that the region of neutral elements is of relatively high density and low temperature $(<3000 \mathrm{~K})$. All of the four observed oxygen lines and five of the six observed sulphur lines correspond to transitions from $n p^{3}\left({ }^{4} \mathrm{~S}\right) n$ 's ${ }^{5} \mathrm{~S}$ or ${ }^{3} \mathrm{~S}$ to the ground term $n p^{4}{ }^{3} \mathrm{P}$. That the ${ }^{3} \mathrm{P}-{ }^{5} \mathrm{~S}$ intercombination lines of S I $\lambda 1900.29$ and O I $\lambda \lambda 1355.60,1358.51$ are observed is interesting since their transition probabilities are $\sim 10^{4}$ times smaller than for the ${ }^{3} \mathrm{P}-{ }^{3} \mathrm{~S}$ transitions. This limits the electron density of the emitting region, presumably the outermost part of the surrounding nebula or the part of the red giant obscured from the white-dwarf emission.

\section{F) Recombination to third, fourth and fifth ionization states}

The population of some levels, from which emission is observed in AG Peg, cannot be understood by collisions or any pumping mechanisms. These include levels with very high excitation energy having no known decay channels that coincide with strong UV emission lines of other elements, and exotic configurations (doubly-excited and/or involving f-electrons) rarely populated in astrophysical plasmas. If an ion is emitting lines from doubly-excited levels or levels close to the ionization energy, recombination is the most plausible explanation. Based on this reasoning we suggest recombination as the excitation mechanism for some lines. The previous discussion of the strong $2 s^{2} \mathrm{~S}-2 \mathrm{p}{ }^{2} \mathrm{P}$ transitions reveals a large abundance of $\mathrm{C} \mathrm{IV}, \mathrm{N}$ V and O VI in a hot region of AG Peg, implying that recombination to C III, N IV and O V is reasonable. Both C III and $\mathrm{O} V$ lines have been observed from levels rarely populated by collisions and are most certainly populated by recombination (such as $4 \mathrm{f}^{3} \mathrm{~F}_{4}$ in $\mathrm{C}$ III and $5 \mathrm{f}^{3} \mathrm{~F}_{4}$ in $\mathrm{O} \mathrm{V}$ ). Although the $\mathrm{N}$ V $\lambda \lambda 1238.80,1242.78$ doublet is almost as strong as the C IV resonance doublet none of the observed N IV lines originate from levels that require recombination excitation. However, the $\mathrm{N}$ IV] $\lambda 1486.50$ emission line is one of the strongest lines in 
Table 8. The relative line strengths of the Fe II multiplet $a^{6} \mathrm{D}-z^{6} \mathrm{D}$.

\begin{tabular}{cccr}
\hline \hline Transition & $\lambda_{\text {vac }}($ lab $)(\AA)$ & $g A^{a}$ & $I^{b}$ \\
\hline $9 / 2-9 / 2$ & 2600.17 & 2.39 & $0^{c}$ \\
$9 / 2-7 / 2$ & 2586.65 & 0.37 & $0^{c}$ \\
$7 / 2-9 / 2$ & 2626.45 & 0.75 & 1.23 \\
$7 / 2-7 / 2$ & 2612.65 & 1.00 & 1.00 \\
$7 / 2-5 / 2$ & 2599.15 & 0.32 & 0.39 \\
$5 / 2-7 / 2$ & 2632.11 & 0.87 & bl \\
$5 / 2-5 / 2$ & 2618.40 & 0.30 & 0.92 \\
$5 / 2-3 / 2$ & 2607.87 & 0.45 & 0.61 \\
$3 / 2-5 / 2$ & 2631.83 & 0.70 & bl \\
$3 / 2-3 / 2$ & 2621.19 & 0.02 & 0.72 \\
$3 / 2-1 / 2$ & 2614.61 & 0.37 & 0.47 \\
$1 / 2-3 / 2$ & 2629.08 & 0.43 & 0.53 \\
$1 / 2-1 / 2$ & 2622.45 & 0.12 & 0.52 \\
\hline
\end{tabular}

${ }^{a}$ The gA values from Schnabel et al. (2004) are scaled in such a way that $\mathrm{gA}$ for the $a^{6} \mathrm{D}_{7 / 2}-z^{6} \mathrm{D}_{7 / 2}$ transition is equal to 1.00 .

${ }^{b}$ The observed intensity relative to $I\left(a^{6} \mathrm{D}_{7 / 2}-z^{6} \mathrm{D}_{7 / 2}\right)=1.00$.

$c$ Both transitions to the ground level $a^{6} \mathrm{D}_{9 / 2}$ are observed in absorption.

the IUE wavelength range, indicating high presence of $\mathrm{N}^{3+}$ ions and the N III spectrum shows a few lines, such as N III $\lambda 1387.38$, with upper level $4 \mathrm{~d}^{2} \mathrm{D}_{3 / 2}$ presumably populated by recombination. Also, recombination lines of the third spectra, C III, N III and O III, were present throughout 1978-1995 and are formed in the extended red-giant atmosphere at a distance from the white dwarf sufficient to provide a temperature that gives a mixture of two and three times ionised elements.

The O V recombination lines first appeared after 1986. Before $1986, \mathrm{O}^{5+}$ ions probably only existed in the whitedwarf wind, but after the transition period in the middle of $1980 \mathrm{~s} \mathrm{O}^{5+}$ ions were produced in the red-giant atmosphere by photo-ionisation, which explains the appearance of $\mathrm{O} \mathrm{V}$ recombination lines. Four emission lines between 1669-1699 A are identified as Mg IV lines corresponding to the multiplet $\left({ }^{3} \mathrm{P}\right) 3 \mathrm{~s}$ ${ }^{4} \mathrm{P}-\left({ }^{3} \mathrm{P}\right) 3 \mathrm{p}{ }^{4} \mathrm{D}$. These lines are the only observed $\mathrm{Mg}$ IV lines in the spectra of AG Peg, and the $\left({ }^{3} \mathrm{P}\right) 3 \mathrm{p}{ }^{4} \mathrm{D}$ term has an excitation energy of $\sim 75 \mathrm{eV}$. The population of these levels is likely to be due to recombination of $\mathrm{Mg} \mathrm{V} 2 \mathrm{p}^{4}{ }^{3} \mathrm{P}$ in less dense parts of the surrounding nebula since only parity forbidden lines from $\mathrm{Mg} \mathrm{V}$ are observed.

\section{G) The Fe II ( $\left.{ }^{5} D\right) 4 p$ levels}

The lowest excited odd-parity levels in Fe II belong to the subconfiguration $\left({ }^{5} \mathrm{D}\right) 4 \mathrm{p}$, which is built on the lowest parent term ${ }^{5} \mathrm{D}$ of Fe III. This subconfiguration contains six LS terms $\left({ }^{4} \mathrm{P}\right.$, ${ }^{4} \mathrm{D}{ }^{4} \mathrm{~F},{ }^{6} \mathrm{P},{ }^{6} \mathrm{D}$ and ${ }^{6} \mathrm{~F}$ ) and accounts for 25 fine-structure levels. Transitions from $\left({ }^{5} \mathrm{D}\right) 4 \mathrm{p}$ are observed in the ultraviolet region to levels within the terms $\left({ }^{5} \mathrm{D}\right) 4 \mathrm{~s}{ }^{6} \mathrm{D},\left({ }^{5} \mathrm{D}\right) 4 \mathrm{~s}{ }^{4} \mathrm{D}, 3 \mathrm{~d}^{7}{ }^{4} \mathrm{~F}$ and $3 d^{7} a^{4} \mathrm{P}$ forming strong Fe II multiplets. Since transitions from all the 25 levels are observed, collisional excitation is the most likely population process. However, the decay of the $\left({ }^{5} \mathrm{D}\right) 5 \mathrm{~s}$ levels, populated by the cascading decay of the H Ly $\alpha$ pumped

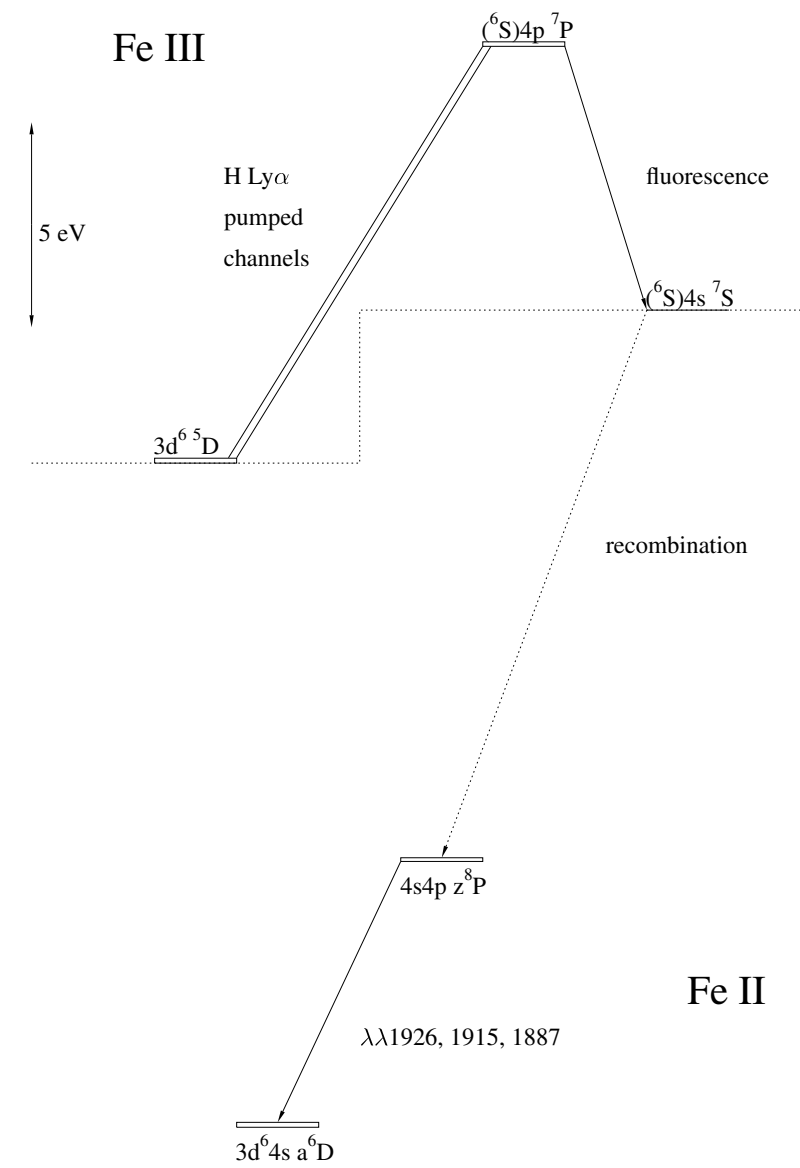

Fig. 11. Figure demonstrating our idea of the excitation mechanism in Fe III and Fe II responsible for the observed octet transitions in Fe II. The presumed recombination channels are presented as dotted lines, the pumped channel as a double lines and the decay channels as solid lines. Only the levels involved in the process are plotted in this Grotrian diagram.

$\left({ }^{5} \mathrm{D}\right) 5 \mathrm{p}$ levels (see Sect. 3.2.1), causes deviations in the thermal population of $\left({ }^{5} \mathrm{D}\right) 4 \mathrm{p}$. Thus, the observed line strengths within the $\left({ }^{5} \mathrm{D}\right) 4 \mathrm{~s}-\left({ }^{5} \mathrm{D}\right) 4 \mathrm{p}$ and $3 \mathrm{~d}^{7}-\left({ }^{5} \mathrm{D}\right) 4 \mathrm{p}$ multiplets are different from what is expected from their $\mathrm{gA}$-values, as measured by Schnabel et al. (2004) (Table 8). Also of importance is that the transition to the ground level $\left({ }^{5} \mathrm{D}\right) 4 \mathrm{~s}^{6} \mathrm{D}_{9 / 2}$ is in absorption, which indicates that the optical depths also will influence the relative line strengths.

\section{H) The octet levels in Fe II}

Three emission lines $(\lambda \lambda 1926.07,1915.62$ and 1887.83) have been identified as originating from the $z^{8} \mathrm{P}$ term in Fe II, which has no spin-allowed decay channels. These three lines require an explanation since the Fe II octet transitions are very rare in stellar spectra. In fact, they have only been observed in the spectrum of the sun Johansson 1977.

If Fe III is to recombine to any octet level of Fe II by electron capture the metastable septet level $\left({ }^{6} \mathrm{~S}\right) 4 \mathrm{~s}{ }^{7} \mathrm{~S}_{3}$ of Fe III has to be populated. The PAR mechanism in Fe III results in population of the $\left({ }^{6} \mathrm{~S}\right) 4 \mathrm{p}{ }^{7} \mathrm{P}$ levels. Furthermore, by the observed Fe III fluorescence lines at 1955.27, 1914.06 and 


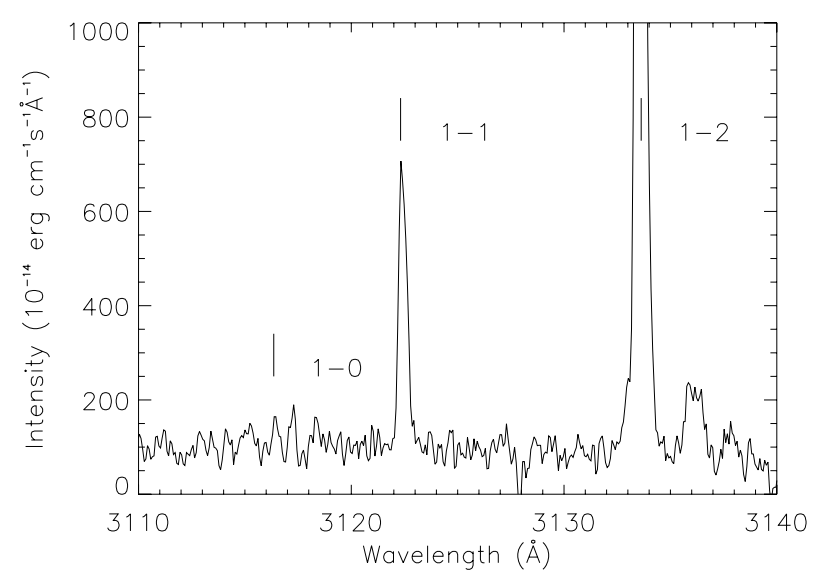

Fig. 12. The three O III $2 p 3 p{ }^{3} S-2 p 3 d{ }^{3} \mathrm{P}$ transitions in spectrum lwp25995. Whit the dynamical range of $I U E$ it is not sufficient to observe the ${ }^{3} \mathrm{~S}_{1}-{ }^{3} \mathrm{P}_{0}$ transition without having the ${ }^{3} \mathrm{~S}_{1}-{ }^{3} \mathrm{P}_{2}$ transition saturated because of the large difference of intensity.

$1895.46 \AA$ A corresponding to $\left({ }^{6} \mathrm{~S}\right) 4 \mathrm{~s}^{7} \mathrm{~S}-\left({ }^{6} \mathrm{~S}\right) 4 \mathrm{p}^{7} \mathrm{P}$ transitions the metastable Fe III ( $\left({ }^{6} \mathrm{~S}\right) 4 \mathrm{~s}^{7} \mathrm{~S}_{3}$ level is known to be populated. In Fig. 11 our suggestion of the process leading to the Fe II octet transitions is shown.

\subsection{The O III Bowen lines}

The first known PAR process was the pumping of O III through the channel $2 \mathrm{p}^{2}{ }^{3} \mathrm{P}_{2}-2 \mathrm{p} 3 \mathrm{~d}{ }^{3} \mathrm{P}_{2}$ at $303.80 \AA$ by He II Ly $\alpha$ at $303.78 \AA$ Bowen 1934, 1935. In the spectra of AG Peg emission lines corresponding to $2 \mathrm{p} 3 \mathrm{p}{ }^{3} \mathrm{~S}-2 \mathrm{p} 3 \mathrm{~d}{ }^{3} \mathrm{P}$ and $2 \mathrm{p} 3 \mathrm{p}{ }^{3} \mathrm{D}-$ $2 \mathrm{p} 3 \mathrm{~d}{ }^{3} \mathrm{P}$ transitions are observed, which concludes that the Bowen mechanism is active in the system. The possibility of allowed primary decays from $2 \mathrm{p} 3 \mathrm{~d}{ }^{3} \mathrm{P}$ to $2 \mathrm{p} 3 \mathrm{p}{ }^{3} \mathrm{P}$, which form emission lines around $3430 \AA$, is outside the IUE range. However, all six possible emission lines corresponding to the secondary decays $2 \mathrm{p} 3 \mathrm{~s}{ }^{3} \mathrm{P}-2 \mathrm{p} 3 \mathrm{p}{ }^{3} \mathrm{P}$ are observed and hence, the $2 \mathrm{p} 3 \mathrm{p}{ }^{3} \mathrm{P}-2 \mathrm{p} 3 \mathrm{~d}{ }^{3} \mathrm{P}$ is certainly active. Also, two emission lines, O III $\lambda 3341.73,3300.34$ are observed as secondary decays from $2 \mathrm{p} 3 \mathrm{~s}^{3} \mathrm{P}-2 \mathrm{p} 3 \mathrm{p}^{3} \mathrm{~S}$ transitions.

It is not only the ${ }^{3} \mathrm{P}_{2}$ level that is populated by PAR in AG Peg, the two other fine structure levels, ${ }^{3} \mathrm{P}_{1}$ and ${ }^{3} \mathrm{P}_{0}$, are also populated through channels within $2 \mathrm{p}^{2}{ }^{3} \mathrm{P}-2 \mathrm{p} 3 \mathrm{~d}{ }^{3} \mathrm{P}$ between $303.41 \AA$ and $303.80 \AA$ (Eriksson et al. 2005). From the three emission lines corresponding to $2 \mathrm{p} 3 \mathrm{p}{ }^{3} \mathrm{~S}-2 \mathrm{p} 3 \mathrm{~d}{ }^{3} \mathrm{P}$ (Fig. 12) the relative population rate of the fine structure levels in $2 \mathrm{p} 3 \mathrm{~d}{ }^{3} \mathrm{P}$ can be estimated. The theoretical relative LS intensities for the transitions $\left({ }^{3} \mathrm{~S}_{1}-{ }^{3} \mathrm{P}_{2}:{ }^{3} \mathrm{~S}_{1}-{ }^{3} \mathrm{P}_{1}:{ }^{3} \mathrm{~S}_{1}-{ }^{3} \mathrm{P}_{0}\right)$ are 100:60:20 and the observed relative intensities, which can not be measured exactly because of saturation of the strongest line, are 100: $<20:<3$. The population rate of ${ }^{3} \mathrm{P}_{1}$ and ${ }^{3} \mathrm{P}_{0}$ is less than for ${ }^{3} \mathrm{P}_{2}$ by a factor of at least 3 and 7 , respectively.

When the observed Balmer $\alpha$ and Pashen lines of He II became narrower by a factor of $\sim 20$ during the middle of the 1980s the He II Ly $\alpha$ pumped O III lines also changed in appearance. In spectra recorded in 1981 and earlier the FWHM of the Bowen lines was $\sim 120 \mathrm{~km} \mathrm{~s}^{-1}$, which was a factor of $\sim 6$ smaller than that of the white-dwarf wind lines but more than a factor of 3 broader than the emission lines from the nebula and the red-giant atmosphere. The FWHM of the O III Bowen lines then decreased and was $\sim 45 \mathrm{~km} \mathrm{~s}^{-1}$ in the early 1990s. The widths of the emission lines associated with the white-dwarf wind in early IUE spectra decreased more rapidly during the 1980s, and the Bowen lines were actually among the broadest UV emission lines in spectra of AG Peg in the early 1990s. After 1986 the net flux of the O III Bowen lines increased by $\sim 50 \%$. This could mean that after the He II region changed location from the white-dwarf wind to the heated part of the red-giant atmosphere more He II emission was able to reach the $\mathrm{O}^{2+}$ ions.

\subsection{A line list for $A G P e g$}

All emission features observed in this work are listed in Table 13. Lines longward of $1980 \AA$ were observed with IUE $(L W P)$, the lines between 1170 and $1980 \AA$ with IUE (SWP) and the lines below 1170 were observed with FUSE (LWRS and $M D R S$ ). In order to make comparison of line strengths useful for lines within the wavelength range of each instrument all peak intensities and FWHM are tabulated as measured in the same spectra, LWP25995 for 1980-3350 A,, SWP47715 for 1170-1980 ̊̊ and Q1110101 for lines below $1170 \AA$, which we call the reference spectra. A few emission features are present in spectra other than the reference spectra. These features are marked with "oth" in the first column in the table and no information about intensity or FWHM are given in Table 14. The reference spectra were selected as such since they have the lowest noise level, which has the disadvantage that the strongest lines are saturated and no information about peak intensity or $F W H M$ can be given in Table 13. The saturated lines are marked by "oe" in the second column. In Cols. 4-7 the identifications of the observed lines are presented. For the unidentified lines those columns are left blank. Features that are considered to be blended with unknown features are marked with the superscript "bl" on the measured intensity in the second column. In Col. 8 we have noted the subsection to which the reader can refer for our suggestion of the process responsible for the formation of the feature. For the wavelength intervals covered by the HST (GHRS) observations Col. 9 presents the intensities.

In Table 14 all of the emission lines absent in the reference spectra are given with the observed wavelengths (Col. 1), peak intensities (Col. 2) and widths (Col. 3). The identifications are given in Cols. 4-7 as in Table 13. Column 9 lists the spectra from which the lines were measured.

Table 15 lists all of the lines that were over-exposed in the reference spectra and is constructed in the same manner as Table 14.

Table 16 is a list of the absorption lines in AG Peg. The first column gives the observed wavelength. If the wavelength is superscripted with a; the line is measured in LWP09698, b; SWP15651 and c; SWP10454, while all other lines are measured in the reference spectra. The superscript "** means that the line is not measured in this work but that its presence is revealed by profile fitting of the $\mathrm{N} \mathrm{V}$ and $\mathrm{C}$ IV resonance lines (Eriksson et al. 2004). The equivalent widths of the lines are given in Col. 2 and the identifications in Cols. 3-6. In Col. 7, 
$I S$ stands for interstellar line and $b l$ for line blended by unknown contributors.

\section{Nature of the emission lines in symbiotic stars}

\subsection{White-dwarf wind lines}

A question one might ask is whether the broad wind features associated with some of the lines between 1000 and $2000 \AA$ in AG Peg (before 1986) are unique to this star or if they are common among the symbiotic stars. To answer this question the lines showing broad wind profiles in AG Peg were analyzed for the symbiotic stars listed in Table 2. It turned out that the widths of over $400 \mathrm{~km} \mathrm{~s}^{-1}$ observed in AG Peg before 1986 are rare but not unique among these other systems, as it was observed for four of the nineteen selected symbiotic systems (PU Vul, T CrB, CH Cyg and EG And).

PU Vul is one of the symbiotic stars classified as symbiotic novae Vogel \& Nussbaumer 1992, just like AG Peg. The Si IV $\lambda 1393$ line shows a P Cygni profile with terminal velocity of $750 \mathrm{~km} \mathrm{~s}^{-1}$, which is similar to the white-dwarf wind velocity of AG Peg (Eriksson et al. 2004). We suggest, therefore, that the broad lines in PU Vul can be explained by a fast wind from the white dwarf triggered by the slow nova outburst. EG And is known to have a fast $\left(\sim 500 \mathrm{~km} \mathrm{~s}^{-1}\right)$ wind from the white dwarf (Vogel 1993), which can explain the broad profiles underlying the narrower nebular lines in its spectrum. Interestingly, in 1995 the C IV $\lambda 1548$ line displayed a P Cygni profile associated with a terminal velocity of only $114 \mathrm{~km} \mathrm{~s}^{-1}$. We have not been able to explain this absorption component but modeling of the same line in AG Peg has revealed an absorption component. This is the collision region of the white dwarf and red giant winds associated with a terminal velocity of half the white dwarf wind velocity. This should be noticed since EG And also has a region where the winds from the two stars collide (Tomov 1995). More surprising are the broad lines in $\mathrm{T} \mathrm{CrB}$ and $\mathrm{CH} \mathrm{Cyg}$, since the white dwarf in these systems is known to be accreting matter from the red-giant wind (Iijima 1982; Kenyon \& Garcia 1986), and therefore no whitedwarf wind is expected. The argument of matter falling into the disk surrounding the white dwarf is further strengthened here as inverted P Cygni profiles are observed in the lines C IV $\lambda 1548$ (both systems) and He II $\lambda 1640$ (only in T CrB). Even if we cannot explain how the lines are broadened to over $700 \mathrm{~km} \mathrm{~s}^{-1}$ the reason can be the infall of matter on the disk surrounding the white dwarf.

The 15 symbiotic systems with no trace of lines having $F W H M$ greater than $400 \mathrm{~km} \mathrm{~s}^{-1}$ can be divided into two distinct categories with respect to the lines showing broad wind profiles in AG Peg. For eight of the stars all of those lines have $F W H M$ between 40 and $70 \mathrm{~km} \mathrm{~s}^{-1}$, which is normal for most of the lines observed by IUE in spectra of symbiotic stars. Such lines are called nebular lines and their origin being the red giant upper atmosphere irradiated by the white dwarf. For the remaining seven systems some of those emission lines have a $F W H M$ between 110 and $140 \mathrm{~km} \mathrm{~s}^{-1}$. Common to these latter systems is that they all have underwent outbursts which could lead to an outflow of matter from the white dwarf. In Table 9 the widths of five lines associated with the white-dwarf wind in a few of the symbiotic systems is given for 20 symbiotic systems.

\subsection{Fe II fluorescence}

From Sect. 3.2.1 it was clear that the $\mathrm{Fe}^{+}$ions in $\mathrm{AG}$ Peg are subjected to radiation from both a high-temperature region and a cool region emitting H Ly $\alpha$. Also, in RR Tel Fe II fluorescence lines are observed, pumped both by lines from highly-ionized ions and by $\mathrm{H} \operatorname{Ly} \alpha$ (Hartman \& Johansson 2000). A study of fluorescence lines in symbiotic stars (Eriksson et al. 2004) indicated that the Fe II regions in stars associated with slow nova eruptions were pumped by both $\mathrm{H} \mathrm{Ly} \alpha$ and high-ionization lines resulting in numerous $(>10)$ actively pumped Fe II channels. Other symbiotic stars (with no indication of slow nova eruptions) showed fewer fluorescence lines and no $\mathrm{H} \operatorname{Ly} \alpha$ pumping. A special case is those objects known to have an accreting hot component, whose spectra showed no Fe II fluorescence.

In the present study ultraviolet Fe II fluorescence lines have been searched for in the symbiotic stars listed in Table 2. The presence of the Fe II lines $\lambda \lambda 2507.55,2509.10$ in emission serves as an indication of $\mathrm{H} \operatorname{Ly} \alpha$ pumping, while lines from the C IV pumped Fe II levels (see Table 5) serve as indicators of an Fe II region subjected to radiation from a high-ionization region. Absence of fluorescence lines in IUE data of a symbiotic star is not a sufficient reason to conclude that there is no pumping of Fe II. The lower limit of the peak intensity, for a line to be detected with the IUE, is around $3 \times 10^{-13} \mathrm{erg} \mathrm{cm}^{-2} \mathrm{~s}^{-1}$. However, in systems where the $\left({ }^{5} \mathrm{D}\right) 4 \mathrm{~s}-\left({ }^{5} \mathrm{D}\right) 4 \mathrm{p}$ resonance transitions but still no Fe II fluorescence lines are observed fluorescence can be ruled out or assumed to play a negligible role. Therefore, a search for Fe II lines corresponding to the $a^{6} \mathrm{D}-$ $z^{6} \mathrm{D}$ and $a^{6} \mathrm{D}-z^{6} \mathrm{P}$ multiplets, which normally form the strongest Fe II lines in the $I U E$ wavelength domain, has been carried out. The results of this search are presented in Table 10.

Among the twenty symbiotic systems considered in this study six belong to the subgroup of symbiotic slow novae: AG Peg, HM Sge, PU Vul, RR Tel, PU Vul, V1016 Cyg and V1329 Cyg. Except for HM Sge, both H Ly $\alpha$ and C IV $\lambda 1548$ pumping of $\mathrm{Fe}$ II occurs in these systems, as observed by Eriksson et al. (2004). Emission lines in HM Sge are, in general, one magnitude fainter than in other symbiotic novae and even the Fe II resonance lines cannot be observed in the $I U E$ spectra. This anomaly for HM Sge could indicate that it has no significant Fe II region or that the $\mathrm{S} / \mathrm{N}$ ratio of $I U E$ is not high enough to see the Fe II emission.

Three of the symbiotic systems ( $\mathrm{CH} \mathrm{Cyg,} \mathrm{CI} \mathrm{Cyg} \mathrm{and}$ $\mathrm{T} \mathrm{CrB}$ ) are known to have accreting disks around their hot components. As pointed out by Eriksson et al. (2004) no Fe II fluorescence can be detected in those systems. However, the Fe II resonance lines are observed in $\mathrm{CH} \mathrm{Cyg}$, which implies that there might be a Fe II region but no fluorescence in symbiotic systems involving accretion onto the hot component.

It becomes more problematic when considering the results of the 11 "normal" symbiotic stars, which do not belong to the 
Table 9. The nature of lines having white dwarf wind profile in AG Peg in symbiotic stars.

\begin{tabular}{|c|c|c|c|c|c|c|}
\hline Object & He II $\lambda 1640$ & C IV $\lambda 1548$ & N IV $\lambda 1486$ & N V $\lambda 1238$ & Si IV $\lambda 1393$ & Comment \\
\hline EG And & (tcp) & $52(\mathrm{~s}, \mathrm{pc})$ & 36 & & 34 & B \\
\hline CH Cyg & $42(s)$ & $730\left(\mathrm{pc}^{*}\right)$ & & 321 & str & B \\
\hline $\mathrm{T} \mathrm{CrB}$ & $573\left(\mathrm{pc}^{*}\right)$ & $821\left(\mathrm{pc}^{*}\right)$ & 320 & 788 & & B \\
\hline PU Vul & & 166 & & & $982(\mathrm{pc})$ & B \\
\hline V1329 Cyg & 159 & 226 & & & & $\mathrm{~b}$ \\
\hline Z And & 113 & 64 & 67 & 114 & 69 & $\mathrm{~N}^{*}$ \\
\hline RX Pup & 68 & $128(\mathrm{~s})$ & 118 & 111 & 112 & $\mathrm{~N}^{*}$ \\
\hline HBV475 & 142 & 130 & & & & $\mathrm{~N}^{*}$ \\
\hline R Aqr & & 112 & & & 110 & $\mathrm{~N}^{*}$ \\
\hline HM Sge & 137 & 111 & 130 & 131 & 110 & $\mathrm{~N}^{*}$ \\
\hline AG Dra & 110 & 58 & 41 & $70(\mathrm{pc})$ & 56 & $\mathrm{~N}^{*}$ \\
\hline RW Hya & 64 & 56 & 55 & & & $\mathrm{~N}$ \\
\hline SY Mus & 66 & 67 & 36 & 58 & 39 & $\mathrm{~N}$ \\
\hline BF Cyg & 38 & $65(\mathrm{~s}, \mathrm{pc})$ & 65 & & 69 & $\mathrm{~N}$ \\
\hline CI Cyg & 68 & 44 & 53 & 55 & 50 & $\mathrm{~N}$ \\
\hline V1016 Cyg & 65 & 65 & 51 & 52 & 64 & $\mathrm{~N}$ \\
\hline RR Tel & 70 & 68 & 39 & 51 & 43 & $\mathrm{~N}$ \\
\hline AX Per & 64 & 52 & 46 & 58 & 58 & $\mathrm{~N}$ \\
\hline KX Tra & 69 & 50 & 36 & 58 & 54 & $\mathrm{~N}$ \\
\hline $\mathrm{AG} \mathrm{Peg}^{a}$ & 770 & (tcp, pc) & (tcp) & 800 & (tcp) & B \\
\hline $\mathrm{AG} \mathrm{Peg}^{b}$ & 66 & 45 & & 56 & 36 & $\mathrm{~N}$ \\
\hline
\end{tabular}

N) All five lines have $F W H M$ less than $70 \mathrm{~km} \mathrm{~s}^{-1}$.

$\mathrm{N}^{*}$ ) One, a few or all of the five lines have a $F W H M$ between 120 and $150 \mathrm{~km} \mathrm{~s}^{-1}$, which is significantly broader than for the majority of lines in their spectra.

b) Two of the five lines are observable in $I U E$ spectra of V1329 Cyg, the widths of those lines are broader than for the stars denoted $\mathrm{N}^{*}$ but narrower than $400 \mathrm{~km} \mathrm{~s}^{-1}$.

B) Very broad lines $\left(F W H M>400 \mathrm{~km} \mathrm{~s}^{-1}\right)$ are observed as single lines or as narrow lines superimposed on broad sockets (str).

pc) P cygni profile.

$\mathrm{pc}^{*}$ ) Inverted $\mathrm{P}$ cygni profile.

tcp = Two component profile as the spectral line has a narrow emission component superimposed on the broad white dwarf wind profile.

subgroup symbiotic novae or show any sign of a disk. Four of those systems, BF Cyg, HBV475, AG Dra and KX Tra, have no detectable Fe II emission lines in the IUE spectra, and they are in a way similar to the symbiotic nova HM Sge as regards Fe II. The systems RW Hya and R Aqr show Fe II fluorescence lines from levels pumped by high-ionization lines only. However, IUE spectra of the systems EG And, SY Mus, Z And and RX Pup have Fe II lines from both C IV $\lambda 1548$ and $\mathrm{H}$ Ly $\alpha$ pumped levels. Even if neither is designated as a symbiotic nova, recurrent outbursts have been observed for $\mathrm{Z}$ And (Tomov et al. 2003) and RX Pup (Mikolajewska et al. 1999). This could mean that the dynamics and structure of a symbiotic system change during the outbursts (both for recurrent and slow novae) so that emission from both highly-ionized regions and $\mathrm{H}$ I regions can reach the $\mathrm{Fe}^{+}$ions. Then the group of symbiotic stars having numerous fluorescence lines (Eriksson et al. 2004) would be expanded to include all symbiotic stars associated with outbursts and not only symbiotic novae. A complication to this simple idea is that outbursts also have been observed in the symbiotic stars CI Cyg and AG Dra (Belczynski et al. 2000), which do not have numerous fluorescence lines. Since CI Cyg is, as discussed in the previous paragraph, a disk-system for which no Fe II fluorescence has been observed and AG Dra is known to be metal deficient, the lack of Fe II emission lines in these two systems is no surprise. Two normal symbiotic stars seem to fall outside the established groups: SY Mus, which emits Fe II fluorescence from both H Ly $\alpha$ and C IV $\lambda 1548$ pumped levels, and AX Per, which is the only symbiotic star known to emit Fe II lines only from H Ly $\alpha$ pumped levels.

\subsection{Forbidden lines}

Forbidden lines indicate low density regions in astrophysical sources. In AG Peg, this low density region must be very hot 
Table 10. Fe II emission in symbiotic stars.

\begin{tabular}{lccc}
\hline \hline Object & $\begin{array}{c}\text { C IV } \\
\text { pumped }\end{array}$ & $\begin{array}{c}\text { H Ly } \alpha \\
\text { pumped }\end{array}$ & $\begin{array}{c}\left({ }^{5} \mathrm{D}\right) 4 \mathrm{~s}-\left({ }^{5} \mathrm{D}\right) 4 \mathrm{p} \\
\text { collisionally excited }\end{array}$ \\
\hline AG Peg & yes & yes & yes \\
SY Mus & yes & yes & yes \\
Z And & yes & yes & yes \\
RX Pup & yes & yes & yes \\
V1016 Cyg & yes & yes & yes \\
RR Tel & yes & yes & yes \\
V1329 Cyg & yes & yes & no \\
PU Vul & yes & yes & no \\
EG And & yes & yes & no \\
CH Cyg & no & yes & yes \\
RW Hya & yes & no & no \\
AX Per & no & yes & no \\
R Aqr & no & no & yes \\
CI Cyg & no & no & no \\
HBV475 & no & no & no \\
T CrB & no & no & no \\
HM Sge & no & no & no \\
AG Dra & no & no & no \\
BF Cyg & no & no & no \\
KX Tra & no & no & no \\
\hline
\end{tabular}

since the forbidden lines belong to highly ionized atoms. As a check whether such a region with high temperature and low density is common in symbiotic stars a search was conducted for forbidden lines in the $I U E$ spectra of the other symbiotic stars. As indicators of lower temperature in the low density regions forbidden lines of N II, O I, O II and O III were selected. Forbidden lines of third to fifth spectra of the noble gases, as well as [Mg V] (observed in AG Peg) serve as indicators of high temperature. Also, the presence of [Mg VI] and [Mg VII] lines would imply an even higher temperature in the low density region than for AG Peg. A list of the forbidden lines searched for in the IUE spectra of all 20 selected symbiotic stars is given in Table 11.

Forbidden lines are detected in IUE spectra for 14 of the 20 selected symbiotic stars (see Table 11). [Mg V] is seen in the spectra of eight of the symbiotic stars, and is the most frequently observed among the forbidden lines. There are four systems showing forbidden lines from magnesium: EG And, RW Hya, CH Cyg and R Aqr. EG And has forbidden lines from [O II], [Ar III] and [Ne III], RW Hya from [O III] and [Ar III], CH Cyg from [O III] and [Ar III] and R Aqr from $[\mathrm{O}$ II] and [O III] and [Ar III]. The absence of [Ar V] and $[\mathrm{Ne} \mathrm{V}]$ in these four systems indicates that the temperature in the low density region is too low for the formation of $\mathrm{Mg}^{4+}$. The system AG Dra has only forbidden lines from [Mg VI] and $[\mathrm{Mg}$ VII]. The relative locations of the forbidden line regions within the symbiotic stars, and thereby the radiation field they are subjected to are poorly known. Therefore, a more detailed analysis of the forbidden line regions are not possible at this point. Assuming local thermal equilibrium, the forbidden lines observed can be explained by one region of one dominant temperature in 6 of the 14 systems showing forbidden lines (see Table 11).

\section{Summary}

The ultraviolet spectrum of AG Peg is indeed complex. In terms of number of lines the emission spectrum is dominated by nebular lines. Overall, the lines reflect a variety of physical processes and locations. A few emission lines are associated with the red-giant chromosphere such as Mg II $\lambda \lambda 2803.53,2796.35$ which are the strongest lines between 2000 and $3000 \AA$. They have a self-absorbed structure, which is typical for resonance lines. In large contrast to the red giant chromospheric lines, the AG Peg spectrum also contains parity-forbidden lines from highly-ionized ions like $\mathrm{Ne}^{3+}$ and $\mathrm{Mg}^{5+}$. These forbidden lines originate in the thin outer nebula. As an indication of the complexity of the system, intercombination and allowed lines from highly ionized ions are also observed. Most of these lines, such as Si III] $\lambda 1892.03$, are excited by collisions while a few lines like $\mathrm{O} V \lambda 1506.76$ are excited by recombination. These lines are formed in the heated part of the extended red-giant atmosphere. A large number of the lines in the AG Peg spectrum are fluorescence lines, for which location of formation is not well understood. Superimposed on the spectra of nebular lines are a few broad wind lines. These lines are from highly-ionized elements and those that decay to the ground level display a P Cygni profile, showing that they are formed in the whitedwarf wind. A segment of the line-list for AG Peg can be seen in Table 13.

During the 1980s the spectrum of AG Peg changed remarkably. Before 1986 six forbidden lines were observable in IUE spectra: [O III] $\lambda 2321.66$, [Ne III] $\lambda 1814.63$ and four [Ne IV] lines. After 1986 the [O III] line has disappeared while six new lines from four times ionized ions $\left(\mathrm{Ar}^{4+}, \mathrm{Ne}^{4+}\right.$ and $\mathrm{Mg}^{4+}$ ) and two lines from $\mathrm{Fe}^{5+}$ are observed. An explanation for the change among the parity forbidden lines can be a temperature increase in the region emitting those lines. All of the 22 emission lines observed by $I U E$ with $F W H M>400 \mathrm{~km} \mathrm{~s}^{-1}$ before 1986 (the white-dwarf wind lines) partially or completely disappeared after 1986 and were replaced by narrow nebular lines. The transformation of the broad wind lines occurred first for the lines of lower ionization energies and later for lines of higher ionization energies. A continuous temperature increase in the white-dwarf wind during the 1980s would explain the order in which the white-dwarf wind lines disappeared, but the temperature of the white dwarf was according to Zanstra determinations constant during the same period (Altamore \& Cassatella 1997). However, a temperature increase of the wind does not mean that the temperature of the white dwarf surface increased. Eriksson et al. (2004) showed that the opacity in the white-dwarf wind for two of the wind emission lines decreased, which means that more radiation from the white dwarf reaches further into the wind. A shell in the white-dwarf wind emitting, for example, $\mathrm{C}^{3+}$ emission moves outward in the white-dwarf wind until all $\mathrm{C}^{3+}$ ions in the wind are ionized to $\mathrm{C}^{4+}$.

A few of the lines which possessed wind profiles in the spectra before 1986 are shown to be pumping Fe II channels and are thereby the cause of many of the observed Fe II fluorescence lines. When the broad wind profiles disappeared in the 1980s, only the Fe II fluorescence lines corresponding to 
Table 11. Forbidden lines searched for in 20 symbiotic stars.

\begin{tabular}{|c|c|c|c|c|c|}
\hline$\lambda_{\text {vac }}(\AA)$ & Spectra & Config. $^{a}$ & Transition & $\mathrm{A}_{i j}\left(\mathrm{~s}^{-1}\right)$ & $\mathrm{No}^{b}$. \\
\hline 3110.08 & [Ar III] & $3 p^{4}$ & ${ }^{3} \mathrm{P}_{1}-{ }^{1} \mathrm{~S}_{0}$ & 4.02 & 3 \\
\hline 3071.44 & {$[\mathrm{~N} \mathrm{II}]$} & $2 p^{2}$ & ${ }^{3} \mathrm{P}_{2}-{ }^{1} \mathrm{~S}_{0}$ & $1.4 \times 10^{-4}$ & 3 \\
\hline 3063.72 & [N II] & $2 p^{2}$ & ${ }^{3} \mathrm{P}_{1}-{ }^{1} \mathrm{~S}_{0}$ & 0.032 & 1 \\
\hline 3006.10 & [Ar III] & $3 p^{4}$ & ${ }^{3} \mathrm{P}_{2}-{ }^{1} \mathrm{~S}_{0}$ & 0.043 & 1 \\
\hline 2993.64 & [Mg V] & $2 p^{4}$ & ${ }^{3} \mathrm{P}_{0}-{ }^{1} \mathrm{D}_{2}$ & $6.7 \times 10^{-5}$ & 2 \\
\hline 2975.66 & {$[\mathrm{Ne} \mathrm{V}]$} & $2 p^{2}$ & ${ }^{1} \mathrm{D}_{2}-{ }^{1} \mathrm{~S}_{0}$ & 2.60 & 2 \\
\hline 2973.15 & [O I] & $2 p^{4}$ & ${ }^{3} \mathrm{P}_{1}-{ }^{1} \mathrm{~S}_{0}$ & 0.075 & 1 \\
\hline 2959.23 & {$[\mathrm{O} \mathrm{I}]$} & $2 p^{4}$ & ${ }^{3} \mathrm{P}_{2}-{ }^{1} \mathrm{~S}_{0}$ & $2.4 \times 10^{-4}$ & 1 \\
\hline 2928.87 & {$[\mathrm{Mg} \mathrm{V}]$} & $2 p^{4}$ & ${ }^{3} \mathrm{P}_{1}-{ }^{1} \mathrm{D}_{2}$ & 0.55 & 8 \\
\hline 2868.99 & [Ar IV] & $3 p^{3}$ & ${ }^{4} \mathrm{~S}_{3 / 2}-{ }^{2} \mathrm{P}_{1 / 2}$ & 0.97 & 3 \\
\hline 2854.48 & [Ar IV] & $3 p^{3}$ & ${ }^{4} \mathrm{~S}_{3 / 2}-{ }^{2} \mathrm{P}_{3 / 2}$ & 2.55 & 4 \\
\hline 2786.82 & [Ar V] & $3 p^{2}$ & ${ }^{3} \mathrm{P}_{2}-{ }^{1} \mathrm{~S}_{0}$ & 0.081 & 0 \\
\hline 2783.50 & {$[\mathrm{Mg} \mathrm{V}]$} & $2 p^{4}$ & ${ }^{3} \mathrm{P}_{2}-{ }^{1} \mathrm{D}_{2}$ & 1.90 & 8 \\
\hline 2692.02 & [Ar V] & $3 p^{2}$ & ${ }^{3} \mathrm{P}_{1}-{ }^{1} \mathrm{~S}_{0}$ & 6.80 & 4 \\
\hline 2629.92 & [Mg VII] & $2 p^{2}$ & ${ }^{3} \mathrm{P}_{2}-{ }^{1} \mathrm{D}_{2}$ & 3.39 & 1 \\
\hline 2509.98 & [Mg VII] & $2 \mathrm{p}^{2}$ & ${ }^{3} \mathrm{P}_{1}-{ }^{1} \mathrm{D}_{2}$ & 1.30 & 1 \\
\hline 2471.09 & [O II] & $2 p^{3}$ & ${ }^{4} \mathrm{~S}_{3 / 2}-{ }^{2} \mathrm{P}_{3 / 2}$ & 0.052 & 6 \\
\hline 2470.97 & [O II] & $2 p^{3}$ & ${ }^{4} \mathrm{~S}_{3 / 2}-{ }^{2} \mathrm{P}_{1 / 2}$ & 0.021 & 6 \\
\hline 2442.12 & [Mg VII] & $2 p^{2}$ & ${ }^{3} \mathrm{P}_{1}-{ }^{1} \mathrm{D}_{2}$ & $1.3 \times 10^{-4}$ & 0 \\
\hline 2425.15 & [Ne IV] & $2 p^{3}$ & ${ }^{4} S_{3 / 2}-{ }^{2} D_{5 / 2}$ & $4.1 \times 10^{-4}$ & 3 \\
\hline 2422.51 & [Ne IV] & $2 \mathrm{p}^{3}$ & ${ }^{4} S_{3 / 2}-{ }^{2} D_{3 / 2}$ & $5.3 \times 10^{-3}$ & 4 \\
\hline 2418.20 & [Mg V] & $2 p^{4}$ & ${ }^{1} \mathrm{D}_{1}-{ }^{1} \mathrm{~S}_{0}$ & 4.20 & 2 \\
\hline 2332.11 & [O III] & $2 p^{2}$ & ${ }^{3} \mathrm{P}_{2}-{ }^{1} \mathrm{~S}_{0}$ & $6.3 \times 10^{-4}$ & 1 \\
\hline 2321.66 & [O III] & $2 p^{2}$ & ${ }^{3} \mathrm{P}_{1}-{ }^{1} \mathrm{~S}_{0}$ & 0.22 & 5 \\
\hline 1814.63 & {$[\mathrm{Ne}$ III] } & $2 p^{4}$ & ${ }^{3} \mathrm{P}_{1}-{ }^{1} \mathrm{~S}_{0}$ & 2.20 & 3 \\
\hline 1806.49 & [Mg VI] & $2 p^{3}$ & ${ }^{4} S_{3 / 2}-{ }^{2} D_{5 / 2}$ & $3.2 \times 10^{-3}$ & 2 \\
\hline 1805.94 & [Mg VI] & $2 \mathrm{p}^{3}$ & ${ }^{4} S_{3 / 2}-{ }^{2} D_{3 / 2}$ & 0.12 & 2 \\
\hline 1793.70 & {$[\mathrm{Ne} I I I]$} & $2 p^{4}$ & ${ }^{3} \mathrm{P}_{2}-{ }^{1} \mathrm{~S}_{0}$ & $5.1 \times 10^{-3}$ & 0 \\
\hline 1601.67 & [Ne IV] & $3 p^{3}$ & ${ }^{4} \mathrm{~S}_{3 / 2}-{ }^{2} \mathrm{P}_{1 / 2}$ & 0.53 & 4 \\
\hline 1601.50 & [Ne IV] & $3 p^{3}$ & ${ }^{4} S_{3 / 2}-{ }^{2} P_{3 / 2}$ & 1.33 & 4 \\
\hline 1592.27 & {$[\mathrm{Ne} \mathrm{V}]$} & $2 p^{2}$ & ${ }^{3} \mathrm{P}_{2}-{ }^{1} \mathrm{~S}_{0}$ & $6.8 \times 10^{-3}$ & 0 \\
\hline 1574.77 & {$[\mathrm{Ne} \mathrm{V}]$} & $2 p^{2}$ & ${ }^{3} \mathrm{P}_{1}-{ }^{1} \mathrm{~S}_{0}$ & 4.20 & 2 \\
\hline
\end{tabular}

${ }^{a}$ All forbidden lines in this table have the ground configuration for both upper and lower level.

${ }^{b}$ The number of symbiotic stars where the lines were observed.

the closest coincidances remained while the other Fe II fluorescence lines vaniched.

Observations by FUSE reveal that the O VI $\lambda 1031,1037$ doublet still showed a broad wind profile in 2001. The evolution of the fluorescence lines followed that of their pumping lines. As the broad wind lines vanished so did the fluorescence lines associated with channels too far apart in wavelength from the replacing nebular lines while the fluorescence lines with very close wavelength coincidences remained in the spectrum. Fe II fluorescence lines pumped by $\mathrm{H}$ Ly $\alpha$ became stronger during the 1980s, indicating growth of the H II region in the system.

Many of the emission lines in spectra of AG Peg have been and surely will continue to be used for various diagnostics. When establishing diagnostics, such as for determining temperatures or densities, it is crucial to understand the nature of the lines employed.

White-dwarf winds in symbiotic stars seem to be quite rare, since broad wind profiles only could be detected in five of the 20 symbiotic systems. In the beginning we suspected that such a wind was linked to the slow nova eruption that has occurred in some of these systems. This idea must be re-considered since only two, PU Vul and AG Peg, of the five systems having broad wind profiles belong to the subclass of symbiotic novae. For seven of the other 15 symbiotic stars the FWHM of the lines show wind profiles in AG Peg are between $110-140 \mathrm{~km} \mathrm{~s}^{-1}$, while the $F W H M$ of the same lines in the other eight symbiotic stars were $40-70 \mathrm{~km} \mathrm{~s}^{-1}$.

Except for the total lack of Fe II emission lines in the $I U E$ spectrum of HM Sge, Fe II fluorescence lines pumped by both H Ly $\alpha$ and C IV $\lambda 1548$ were observed in the symbiotic novae. 
Table 12. Forbidden spectra in symbiotic stars.

\begin{tabular}{llc}
\hline \hline Object & Spectra & comm. \\
\hline Z And & O I, N II, Mg V & $*$ \\
EG And & O II, Ne III, Ar III & $*$ \\
R Aqr & O II+III, Ar III & \\
T CrB & & \\
BF Cyg & & \\
CH Cyg & O II, Ar III & $*$ \\
CI Cyg & & $*$ \\
AG Dra & Mg VI+VII & \\
RW Hya & O III, Ar IV & \\
SY Mus & Ar V, Mg V & \\
AG Peg & O III, Ne III+IV+V, Ar V, Mg V & \\
AX Per & & $*$ \\
RX Pup & & \\
HM Sge & O II, Ar IV, Ne IV, Mg V & \\
RR Tel & N II, O II+III, Ar III+IV+V, Ne III+IV+V, Mg V+VI & \\
KX Tra & Mg V+VI & $*$ \\
PU Vul & & N II, O II+III, Ar IV, Ne IV, Mg V \\
V1016 Cyg & & \\
V1329 Cyg & & \\
HBV475 & Mg V & \\
\hline
\end{tabular}

* All forbidden lines in the system can be explaind by a low density region in local thermal equilibrium and of one dominant temperature.

Table 13. A sample of the AG Peg line list.

\begin{tabular}{lrrrlllrr}
\hline \hline$\lambda_{\text {obs }}(\AA)$ & $I^{a}$ & $W^{b}$ & $\lambda_{\text {id }}(\AA)$ & Spec. & Lower level & Upper level & Sec $^{c}$ & Exc $^{f}$ \\
\hline 2837.13 & 652 & 43 & 2837.14 & O III & $2 \mathrm{p} 3 \mathrm{p}^{3} \mathrm{D}_{3}$ & $2 \mathrm{p} 3 \mathrm{~d}^{3} \mathrm{P}_{2}$ & 3 & $\mathrm{fl}$ \\
& & & 7.10 & O IV & $2 \mathrm{~s} 2 \mathrm{p}\left({ }^{3} \mathrm{P}\right) 3 \mathrm{~s}{ }^{4} \mathrm{P}_{5 / 2}$ & $2 \mathrm{~s} 2 \mathrm{p}\left({ }^{3} \mathrm{P}\right) 3 \mathrm{p}^{4} \mathrm{~S}_{3 / 2}$ & unk & \\
2836.43 & 46 & 24 & 2836.55 & Fe II & $4 \mathrm{~s} b^{2} \mathrm{P}_{3 / 2}$ & $4 \mathrm{p} z^{4} \mathrm{G}_{5 / 2}$ & 2.1 & $\mathrm{fl}$ \\
2833.91 & 50 & 56 & 2834.20 & Fe II & $4 \mathrm{~s} a^{4} \mathrm{D}_{7 / 2}$ & $4 \mathrm{p} z^{6} \mathrm{P}_{5 / 2}$ & $2.3 \mathrm{G}$ & col \\
& & & 3.92 & Fe II & $4 \mathrm{p} z^{6} \mathrm{P}_{5 / 2}$ & $5 \mathrm{~s} e^{6} \mathrm{D}_{5 / 2}$ & 2.1 & $\mathrm{fl}$ \\
2832.28 & 46 & 26 & 2832.40 & Fe II & $4 \mathrm{~s} b^{2} \mathrm{P}_{3 / 2}$ & $4 \mathrm{p} z^{2} \mathrm{D}_{5 / 2}$ & & unk \\
Oth & & & 2831.76 & Fe II & $4 \mathrm{~s} b^{2} \mathrm{G}_{7 / 2}$ & $4 \mathrm{p} x^{4} \mathrm{G}_{5 / 2}$ & 2.1 & $\mathrm{fl}$ \\
2829.82 & 59 & 34 & 2829.91 & He I & $2 \mathrm{~s}{ }^{3} \mathrm{~S}_{1}$ & $6 \mathrm{p}{ }^{3} \mathrm{P}_{2}$ & $2.3 \mathrm{~A}$ & $\mathrm{rec}$ \\
\hline
\end{tabular}

Even if Fe II fluorescence lines were observed in most symbiotic stars only four of the 14 symbiotic systems with no slow nova eruption known had Fe II pumped by both $\mathrm{H}$ Ly $\alpha$ and C IV. Three systems in our selection have suggested accretion disks around the hot component. The spectra of these three systems showed no signs of Fe II fluorescence. During slow nova eruptions the cool $\mathrm{H}$ I region and a region hot enough to create ions like $\mathrm{C}^{3+}$ simultaneously are in the line of sight with the large region with $\mathrm{Fe}^{+}$ions, while this rarely is the case for symbiotic systems under "normal" conditions.

Acknowledgements. All of the data presented in this paper were obtained from the Multimission Archive at the Space Telescope Science Institute (MAST). STScI is operated by the Association of Universities for Research in Astronomy, Inc., under NASA contract NAS5-26555. Support for MAST for non-HST data is provided by the NASA Office of Space Science via grant NAG-7584 and by other grants and contracts. We are grateful to the anonymous referee for a careful reading of the manuscript.

\section{References}

Allen, D. A. 1982, Nature of Symbiotic Stars, ed. M. Friedjung, \& R. Viotti (Reidel: Dordrecht), IAU Coll., 70, 27

Altamore, A., \& Cassatella, A. 1997, A\&A, 317, 712

Belczynski, K., \& Mikolajewska, J. 1998, MNRAS, 296, 77

Belczynski, K., Mikolajewska, J., Munari, U., Ivison, R. J., \& Friedjung, M. 2000, A\&AS, 146, 407

Bowen, I. S. 1934, PASP, 46, 146

Bowen, I. S. 1935, ApJ, 81, 1

Burgarella, D., Paresce, F., \& Vogel, M. 1992, ed. L. Drissen., C. Leitherer., \& A. Nota (San Francisco: Astron. Soc. Pac.), ASP Conf. Ser., 22, 298

Contini, M. 1997, ApJ, 483, 887

Contini, M. 2003, MNRAS, 339, 125 
Eriksson, M., Johansson, S., \& Wahlgren, G. M. 2001, ASP Conf. Ser., 242, ed. T. R. Gull, S. Johansson, \& K. Davidsson (San Francisco: ASP), 325

Eriksson, M., Johansson, S., \& Wahlgren, G. M. 2003, ed. R. L. M. Corradi, R. Mikolajewska, \& T. J. Mahoney (San Francisco: Aston. Soc. Pac.), ASP Conf. Ser., 303, 109

Eriksson, M., Johansson, S., \& Wahlgren, G. M. 2004a, A\&A, 422, 987

Eriksson, M., Veenhuizen, H., Johansson, S. J., \& Wahlgren, G. M. 2004b, RMxAC, 21, 132

Eriksson, M., Johansson, S. J., Wahlgren, G. M., et al. 2005, A\&A, 434, 397

Iijima, T. 1982, A\&A, 116, 210

Imhoff, C. L. 1984, A Progress Report: The Point-Spread Functions of the Platinum Lines with the New High Dispersion Processing Software, in Record of the International Ultraviolet Explorer NASA/ESA/SERC Three Agency Coordination Meeting, October 3-5, 1983, Computer Sciences Corporation, CSC/TM84/6042, March 1984, pp. A139

Johansson, S. 1977, ApJ, 212, 923

Johansson, S. 1983, MNRAS, 205, 71

Johansson, S., \& Jordan, C. 1984, MNRAS, 210, 239

Johansson, S., \& Letokhov, V. S. 2004, A\&A, 428, 497

Hartman, H., \& Johansson, S. 2000, A\&A, 359, 627

Kenyon, S. J., \& Garcia, M. R. 1986, AJ, 91, 125

Kenyon, S. J., \& Webbink, R. F. 1984, ApJ, 279, 252

Kenyon, S. J., Proga, D., \& Keyes, C. D. 2001, AJ, 122, 349

Kenyon, S. J., Mikolajewska, J., Mikolajewski, M., Polidan, R. S., \& Slovak, M. H. 1993, AJ, 106, 1573
Keyes, C. E., \& Plavec, M. J. 1980, NASA-GSFC Symp. The Universe in Ultraviolet Wavelengths, ed. R. Chapman, (NASA CP-2717), 443

Kondo, Y., Morgan, T. H., \& Modisette, J. L. 1976, ApJ, 207, 167

Mikolajewska, J., Brandi, E., Hack, W., et al. 1999, MNRAS, 305, 109

Mürset, U., \& Nussbaumer, H. 1994, A\&A, 282, 604

Mürset, U., Jordan, S., \& Walder, R. 1995, A\&A, 297, 87

Mürset, U., Wolff, B., \& Jordan, S. 1997, A\&A, 319, 201

Nussbaumer, H., \& Schild, H. 1979, A\&A, 75, 17

Nussbaumer, H., \& Storey, P. J. 1979, A\&A, 71, 5

Nussbaumer, H., \& Schild, H. 1981, A\&A, 101, 118

Nussbaumer, H., \& Storey, P. J. 1982, A\&A, 115, 205

Nussbaumer, H., Schmutz, W., \& Vogel, M. 1995, A\&A, 293, L13

Penston, M. V., \& Allen, D. A. 1985, MNRAS, 212, 939

Penston, M. V., Benvenuti, P., Cassatella, A., Heck, A., et al. 1983, MNRAS, 202, 833

Schmutz, W. 1996, Science with the HST-II, ed. F. D. M. Piero Benvenuti, \& J. S. Ethan (Baltimore: STScI), 366

Schnabel, R., Schultz-Johanning, M., \& Kock, M. 2004, A\&A, 414, 1169

Tomov, N. A., Taranova, O. G., \& Tomova, M. T. 2003, A\&A, 401, 669

Tomov, N. 1995, MNRAS, 272, 189

Vogel, M. 1993, A\&A, 274, 21

Vogel, M., \& Nussbaumer, H. 1992, A\&A, 259, 525

Vogel, M., \& Nussbaumer, H. 1994, A\&A, 248, 145

Yoo, J. J., Lee, H., \& Ahn, S. 2002, MNRAS, 334, 974 


\section{Online Material}


Table 13. All emission lines observed in AG Peg.

\begin{tabular}{|c|c|c|c|c|c|c|c|c|c|c|}
\hline$\lambda_{\text {obs }}(\AA)$ & $I^{a}$ & $w^{b}$ & $\lambda_{\text {id }}(\AA)$ & spec. & Lower level & Upper level & $\mathrm{Sec}^{c}$ & $\operatorname{Exc}^{f}$ & $I_{\mathrm{ghrs}}^{d}$ & $w_{\text {ghrs }}^{e}$ \\
\hline 3341.62 & 996 & 40 & 3341.73 & O III & $2 \mathrm{p} 3 \mathrm{~s}^{3} \mathrm{P}_{2}$ & $2 p 3 p^{3} S_{1}$ & 3 & $\mathrm{fl}$ & & \\
\hline 3311.70 & 171 & 21 & 3311.97 & $\mathrm{Fe}$ II & $4 s^{2} c^{4} D_{5 / 2}$ & $\left({ }^{5} \mathrm{D}\right) 5 \mathrm{p}{ }^{4} \mathrm{D}_{5 / 2}$ & 2.1 & fl & & \\
\hline Oth & & & 3300.34 & O III & $2 \mathrm{p} 3 \mathrm{~s}{ }^{3} \mathrm{P}_{0}$ & $2 \mathrm{p} 3 \mathrm{p}^{3} \mathrm{~S}_{1}$ & 3 & $\mathrm{fl}$ & & \\
\hline 3299.10 & 292 & 17 & & & & & & & & \\
\hline 3297.84 & 168 & 18 & 3297.72 & $\mathrm{He} \mathrm{I}$ & $1 \mathrm{~s} 2 \mathrm{~s}^{1} \mathrm{~S}_{1}$ & $1 \mathrm{~s} 8 \mathrm{p}{ }^{1} \mathrm{P}_{1}$ & $2.3 \mathrm{~A}$ & rec & & \\
\hline 3296.86 & 136 & 20 & 3296.77 & $\mathrm{Fe}$ II & $4 s a^{4} D_{3 / 2}$ & $4 p z^{6} D_{3 / 2}$ & $2.3 \mathrm{G}$ & col & & \\
\hline 3255.69 & 205 & 38 & & & & & & & & \\
\hline 3249.08 & 225 & 39 & & & & & & & & \\
\hline 3245.18 & 126 & 18 & 3245.44 & Fe II & $3 d^{7} d^{2} D_{3 / 2}$ & $4 \mathrm{pw}^{2} \mathrm{D}_{3 / 2}$ & 2.1 & fl & & \\
\hline 3244.66 & 121 & 20 & 3244.66 & Fe II & $4 \mathrm{~s} \mathrm{c}^{2} \mathrm{G}_{9 / 2}$ & $4 \mathrm{p} \mathrm{z}^{2} \mathrm{~F}_{7 / 2}$ & & $\mathrm{fl}$ & & \\
\hline 3203.97 & 991 & 61 & 3204.02 & $\mathrm{He}$ II & $n=3$ & $n=5$ & 1 & rec & & \\
\hline 3163.86 & 97 & & 3164.01 & $\mathrm{Fe}$ II & $3 d^{7} a^{4} P_{5 / 2}$ & $4 \mathrm{p} \mathrm{z}^{4} \mathrm{~F}_{5 / 2}$ & $2.3 \mathrm{G}$ & col & & \\
\hline 3162.72 & 91 & 23 & 3162.89 & Fe II & $3 d^{7} a^{4} P_{3 / 2}$ & $4 \mathrm{p} \mathrm{z}^{4} \mathrm{~F}_{3 / 2}$ & $2.3 \mathrm{G}$ & col & & \\
\hline 3157.15 & 71 & 42 & & & & & & & & \\
\hline 3154.96 & 133 & & 3155.12 & $\mathrm{Fe}$ II & $4 \mathrm{~s} \mathrm{~b}^{2} \mathrm{G}_{9 / 2}$ & $4 \mathrm{p} \mathrm{z}^{2} \mathrm{G}_{9 / 2}$ & 2.1 & $\mathrm{fl}$ & & \\
\hline 3136.1 & 160 & 91 & & & & & & & & \\
\hline 3133.64 & oe & & 3133.70 & O III & $2 p 3 p^{3} S_{1}$ & $2 \mathrm{p} 3 \mathrm{~d}^{3} \mathrm{P}_{2}$ & 3 & $\mathrm{fl}$ & & \\
\hline 3122.43 & 628 & 45 & 3122.54 & O III & $2 p 3 p^{3} S_{1}$ & $2 \mathrm{p} 3 \mathrm{~d}^{3} \mathrm{P}_{1}$ & 3 & $\mathrm{fl}$ & & \\
\hline 3117.23 & 112 & 36 & & & & & & & & \\
\hline 3116.47 & 82 & 38 & 3116.58 & O III & $2 \mathrm{p} 3 \mathrm{p}^{3} \mathrm{~S}_{1}$ & $2 \mathrm{p} 3 \mathrm{~d}^{3} \mathrm{P}_{0}$ & 3 & $\mathrm{fl}$ & & \\
\hline 3079.41 & 55 & 25 & 3079.57 & $\mathrm{Fe}$ II & $4 p z^{4} P_{5 / 2}$ & $5 \mathrm{~s} \mathrm{e}^{4} \mathrm{D}_{7 / 2}$ & 2.1 & $\mathrm{fl}$ & & \\
\hline 3072.44 & 50 & 21 & 3072.49 & O IV & $3 \mathrm{~s}^{2} \mathrm{~S}_{1 / 2}$ & $3 p^{2} \mathrm{P}_{1 / 2}$ & & rec & & \\
\hline 3072.05 & 44 & 19 & 3072.02 & Fe II & $4 p z^{4} P_{1 / 2}$ & $5 \mathrm{~s} \mathrm{e}^{4} \mathrm{D}_{3 / 2}$ & 2.1 & $\mathrm{fl}$ & & \\
\hline 3064.23 & 75 & & 3064.32 & O IV & $3 \mathrm{~s}^{2} \mathrm{~S}_{1 / 2}$ & $3 p^{2} \mathrm{P}_{3 / 2}$ & & rec & & \\
\hline 3060.09 & 131 & & 3060.17 & O III & $2 \mathrm{p} 3 \mathrm{~s}^{3} \mathrm{P}_{2}$ & $2 \mathrm{p} 3 \mathrm{p}^{3} \mathrm{P}_{1}$ & 3 & $\mathrm{fl}$ & & \\
\hline Oth & & & 3049.88 & $\mathrm{Fe}$ II & $4 p z^{4} P_{3 / 2}$ & $5 \mathrm{se}^{4} \mathrm{D}_{3 / 2}$ & 2.1 & $\mathrm{fl}$ & & \\
\hline 3047.98 & oe & & 3047.99 & O III & $2 \mathrm{p} 3 \mathrm{~s}{ }^{3} \mathrm{P}_{2}$ & $2 p 3 p^{3} P_{2}$ & 3 & $\mathrm{fl}$ & & \\
\hline 3043.81 & 90 & 32 & & & & & & & & \\
\hline 3040.62 & 32 & & 3040.67 & $\mathrm{Fe}$ II & $4 s^{2} c^{4} D_{3 / 2}$ & $4 p u^{4} F_{3 / 2}$ & 2.1 & fl & & \\
\hline 3036.23 & 53 & & 3036.30 & O III & $2 \mathrm{p} 3 \mathrm{~s}^{3} \mathrm{P}_{1}$ & $2 \mathrm{p} 3 \mathrm{p}^{3} \mathrm{P}_{1}$ & 3 & $\mathrm{fl}$ & & \\
\hline 3034.26 & 32 & & 3034.33 & Fe II & $4 p z^{4} P_{3 / 2}$ & $5 \mathrm{~s} \mathrm{e}^{4} \mathrm{D}_{1 / 2}$ & 2.1 & $\mathrm{fl}$ & & \\
\hline 3030.6 & $35^{b l}$ & & 3030.57 & Fe II & $4 \mathrm{~s} \mathrm{c}^{2} \mathrm{G}_{9 / 2}$ & $4 p y^{4} \mathrm{H}_{11 / 2}$ & 2.1 & $\mathrm{fl}$ & & \\
\hline 3025.74 & 78 & & & & & & & & & \\
\hline 3025.36 & 94 & & 3025.42 & O III & $2 \mathrm{p} 3 \mathrm{~s}{ }^{3} \mathrm{P}_{0}$ & $2 \mathrm{p} 3 \mathrm{p}^{3} \mathrm{P}_{1}$ & 3 & fl & & \\
\hline 3024.26 & 217 & 50 & 3024.31 & O III & $2 \mathrm{p} 3 \mathrm{~s}^{3} \mathrm{P}_{1}$ & $2 \mathrm{p} 3 \mathrm{p}^{3} \mathrm{P}_{2}$ & 3 & $\mathrm{fl}$ & & \\
\hline 3003.36 & $128^{b l}$ & 32 & 3003.52 & $\mathrm{Fe}$ II & $3 d^{7} a^{4} P_{3 / 2}$ & $4 \mathrm{p} \mathrm{z}^{4} \mathrm{P}_{5 / 2}$ & $2.3 \mathrm{G}$ & col & & \\
\hline 2989.89 & 45 & 29 & 2989.94 & Fe II & $4 p z^{4} F_{5 / 2}$ & $5 \mathrm{se}^{6} \mathrm{D}_{5 / 2}$ & 2.1 & $\mathrm{fl}$ & & \\
\hline 2988.36 & 66 & 35 & & & & & & & & \\
\hline \multirow[t]{2}{*}{2986.38} & 66 & & 2986.51 & Fe II & $4 p z^{4} F_{7 / 2}$ & $5 \mathrm{~s} \mathrm{e}^{6} \mathrm{D}_{7 / 2}$ & 2.1 & $\mathrm{fl}$ & & \\
\hline & & & 6.42 & Fe II & $3 d^{7} a^{4} P_{1 / 2}$ & $4 \mathrm{p} \mathrm{z}^{4} \mathrm{P}_{3 / 2}$ & $2.3 \mathrm{G}$ & col & & \\
\hline \multirow[t]{2}{*}{2985.63} & 163 & & 2985.96 & Fe II & $4 s^{2} d^{4} P_{5 / 2}$ & $\left({ }^{5} \mathrm{D}\right) 5 \mathrm{p}{ }^{4} \mathrm{P}_{5 / 2}$ & 2.1 & fl & & \\
\hline & & & 5.70 & Fe II & $3 d^{7} a^{4} P_{5 / 2}$ & $4 \mathrm{p} \mathrm{z}^{4} \mathrm{P}_{5 / 2}$ & $2.3 \mathrm{G}$ & col & & \\
\hline 2984.54 & 149 & 48 & 2984.65 & O III & $2 \mathrm{p} 3 \mathrm{~s}{ }^{1} \mathrm{P}_{1}$ & $2 \mathrm{p} 3 \mathrm{p}^{1} \mathrm{D}_{2}$ & $2.3 \mathrm{~F}$ & rec & & \\
\hline \multirow[t]{2}{*}{2980.1} & 108 & & 2980.22 & $\mathrm{Fe}$ II & $4 \mathrm{~s} \mathrm{a}^{4} \mathrm{D}_{1 / 2}$ & $4 p z^{6} F_{3 / 2}$ & $2.3 \mathrm{G}$ & col & & \\
\hline & & & 0.19 & Fe II & $4 s^{2} d^{4} P_{3 / 2}$ & $\left({ }^{5} \mathrm{D}\right) 5 \mathrm{p}{ }^{4} \mathrm{D}_{3 / 2}$ & 2.1 & $\mathrm{fl}$ & & \\
\hline 2979.87 & 220 & & 2979.95 & Fe II & $4 \mathrm{~s} \mathrm{c}^{2} \mathrm{~F}_{5 / 2}$ & $4 \mathrm{pw}^{2} \mathrm{D}_{3 / 2}$ & 2.1 & $\mathrm{fl}$ & & \\
\hline 2977.23 & 39 & & 2977.26 & Fe II & $4 \mathrm{~s} \mathrm{a}^{2} \mathrm{I}_{13 / 2}$ & $4 p y^{4} H_{11 / 2}$ & 2.1 & $\mathrm{fl}$ & & \\
\hline 2976.71 & 46 & & 2976.81 & Fe II & $4 s a^{4} D_{1 / 2}$ & $4 p z^{6} F_{1 / 2}$ & $2.3 \mathrm{G}$ & col & & \\
\hline
\end{tabular}


Table 13. continued.

\begin{tabular}{|c|c|c|c|c|c|c|c|c|c|c|}
\hline$\lambda_{\mathrm{obs}}(\AA)$ & $I^{a}$ & $w^{b}$ & $\lambda_{\mathrm{id}}(\AA)$ & spec. & Lower level & Upper level & $\mathrm{Sec}^{c}$ & $\operatorname{Exc}^{f}$ & $I_{\mathrm{ghrs}}^{d}$ & $w_{\mathrm{ghrs}}^{e}$ \\
\hline 2974.15 & 103 & 51 & 2975.66 & {$[\mathrm{Ne} \mathrm{V}]$} & $2 \mathrm{p}^{21} \mathrm{D}_{2}$ & $2 \mathrm{p}^{2}{ }^{1} \mathrm{~S}_{0}$ & 2.2 & col & & \\
\hline 2971.23 & 97 & 30 & 2971.38 & $\mathrm{Fe}$ II & $4 \mathrm{~s} \mathrm{a}^{4} \mathrm{D}_{3 / 2}$ & $4 p z^{6} F_{5 / 2}$ & $2.3 \mathrm{G}$ & col & & \\
\hline 2970.66 & 26 & & 2970.80 & $\mathrm{Fe}$ II & $4 \mathrm{~s} \mathrm{~b}^{2} \mathrm{G}_{7 / 2}$ & $4 \mathrm{p} \mathrm{z}^{2} \mathrm{~F}_{5 / 2}$ & & $\mathrm{fl}$ & & \\
\hline \multirow[t]{3}{*}{2965.6} & 64 & & 2965.90 & $\mathrm{Fe}$ II & $3 d^{7} a^{4} P_{3 / 2}$ & $4 p z^{4} P_{3 / 2}$ & $2.3 \mathrm{G}$ & col & & \\
\hline & & & 5.53 & $\mathrm{Fe}$ II & $4 \mathrm{~s} \mathrm{a}^{4} \mathrm{D}_{3 / 2}$ & $4 p z^{6} F_{3 / 2}$ & $2.3 \mathrm{G}$ & col & & \\
\hline & & & 5.49 & $\mathrm{Fe}$ II & $3 d^{7} a^{4} P_{1 / 2}$ & $4 p z^{4} P_{1 / 2}$ & $2.3 \mathrm{G}$ & col & & \\
\hline 2962.05 & 41 & & 2962.14 & $\mathrm{Fe} I \mathrm{II}$ & $4 \mathrm{~s} \mathrm{a}^{4} \mathrm{D}_{3 / 2}$ & $4 p z^{6} F_{1 / 2}$ & $2.3 \mathrm{G}$ & col & & \\
\hline 2960.47 & 61 & 38 & 2960.56 & O III & $2 \mathrm{p} 3 \mathrm{p}^{1} \mathrm{P}_{1}$ & $2 \mathrm{p} 3 \mathrm{~d}^{1} \mathrm{D}_{2}$ & $2.3 \mathrm{~F}$ & rec & & \\
\hline 2954.55 & 130 & 23 & 2954.64 & $\mathrm{Fe}$ II & $4 \mathrm{~s} \mathrm{a}^{4} \mathrm{D}_{5 / 2}$ & $4 p z^{6} F_{7 / 2}$ & $2.3 \mathrm{G}$ & col & & \\
\hline 2949.95 & $62^{b l}$ & 32 & 2950.04 & $\mathrm{Fe}$ II & $4 s^{2} G_{7 / 2}$ & $4 p z^{2} F_{7 / 2}$ & & $\mathrm{fl}$ & & \\
\hline 2948.40 & 86 & 28 & 2948.52 & $\mathrm{Fe}$ II & $3 d^{7} a^{4} P_{5 / 2}$ & $4 \mathrm{p} \mathrm{z}^{4} \mathrm{P}_{3 / 2}$ & $2.3 \mathrm{G}$ & col & & \\
\hline \multirow[t]{2}{*}{2945.9} & 113 & & 2946.13 & $\mathrm{Fe}$ II & $4 \mathrm{~s} \mathrm{a}^{4} \mathrm{D}_{5 / 2}$ & $4 p z^{6} F_{5 / 2}$ & $2.3 \mathrm{G}$ & col & & \\
\hline & & & 5.97 & $\mathrm{He} \mathrm{I}$ & $2 \mathrm{~s}{ }^{3} \mathrm{~S}_{1}$ & $5 \mathrm{p}^{3} \mathrm{P}_{2}$ & $2.3 \mathrm{~A}$ & rec & & \\
\hline 2945.17 & 74 & 26 & 2945.26 & $\mathrm{Fe}$ II & $3 d^{7} a^{4} P_{3 / 2}$ & $4 \mathrm{p} \mathrm{z}^{4} \mathrm{P}_{1 / 2}$ & $2.3 \mathrm{G}$ & col & & \\
\hline 2940.23 & $51^{b l}$ & 37 & 2940.37 & $\mathrm{Fe}$ II & $4 \mathrm{~s} \mathrm{a}^{4} \mathrm{D}_{5 / 2}$ & $4 p z^{6} F_{3 / 2}$ & $2.3 \mathrm{G}$ & col & & \\
\hline 2937.23 & 184 & 36 & 2937.37 & Mg II & $3 p^{2} \mathrm{P}_{3 / 2}$ & $4 s^{2} S_{1 / 2}$ & & unk & & \\
\hline 2935.02 & 43 & 29 & & & & & & & & \\
\hline 2933.70 & 34 & 29 & & & & & & & & \\
\hline 2931.74 & 99 & 30 & & & & & & & & \\
\hline 2929.33 & 259 & & 2929.49 & Mg II & $3 p^{2} P_{1 / 2}$ & $4 s^{2} S_{1 / 2}$ & & unk & & \\
\hline \multirow[t]{2}{*}{2927.29} & 208 & & 2926.44 & $\mathrm{Fe}$ II & $4 \mathrm{~s} \mathrm{a}^{4} \mathrm{D}_{7 / 2}$ & $4 p z^{6} F_{9 / 2}$ & $2.3 \mathrm{G}$ & col & & \\
\hline & & & 8.0 & {$[\mathrm{Mg} \mathrm{V}]$} & $2 \mathrm{p}^{4}{ }^{3} \mathrm{P}_{1}$ & $2 \mathrm{p}^{41} \mathrm{D}_{2}$ & 2.2 & col & & \\
\hline 2918.19 & 27 & & 2918.32 & $\mathrm{Fe}$ II & $4 \mathrm{~s} \mathrm{a}^{4} \mathrm{D}_{5 / 2}$ & $4 p z^{6} P_{7 / 2}$ & $2.3 \mathrm{G}$ & col & & \\
\hline 2916.91 & 58 & 16 & 2917.01 & $\mathrm{Fe}$ II & $4 \mathrm{~s} \mathrm{a}^{4} \mathrm{D}_{7 / 2}$ & $4 p z^{6} F_{7 / 2}$ & $2.3 \mathrm{G}$ & col & & \\
\hline 2908.57 & 34 & & 2908.71 & $\mathrm{Fe}$ II & $4 s a^{4} D_{7 / 2}$ & $4 \mathrm{p} \mathrm{z}^{6} \mathrm{~F}_{5 / 2}$ & $2.3 \mathrm{G}$ & col & & \\
\hline 2903.17 & 59 & 33 & & & & & & & & \\
\hline 2895.86 & 51 & 23 & & & & & & & & \\
\hline 2895.52 & 31 & 13 & 2895.63 & $\mathrm{Fe}$ II & $4 \mathrm{~s} \mathrm{~b}^{4} \mathrm{H}_{9 / 2}$ & $4 p z^{4} H_{11 / 2}$ & 2.1 & $\mathrm{fl}$ & & \\
\hline 2893.57 & 59 & 23 & 2893.68 & $\mathrm{Fe}$ II & $4 s a^{4} D_{3 / 2}$ & $4 p z^{6} P_{5 / 2}$ & $2.3 \mathrm{G}$ & col & & \\
\hline 2892.29 & 30 & & & & & & & & & \\
\hline 2891.84 & 50 & & & & & & & & & \\
\hline 2890.40 & $48^{b l}$ & 33 & 2890.53 & $\mathrm{Fe}$ II & $4 p z^{4} F_{3 / 2}$ & $5 \mathrm{~s} \mathrm{e}^{4} \mathrm{D}_{5 / 2}$ & 2.1 & fl & & \\
\hline 2888.81 & 139 & 24 & 2888.94 & $\mathrm{Fe}$ II & $4 \mathrm{~s} \mathrm{~b}^{2} \mathrm{P}_{3 / 2}$ & $4 p y^{4} P_{5 / 2}$ & 2.1 & $\mathrm{fl}$ & & \\
\hline 2886.89 & 39 & 20 & 2887.08 & $\mathrm{Fe}$ II & $4 \mathrm{~s} \mathrm{~b}^{2} \mathrm{H}_{11 / 2}$ & $4 p z^{4} G_{9 / 2}$ & 2.1 & $\mathrm{fl}$ & & \\
\hline 2885.46 & 78 & 23 & 2885.61 & Fe II & $4 p z^{4} D_{5 / 2}$ & $5 \mathrm{~s} \mathrm{e}^{4} \mathrm{D}_{7 / 2}$ & 2.1 & $\mathrm{fl}$ & & \\
\hline 2884.53 & $55^{b l}$ & 36 & 2884.56 & $\mathrm{Fe}$ II & $4 \mathrm{~s} \mathrm{~b}^{2} \mathrm{H}_{11 / 2}$ & $4 \mathrm{p} \mathrm{z}^{4} \mathrm{H}_{13 / 2}$ & & unk & & \\
\hline 2883.13 & $19^{b l}$ & & 2883.04 & $\mathrm{Fe}$ II & $4 p z^{4} F_{7 / 2}$ & $5 \mathrm{~s} \mathrm{e}^{4} \mathrm{D}_{7 / 2}$ & 2.1 & $\mathrm{fl}$ & & \\
\hline 2882.36 & 80 & 20 & & & & & & & & \\
\hline 2881.60 & $42^{b l}$ & & 2881.60 & $\mathrm{Fe}$ II & $4 \mathrm{~s} \mathrm{a}^{4} \mathrm{D}_{7 / 2}$ & $4 p z^{6} P_{7 / 2}$ & $2.3 \mathrm{G}$ & col & & \\
\hline 2876.08 & 100 & 26 & 2876.19 & $\mathrm{Fe}$ II & $4 \mathrm{~s} \mathrm{a}^{2} \mathrm{~F}_{7 / 2}$ & $4 \mathrm{p} \mathrm{z}^{2} \mathrm{G}_{9 / 2}$ & 2.1 & $\mathrm{fl}$ & & \\
\hline 2869.66 & 75 & & 2869.72 & $\mathrm{Fe}$ II & $4 s a^{4} D_{5 / 2}$ & $4 p z^{6} P_{5 / 2}$ & $2.3 \mathrm{G}$ & col & & \\
\hline 2865.89 & $52^{b l}$ & 69 & 2866.30 & $\mathrm{Fe}$ II & $4 p z^{4} F_{3 / 2}$ & $5 \mathrm{~s} \mathrm{e}^{4} \mathrm{D}_{3 / 2}$ & 2.1 & $\mathrm{fl}$ & & \\
\hline 2865.13 & 51 & 36 & & & & & & & & \\
\hline 2859.40 & $46^{b l}$ & & 2859.47 & $\mathrm{Fe}$ II & $4 p z^{4} D_{1 / 2}$ & $5 \mathrm{~s} \mathrm{e}^{4} \mathrm{D}_{3 / 2}$ & 2.1 & $\mathrm{fl}$ & & \\
\hline 2857.64 & 166 & 35 & 2857.75 & $\mathrm{Fe}$ II & $4 \mathrm{p} \mathrm{z}^{4} \mathrm{D}_{7 / 2}$ & $5 \mathrm{~s} \mathrm{e}^{4} \mathrm{D}_{7 / 2}$ & 2.1 & $\mathrm{fl}$ & & \\
\hline \multirow[t]{2}{*}{2856.92} & 94 & 43 & 2857.22 & $\mathrm{Fe}$ II & $4 p z^{6} P_{5 / 2}$ & $5 \mathrm{~s} \mathrm{e}^{6} \mathrm{D}_{7 / 2}$ & 2.1 & $\mathrm{fl}$ & & \\
\hline & & & 6.99 & Fe II & $4 s a^{4} G_{9 / 2}$ & $4 p z^{4} G_{9 / 2}$ & 2.1 & $\mathrm{fl}$ & & \\
\hline 2852.53 & 120 & & 2852.56 & Fe II & $4 \mathrm{p} \mathrm{z}^{4} \mathrm{~F}_{3 / 2}$ & $5 \mathrm{~s} \mathrm{e}^{4} \mathrm{D}_{1 / 2}$ & 2.1 & $\mathrm{fl}$ & & \\
\hline 2850.45 & 44 & 22 & 2850.44 & $\mathrm{Fe}$ II & $4 \mathrm{~s} \mathrm{a}^{4} \mathrm{G}_{9 / 2}$ & $4 \mathrm{p} \mathrm{z}^{4} \mathrm{H}_{11 / 2}$ & & unk & & \\
\hline
\end{tabular}


Table 13. continued.

\begin{tabular}{|c|c|c|c|c|c|c|c|c|c|c|}
\hline$\lambda_{\text {obs }}(\AA)$ & $I^{a}$ & $w^{b}$ & $\lambda_{\text {id }}(\AA)$ & spec. & Lower level & Upper level & $\mathrm{Sec}^{c}$ & $\operatorname{Exc}^{f}$ & $I_{\text {ghrs }}^{d}$ & $w_{\text {ghrs }}^{e}$ \\
\hline 2849.11 & 57 & & 2849.16 & Fe II & $4 p z^{4} F_{5 / 2}$ & $5 \mathrm{~s} \mathrm{e}^{4} \mathrm{D}_{3 / 2}$ & 2.1 & $\mathrm{fl}$ & & \\
\hline \multirow{2}{*}{2848.81} & 44 & & 2848.94 & $\mathrm{Fe}$ II & $4 \mathrm{p} \mathrm{z}^{4} \mathrm{D}_{5 / 2}$ & $5 \mathrm{~s} \mathrm{e}^{4} \mathrm{D}_{5 / 2}$ & 2.1 & $\mathrm{fl}$ & & \\
\hline & & & 8.61 & $\mathrm{Fe}$ II & $4 p z^{6} P_{3 / 2}$ & $5 \mathrm{~s} \mathrm{e}^{6} \mathrm{D}_{3 / 2}$ & 2.1 & $\mathrm{fl}$ & & \\
\hline \multirow[t]{3}{*}{2846.23} & 152 & 39 & 2846.43 & $\mathrm{Fe}$ II & $4 \mathrm{pz}^{4} \mathrm{~F}_{7 / 2}$ & $5 \mathrm{~s} \mathrm{e}^{4} \mathrm{D}_{5 / 2}$ & 2.1 & $\mathrm{fl}$ & & \\
\hline & & & 6.26 & $\mathrm{Fe}$ II & $4 \mathrm{p} \mathrm{z}^{4} \mathrm{D}_{3 / 2}$ & $5 \mathrm{~s} \mathrm{e}^{4} \mathrm{D}_{3 / 2}$ & 2.1 & $\mathrm{fl}$ & & \\
\hline & & & 6.22 & $\mathrm{Fe}$ II & $4 \mathrm{~s} \mathrm{~b}^{4} \mathrm{D}_{5 / 2}$ & $4 \mathrm{px}^{4} \mathrm{~F}_{5 / 2}$ & 2.1 & $\mathrm{fl}$ & & \\
\hline \multirow[t]{2}{*}{2844.21} & 67 & 44 & 2844.31 & $\mathrm{Fe}$ II & $4 \mathrm{~s} \mathrm{~b}^{4} \mathrm{D}_{3 / 2}$ & $4 \mathrm{px}^{4} \mathrm{~F}_{5 / 2}$ & 2.1 & $\mathrm{fl}$ & & \\
\hline & & & 4.15 & $\mathrm{Fe}$ II & $4 \mathrm{~s} \mathrm{~b}^{2} \mathrm{H}_{9 / 2}$ & $4 \mathrm{p} \mathrm{z}^{4} \mathrm{I}_{9 / 2}$ & & unk & & \\
\hline 2841.34 & $51^{b l}$ & & 2841.49 & Fe II & $4 \mathrm{~s} \mathrm{~b}^{2} \mathrm{P}_{1 / 2}$ & $4 \mathrm{p} \mathrm{z}^{2} \mathrm{D}_{3 / 2}$ & & unk & & \\
\hline 2840.26 & 241 & 24 & 2840.35 & $\mathrm{Fe}$ II & $4 p z^{4} F_{9 / 2}$ & $5 \mathrm{~s} \mathrm{e}^{4} \mathrm{D}_{7 / 2}$ & 2.1 & $\mathrm{fl}$ & & \\
\hline 2838.91 & 49 & 22 & 2839.05 & $\mathrm{Fe}$ II & $4 \mathrm{p} \mathrm{z}^{6} \mathrm{P}_{3 / 2}$ & $5 \mathrm{~s} \mathrm{e}^{6} \mathrm{D}_{1 / 2}$ & 2.1 & $\mathrm{fl}$ & & \\
\hline \multirow[t]{2}{*}{2837.13} & 652 & 43 & 2837.14 & O III & $2 \mathrm{p} 3 \mathrm{p}^{3} \mathrm{D}_{3}$ & $2 \mathrm{p} 3 \mathrm{~d}^{3} \mathrm{P}_{2}$ & 3 & $\mathrm{fl}$ & & \\
\hline & & & 7.10 & O IV & $2 \mathrm{~s} 2 \mathrm{p}\left({ }^{3} \mathrm{P}\right) 3 \mathrm{~s}{ }^{4} \mathrm{P}_{5 / 2}$ & $2 s 2 p\left({ }^{3} \mathrm{P}\right) 3 p{ }^{4} S_{3 / 2}$ & unk & & & \\
\hline 2836.43 & 46 & 24 & 2836.55 & $\mathrm{Fe}$ II & $4 \mathrm{~s} \mathrm{~b}^{2} \mathrm{P}_{3 / 2}$ & $4 \mathrm{p} \mathrm{z}^{4} \mathrm{G}_{5 / 2}$ & 2.1 & $\mathrm{fl}$ & & \\
\hline \multirow[t]{2}{*}{2833.91} & 50 & 56 & 2834.20 & $\mathrm{Fe}$ II & $4 \mathrm{~s} \mathrm{a}^{4} \mathrm{D}_{7 / 2}$ & $4 p z^{6} P_{5 / 2}$ & $2.3 \mathrm{G}$ & col & & \\
\hline & & & 3.92 & $\mathrm{Fe}$ II & $4 p z^{6} P_{5 / 2}$ & $5 \mathrm{~s} \mathrm{e}^{6} \mathrm{D}_{5 / 2}$ & 2.1 & $\mathrm{fl}$ & & \\
\hline 2832.28 & 46 & 26 & 2832.40 & $\mathrm{Fe}$ II & $4 \mathrm{~s} \mathrm{~b}^{2} \mathrm{P}_{3 / 2}$ & $4 \mathrm{p} \mathrm{z}^{2} \mathrm{D}_{5 / 2}$ & & unk & & \\
\hline Oth & & & 2831.76 & Fe II & $4 \mathrm{~s} \mathrm{~b}^{2} \mathrm{G}_{7 / 2}$ & $4 \mathrm{px}^{4} \mathrm{G}_{5 / 2}$ & 2.1 & $\mathrm{fl}$ & & \\
\hline 2829.82 & 59 & 34 & 2829.91 & $\mathrm{He} \mathrm{I}$ & $2{ }^{3} S_{1}$ & $6 \mathrm{p}^{3} \mathrm{P}_{2}$ & $2.3 \mathrm{~A}$ & rec & & \\
\hline 2829.38 & 57 & 24 & 2829.46 & $\mathrm{Fe}$ II & $4 \mathrm{~s} \mathrm{~b}^{2} \mathrm{H}_{11 / 2}$ & $4 \mathrm{pz}^{4} \mathbf{I}_{9 / 2}$ & & unk & & \\
\hline 2828.17 & 57 & 30 & 2828.26 & $\mathrm{Fe}$ II & $4 \mathrm{~s} \mathrm{~b}^{2} \mathrm{H}_{11 / 2}$ & $4 \mathrm{p} \mathrm{z}^{4} \mathrm{I}_{13 / 2}$ & & unk & & \\
\hline 2826.53 & $64^{b l}$ & 52 & 2826.58 & $\mathrm{Fe}$ II & $4 \mathrm{~s} \mathrm{a}^{4} \mathrm{G}_{11 / 2}$ & $4 \mathrm{p} \mathrm{z}^{4} \mathrm{G}_{9 / 2}$ & 2.1 & $\mathrm{fl}$ & & \\
\hline 2824.06 & 30 & & 2824.16 & $\mathrm{Fe}$ II & $4 \mathrm{~s} \mathrm{a}^{4} \mathrm{G}_{11 / 2}$ & $4 \mathrm{p} \mathrm{z}^{4} \mathrm{H}_{13 / 2}$ & & unk & & \\
\hline 2820.08 & 48 & 27 & 2820.17 & $\mathrm{Fe}$ II & $4 \mathrm{~s} \mathrm{a}^{4} \mathrm{G}_{11 / 2}$ & $4 \mathrm{p} \mathrm{z}^{4} \mathrm{H}_{11 / 2}$ & & unk & & \\
\hline 2819.43 & 62 & & 2819.53 & O III & $2 \mathrm{p} 3 \mathrm{p}^{3} \mathrm{D}_{2}$ & $2 \mathrm{p} 3 \mathrm{~d}^{3} \mathrm{P}_{2}$ & 3 & $\mathrm{fl}$ & & \\
\hline $\begin{array}{l}2817.70 \\
\text { oth }\end{array}$ & 53 & 26 & 2817.92 & $\mathrm{Fe}$ II & $4 \mathrm{p} \mathrm{z}^{6} \mathrm{P}_{5 / 2}$ & $5 \mathrm{~s} \mathrm{e}^{6} \mathrm{D}_{3 / 2}$ & 2.1 & $\mathrm{fl}$ & & \\
\hline \multirow[t]{2}{*}{2810.49} & 134 & 46 & 2810.61 & $\mathrm{Fe}$ II & $4 p z^{6} P_{7 / 2}$ & $5 \mathrm{~s} \mathrm{e}^{6} \mathrm{D}_{7 / 2}$ & 2.1 & $\mathrm{fl}$ & & \\
\hline & & & 0.49 & O III & $2 p 3 p^{3} D_{2}$ & $2 \mathrm{p} 3 \mathrm{~d}^{3} \mathrm{P}_{1}$ & 3 & $\mathrm{fl}$ & & \\
\hline 2808.62 & 31 & & 2808.73 & O III & $2 \mathrm{p} 3 \mathrm{p}^{3} \mathrm{D}_{1}$ & $2 \mathrm{p} 3 \mathrm{~d}^{3} \mathrm{P}_{2}$ & 3 & $\mathrm{fl}$ & & \\
\hline 2807.94 & $48^{b l}$ & & 2808.00 & $\mathrm{Fe}$ II & $4 \mathrm{~s} \mathrm{~b}^{4} \mathrm{D}_{5 / 2}$ & $4 p y^{2} D_{5 / 2}$ & 2.1 & $\mathrm{fl}$ & & \\
\hline 2806.04 & 31 & & 2806.15 & $\mathrm{Fe}$ II & $4 \mathrm{~s} \mathrm{~b}^{4} \mathrm{D}_{3 / 2}$ & $4 \mathrm{p} \mathrm{y}^{2} \mathrm{D}_{5 / 2}$ & 2.1 & $\mathrm{fl}$ & & \\
\hline 2803.5 & oe & & 2803.53 & Mg II & $3 \mathrm{~s}^{2} \mathrm{~S}_{1 / 2}$ & $3 \mathrm{p}^{2} \mathrm{P}_{1 / 2}$ & $2.3 \mathrm{~B}$ & $\mathrm{col}$ & & \\
\hline 2799.60 & $34^{b l}$ & & 2799.76 & O III & $2 p 3 p{ }^{3} D_{1}$ & $2 \mathrm{p} 3 \mathrm{~d}^{3} \mathrm{P}_{1}$ & 3 & $\mathrm{fl}$ & & \\
\hline 2798.72 & 283 & 29 & 2798.82 & Mg II & $3 p^{2} \mathrm{P}_{3 / 2}$ & $3 d^{2} D_{5 / 2}$ & & unk & & \\
\hline 2796.3 & oe & & 2796.35 & Mg II & $3 \mathrm{~s}^{2} \mathrm{~S}_{1 / 2}$ & $3 p^{2} \mathrm{P}_{3 / 2}$ & $2.3 \mathrm{~B}$ & col & & \\
\hline 2794.88 & 15 & & 2794.96 & O III & $2 p 3 p^{3} D_{1}$ & $2 \mathrm{p} 3 \mathrm{~d}^{3} \mathrm{P}_{0}$ & 3 & $\mathrm{fl}$ & & \\
\hline 2791.49 & 193 & 36 & 2791.60 & Mg II & $3 p^{2} \mathrm{P}_{1 / 2}$ & $3 d^{2} D_{3 / 2}$ & & unk & & \\
\hline \multirow[t]{3}{*}{2785.98} & 41 & & 2786.12 & $\mathrm{Ne}$ III & $2 \mathrm{p}^{3}\left({ }^{2} \mathrm{D}\right) 3 \mathrm{~s}{ }^{3} \mathrm{D}_{2}$ & $2 p^{3}\left({ }^{2} D\right) 3 p^{3} D_{2}$ & $3.2 \mathrm{~F}$ & rec & & \\
\hline & & & 6.01 & Fe II & $4 p z^{6} F_{11 / 2}$ & $5 \mathrm{~s} \mathrm{e}^{6} \mathrm{D}_{9 / 2}$ & 2.1 & $\mathrm{fl}$ & & \\
\hline & & & 5.85 & $\mathrm{Fe}$ II & $3 d^{7} a^{4} F_{3 / 2}$ & $4 p z^{6} D_{3 / 2}$ & $2.3 \mathrm{G}$ & col & & \\
\hline \multirow[t]{2}{*}{2783.91} & 363 & 113 & 2784.51 & $\mathrm{Fe}$ II & $4 \mathrm{~s} \mathrm{~b}^{2} \mathrm{H}_{11 / 2}$ & $4 \mathrm{p} \mathrm{z}^{2} \mathrm{G}_{9 / 2}$ & 2.1 & $\mathrm{fl}$ & & \\
\hline & & & 3.50 & {$[\mathrm{Mg} \mathrm{V}]$} & $2 \mathrm{p}^{4}{ }^{3} \mathrm{P}_{2}$ & $2 \mathrm{p}^{4}{ }^{1} \mathrm{D}_{2}$ & 2.2 & col & & \\
\hline 2781.68 & 29 & & 2781.83 & $\mathrm{OV}$ & $2 \mathrm{~s} 3 \mathrm{~s}^{3} \mathrm{~S}_{1}$ & $2 \mathrm{~s} 3 \mathrm{p}^{3} \mathrm{P}_{2}$ & 1 & rec & & \\
\hline 2780.02 & 44 & 31 & & & & & & & & \\
\hline 2778.80 & 72 & & & & & & & & & \\
\hline 2778.45 & $53^{b l}$ & & 2778.47 & $\mathrm{Ne}$ III & $2 \mathrm{p}^{3}\left({ }^{2} \mathrm{D}\right) 3 \mathrm{~s}{ }^{3} \mathrm{D}_{3}$ & $2 p^{3}\left({ }^{2} D\right) 3 p^{3} D_{3}$ & $3.2 \mathrm{~F}$ & rec & & \\
\hline 2777.62 & 83 & 21 & 2777.73 & $\mathrm{Fe}$ II & $4 p z^{6} F_{7 / 2}$ & $5 \mathrm{~s} \mathrm{e}^{6} \mathrm{D}_{7 / 2}$ & 2.1 & $\mathrm{fl}$ & & \\
\hline 2776.08 & 96 & 21 & 2776.16 & $\mathrm{Fe} I \mathrm{II}$ & $3 d^{7} a^{4} F_{5 / 2}$ & $4 \mathrm{p} \mathrm{z}^{6} \mathrm{D}_{5 / 2}$ & $2.3 \mathrm{G}$ & col & & \\
\hline
\end{tabular}


Table 13. continued.

\begin{tabular}{|c|c|c|c|c|c|c|c|c|c|c|}
\hline$\lambda_{\mathrm{obs}}(\AA)$ & $I^{a}$ & $w^{b}$ & $\lambda_{\text {id }}(\AA)$ & spec. & Lower level & Upper level & $\mathrm{Sec}^{c}$ & $\operatorname{Exc}^{f}$ & $I_{\mathrm{ghrs}}^{d}$ & $w_{\text {ghrs }}^{e}$ \\
\hline 2775.47 & 88 & 23 & 2775.55 & $\mathrm{Fe}$ II & $3 d^{7} a^{4} F_{7 / 2}$ & $4 \mathrm{p} \mathrm{z}^{6} \mathrm{D}_{9 / 2}$ & $2.3 \mathrm{G}$ & col & & \\
\hline 2773.45 & 43 & 16 & 2773.55 & $\mathrm{Fe} I I$ & $4 \mathrm{~s} \mathrm{a}^{4} \mathrm{D}_{5 / 2}$ & $4 \mathrm{p} \mathrm{z}^{4} \mathrm{D}_{7 / 2}$ & $2.3 \mathrm{G}$ & col & & \\
\hline 2771.89 & 631 & 28 & 2772.00 & $\mathrm{Fe} I I$ & $4 \mathrm{~s} \mathrm{~b}^{2} \mathrm{G}_{9 / 2}$ & $4 \mathrm{p} \mathrm{y}^{4} \mathrm{H}_{11 / 2}$ & 2.1 & fl & & \\
\hline \multirow[t]{2}{*}{2770.00} & 104 & 76 & 2770.17 & $\mathrm{Fe} I I$ & $4 \mathrm{~s} \mathrm{a}^{4} \mathrm{G}_{11 / 2}$ & $4 \mathrm{p} \mathrm{z}^{4} \mathrm{I}_{13 / 2}$ & & unk & & \\
\hline & & & 9.97 & $\mathrm{Fe} I I$ & $4 \mathrm{~s} \mathrm{a}^{4} \mathrm{G}_{7 / 2}$ & $4 \mathrm{p} \mathrm{z}^{2} \mathrm{G}_{9 / 2}$ & 2.1 & $\mathrm{fl}$ & & \\
\hline \multirow[t]{2}{*}{2768.21} & 90 & 30 & 2768.33 & $\mathrm{Fe} I I$ & $4 p z^{6} F_{9 / 2}$ & $5 \mathrm{~s} \mathrm{e}^{6} \mathrm{D}_{7 / 2}$ & 2.1 & $\mathrm{fl}$ & & \\
\hline & & & 8.23 & $\mathrm{Fe} I I$ & $4 \mathrm{pz}^{6} \mathrm{~F}_{3 / 2}$ & $5 \mathrm{~s} \mathrm{e}^{6} \mathrm{D}_{5 / 2}$ & 2.1 & $\mathrm{fl}$ & & \\
\hline 2764.40 & 65 & 49 & 2764.62 & He I & $2 s^{3} S_{1}$ & $7 p^{3} \mathrm{P}_{2}$ & $2.3 \mathrm{~A}$ & rec & & \\
\hline 2762.59 & 41 & & 2762.63 & $\mathrm{Fe} I I$ & $4 \mathrm{~s} \mathrm{a}^{4} \mathrm{D}_{1 / 2}$ & $4 p z^{4} D_{3 / 2}$ & $2.3 \mathrm{G}$ & col & & \\
\hline 2760.01 & $69^{b l}$ & 35 & 2760.15 & $\mathrm{Fe}$ II & $3 d^{7} a^{4} F_{7 / 2}$ & $4 \mathrm{p} \mathrm{z}^{6} \mathrm{D}_{7 / 2}$ & $2.3 \mathrm{G}$ & col & & \\
\hline 2756.44 & 153 & 29 & 2756.55 & $\mathrm{Fe} I I$ & $4 s a^{4} D_{7 / 2}$ & $4 \mathrm{p} \mathrm{z}^{4} \mathrm{~F}_{9 / 2}$ & $2.3 \mathrm{G}$ & col & & \\
\hline 2755.60 & 57 & 33 & 2755.70 & $\mathrm{Fe} I I$ & $4 p z^{6} F_{7 / 2}$ & $5 \mathrm{~s} \mathrm{e}^{6} \mathrm{D}_{5 / 2}$ & 2.1 & $\mathrm{fl}$ & & \\
\hline 2753.96 & $56^{b l}$ & 42 & 2754.10 & $\mathrm{Fe}$ II & $4 \mathrm{~s} \mathrm{~b}^{2} \mathrm{H}_{9 / 2}$ & $4 p z^{2} I_{11 / 2}$ & & unk & & \\
\hline 2752.66 & $39^{b l}$ & 57 & 2752.96 & $\mathrm{Fe}$ II & $4 p z^{6} F_{3 / 2}$ & $5 \mathrm{~s} \mathrm{e}^{6} \mathrm{D}_{3 / 2}$ & 2.1 & $\mathrm{fl}$ & & \\
\hline 2751.77 & 29 & 23 & 2751.94 & $\mathrm{Fe} I I$ & $4 \mathrm{~s} \mathrm{~b}^{2} \mathrm{P}_{3 / 2}$ & $4 \mathrm{p} \mathrm{z}^{2} \mathrm{D}_{3 / 2}$ & & unk & & \\
\hline 2751.36 & 32 & 16 & & & & & & & & \\
\hline 2750.75 & 45 & 16 & & & & & & & & \\
\hline \multirow[t]{3}{*}{2750.07} & 137 & 47 & 2750.30 & $\mathrm{Fe} I I$ & $4 s a^{4} D_{1 / 2}$ & $4 p z^{4} D_{1 / 2}$ & $2.3 \mathrm{G}$ & col & & \\
\hline & & & 0.13 & $\mathrm{Fe} I I$ & $4 s \mathrm{a}^{4} \mathrm{D}_{5 / 2}$ & $4 p z^{4} F_{7 / 2}$ & $2.3 \mathrm{G}$ & col & & \\
\hline & & & 9.99 & $\mathrm{Fe}$ II & $4 \mathrm{~s} \mathrm{a}^{4} \mathrm{D}_{3 / 2}$ & $4 \mathrm{p} \mathrm{z}^{4} \mathrm{D}_{3 / 2}$ & $2.3 \mathrm{G}$ & col & & \\
\hline 2747.74 & 118 & 24 & 2747.79 & $\mathrm{Fe}$ II & $4 s a^{4} D_{5 / 2}$ & $4 \mathrm{p} \mathrm{z}^{4} \mathrm{D}_{5 / 2}$ & $2.3 \mathrm{G}$ & col & & \\
\hline 2747.22 & 123 & 22 & 2747.30 & $\mathrm{Fe} I I$ & $4 \mathrm{~s} \mathrm{a}^{4} \mathrm{D}_{3 / 2}$ & $4 p z^{4} F_{5 / 2}$ & $2.3 \mathrm{G}$ & col & & \\
\hline 2745.03 & 39 & 13 & 2745.08 & $\mathrm{Fe} I I$ & $3 d^{7} a^{4} F_{7 / 2}$ & $4 p z^{6} D_{5 / 2}$ & $2.3 \mathrm{G}$ & col & & \\
\hline \multirow[t]{2}{*}{2743.94} & 93 & 42 & 2794.04 & $\mathrm{Fe}$ II & $4 p z^{6} F_{3 / 2}$ & $5 s e^{6} D_{1 / 2}$ & 2.1 & $\mathrm{fl}$ & & \\
\hline & & & 4.01 & $\mathrm{Fe}$ II & $4 s a^{4} D_{1 / 2}$ & $4 \mathrm{p} \mathrm{z}^{4} \mathrm{~F}_{3 / 2}$ & $2.3 \mathrm{G}$ & col & & \\
\hline 2742.09 & 100 & 16 & 2742.21 & $\mathrm{Fe} I I$ & $4 \mathrm{~s} \mathrm{a}^{2} \mathrm{~F}_{5 / 2}$ & $4 p y^{4} G_{5 / 2}$ & 2.1 & $\mathrm{fl}$ & & \\
\hline 2740.27 & 141 & 33 & 2740.36 & $\mathrm{Fe} I I$ & $4 \mathrm{~s} \mathrm{a}^{4} \mathrm{D}_{7 / 2}$ & $4 \mathrm{p} \mathrm{z}^{4} \mathrm{D}_{7 / 2}$ & $2.3 \mathrm{G}$ & col & & \\
\hline 2737.71 & 41 & 21 & 2737.78 & $\mathrm{Fe} I I$ & $4 s a^{4} D_{3 / 2}$ & $4 p z^{4} D_{1 / 2}$ & $2.3 \mathrm{G}$ & col & & \\
\hline 2734.09 & oe & & 2734.10 & He II & $n=3$ & $n=6$ & 1 & $\mathrm{rec}$ & & \\
\hline 2733.15 & 111 & 31 & 2733.26 & $\mathrm{Fe}$ II & $3 d^{7} a^{4} F_{9 / 2}$ & $4 p z^{6} D_{9 / 2}$ & $2.3 \mathrm{G}$ & col & & \\
\hline 2731.45 & 116 & 33 & 2731.54 & $\mathrm{Fe} I I$ & $4 s a^{4} D_{3 / 2}$ & $4 \mathrm{p} \mathrm{z}^{4} \mathrm{~F}_{3 / 2}$ & $2.3 \mathrm{G}$ & col & & \\
\hline \multirow[t]{2}{*}{2728.11} & 126 & 35 & 2728.35 & $\mathrm{Fe} I I$ & $4 \mathrm{~s} \mathrm{a}^{4} \mathrm{D}_{5 / 2}$ & $4 \mathrm{p} \mathrm{z}^{4} \mathrm{D}_{3 / 2}$ & $2.3 \mathrm{G}$ & col & & \\
\hline & & & 8.19 & $\mathrm{Fe} I I$ & $4 s a^{4} G_{11 / 2}$ & $4 p z^{2} G_{9 / 2}$ & 2.1 & $\mathrm{fl}$ & & \\
\hline 2725.60 & 103 & 21 & 2725.69 & $\mathrm{Fe}$ II & $4 \mathrm{~s} \mathrm{a}^{4} \mathrm{D}_{5 / 2}$ & $4 p z^{4} F_{5 / 2}$ & $2.3 \mathrm{G}$ & col & & \\
\hline 2723.92 & 38 & 24 & 2724.00 & $\mathrm{He} \mathrm{I}$ & $2 \mathrm{~s}{ }^{3} \mathrm{~S}_{1}$ & $8 p^{3} \mathrm{P}_{2}$ & $2.3 \mathrm{~A}$ & rec & & \\
\hline 2723.39 & 48 & 17 & 2723.43 & $\mathrm{Fe}$ II & $4 s^{2} d^{4} P_{3 / 2}$ & $\left({ }^{4} \mathrm{P}\right) 4 \mathrm{sp}{ }^{4} \mathrm{P}_{5 / 2}$ & 2.1 & $\mathrm{fl}$ & & \\
\hline 2722.77 & 43 & 17 & 2722.94 & $\mathrm{Fe} I I$ & $4 \mathrm{pz}^{6} \mathrm{P}_{3 / 2}$ & $5 \mathrm{se}^{4} \mathrm{D}_{1 / 2}$ & 2.1 & $\mathrm{fl}$ & & \\
\hline \multirow[t]{3}{*}{2719.33} & 68 & 71 & 2719.42 & $\mathrm{Fe}$ II & $4 s a^{2} F_{7 / 2}$ & $4 \mathrm{p} \mathrm{y}^{4} \mathrm{G}_{5 / 2}$ & 2.1 & $\mathrm{fl}$ & & \\
\hline & & & 9.42 & $\mathrm{Fe}$ II & $4 s^{2} b^{4} G_{5 / 2}$ & $\left({ }^{5} D\right) 5 p{ }^{4} D_{3 / 2}$ & 2.1 & $\mathrm{fl}$ & & \\
\hline & & & 9.16 & $\mathrm{Fe}$ II & $4 s c^{2} P_{1 / 2}$ & $\left(b^{3} P\right) 4 p{ }^{4} P_{1 / 2}$ & 2.1 & $\mathrm{fl}$ & & \\
\hline \multirow[t]{2}{*}{2717.11} & 51 & 71 & 2717.34 & $\mathrm{Fe}$ II & $4 s^{2} d^{4} P_{5 / 2}$ & $\left({ }^{4} \mathrm{P}\right) 4 \mathrm{sp}{ }^{4} \mathrm{P}_{5 / 2}$ & 2.1 & $\mathrm{fl}$ & & \\
\hline & & & 7.02 & $\mathrm{Fe} I I$ & $4 \mathrm{~s} \mathrm{a}^{2} \mathrm{~F}_{5 / 2}$ & $4 p z^{2} F_{5 / 2}$ & & $\mathrm{fl}$ & & \\
\hline 2715.13 & 102 & 24 & 2715.22 & $\mathrm{Fe}$ II & $4 s \mathrm{a}^{4} \mathrm{D}_{7 / 2}$ & $4 \mathrm{p} \mathrm{z}^{4} \mathrm{D}_{5 / 2}$ & $2.3 \mathrm{G}$ & col & & \\
\hline 2712.58 & 94 & 19 & & & & & & & & \\
\hline \multirow[t]{2}{*}{2709.90} & 49 & 46 & 2710.18 & Fe II & $4 s a^{4} D_{5 / 2}$ & $4 p z^{4} F_{3 / 2}$ & $2.3 \mathrm{G}$ & col & & \\
\hline & & & 9.86 & $\mathrm{Fe}$ II & $4 \mathrm{~s} \mathrm{~b}^{2} \mathrm{P}_{3 / 2}$ & $4 p y^{4} D_{5 / 2}$ & & $\mathrm{fl}$ & & \\
\hline \multirow[t]{2}{*}{2707.36} & 64 & 48 & 2707.37 & $\mathrm{Fe} I I$ & $4 \mathrm{~s} \mathrm{~b}^{2} \mathrm{D}_{5 / 2}$ & $4 p y^{2} P_{3 / 2}$ & & unk & & \\
\hline & & & 7.14 & $\mathrm{Fe}$ II & $4 \mathrm{p} \mathrm{z}^{6} \mathrm{P}_{5 / 2}$ & $5 \mathrm{~s} \mathrm{e}^{4} \mathrm{D}_{3 / 2}$ & 2.1 & $\mathrm{fl}$ & & \\
\hline 2704.77 & 36 & 21 & 2704.79 & $\mathrm{Fe}$ II & $4 \mathrm{~s} \mathrm{a}^{2} \mathrm{~F}_{7 / 2}$ & $4 \mathrm{p} \mathrm{z}^{2} \mathrm{~F}_{7 / 2}$ & & $\mathrm{fl}$ & & \\
\hline
\end{tabular}


Table 13. continued.

\begin{tabular}{|c|c|c|c|c|c|c|c|c|c|c|}
\hline$\lambda_{\text {obs }}(\AA)$ & $I^{a}$ & $w^{b}$ & $\lambda_{\text {id }}(\AA)$ & spec. & Lower level & Upper level & $\mathrm{Sec}^{c}$ & $\operatorname{Exc}^{f}$ & $I_{\mathrm{ghrs}}^{d}$ & $w_{\text {ghrs }}^{e}$ \\
\hline 2698.14 & 48 & 33 & & & & & & & & \\
\hline \multirow[t]{2}{*}{2696.77} & 30 & 39 & 2696.92 & $\mathrm{He} \mathrm{I}$ & $2 s^{3} S_{1}$ & $9 \mathrm{p}^{3} \mathrm{P}_{2}$ & $2.3 \mathrm{~A}$ & rec & & \\
\hline & & & 6.91 & N III & $4 s^{2} S_{1 / 2}$ & $5 p^{2} \mathrm{P}_{3 / 2}$ & $2.3 \mathrm{~F}$ & rec & & \\
\hline 2693.54 & 70 & 28 & 2693.63 & Fe II & $4 \mathrm{~s} \mathrm{a}^{4} \mathrm{D}_{7 / 2}$ & $4 \mathrm{p} \mathrm{z}^{4} \mathrm{~F}_{5 / 2}$ & $2.3 \mathrm{G}$ & col & & \\
\hline 2691.65 & 101 & 40 & 2692.02 & {$[\mathrm{Ar} \mathrm{V}]$} & $3 \mathrm{p}^{2}{ }^{3} \mathrm{P}_{1}$ & $3 \mathrm{p}^{2}{ }^{1} \mathrm{~S}_{0}$ & 2.2 & col & & \\
\hline 2689.93 & $54^{b l}$ & 36 & 2690.01 & Fe II & $4 \mathrm{~s} \mathrm{~b}^{2} \mathrm{P}_{3 / 2}$ & $4 p y^{4} D_{3 / 2}$ & & $\mathrm{fl}$ & & \\
\hline 2687.18 & $37^{b l}$ & & 2687.27 & $\mathrm{Fe}$ II & $4 \mathrm{~s} \mathrm{~d}^{2} \mathrm{~F}_{7 / 2}$ & $4 \mathrm{~s} 4 \mathrm{p} \mathrm{x}^{4} \mathrm{H}_{9 / 2}$ & 2.1 & $\mathrm{fl}$ & & \\
\hline 2686.85 & 26 & 21 & 2686.95 & O III & $2 \mathrm{~s} 2 \mathrm{p}^{2}\left({ }^{4} \mathrm{P}\right) 3 \mathrm{~s}{ }^{5} \mathrm{P}_{3}$ & $2 \mathrm{~s} 2 \mathrm{p}^{2}\left({ }^{4} \mathrm{P}\right) 3 \mathrm{p}{ }^{5} \mathrm{~S}_{2}$ & $2.3 \mathrm{~F}$ & rec & & \\
\hline 2683.24 & 86 & 19 & 2683.30 & $\mathrm{Fe}$ II & $4 \mathrm{~s} \mathrm{~d}^{2} \mathrm{~F}_{3 / 2}$ & $4 \mathrm{pu}^{2} \mathrm{G}_{9 / 2}$ & 2.1 & fl & & \\
\hline 2681.56 & 50 & 34 & & & & & & & & \\
\hline 2679.50 & 43 & 34 & 2679.44 & $\mathrm{Ne}$ III & $2 p^{3}\left({ }^{4} S\right) 3 s^{3} S_{1}$ & $2 p^{3}\left({ }^{4} S\right) 3 p^{3} P_{1}$ & 1 & rec & & \\
\hline 2678.67 & 28 & & 2678.70 & $\mathrm{Ne} I I I$ & $2 p^{3}\left({ }^{4} S\right) 3 s^{3} S_{1}$ & $2 p^{3}\left({ }^{4} S\right) 3 p^{3} P_{2}$ & 1 & rec & & \\
\hline 2677.73 & 102 & 34 & 2677.93 & He I & $2 s^{3} S_{1}$ & $10{ }^{3} \mathrm{P}_{2}$ & $2.3 \mathrm{~A}$ & rec & & \\
\hline 2675.20 & 90 & 21 & 2675.38 & O III & $2 \mathrm{~s} 2 \mathrm{p}^{2}\left({ }^{4} \mathrm{P}\right) 3 \mathrm{~s}{ }^{5} \mathrm{P}_{2}$ & $2 \mathrm{~s} 2 \mathrm{p}^{2}\left({ }^{4} \mathrm{P}\right) 3 \mathrm{p}{ }^{5} \mathrm{~S}_{2}$ & $2.3 \mathrm{~F}$ & rec & & \\
\hline 2669.85 & 436 & 29 & 2669.95 & $\mathrm{Al} \mathrm{II}]$ & $3 \mathrm{~s}^{2}{ }^{1} \mathrm{~S}_{0}$ & $3 p^{3} \mathrm{P}_{1}$ & $2.3 \mathrm{C}$ & col & & \\
\hline 2667.35 & 56 & 24 & & & & & & & & \\
\hline 2666.69 & 50 & 29 & & & & & & & & \\
\hline 2664.89 & $46^{b l}$ & & 2664.99 & Fe II & $4 \mathrm{~s} \mathrm{~b}^{2} \mathrm{H}_{9 / 2}$ & $4 p y^{4} G_{11 / 2}$ & & unk & & \\
\hline 2664.01 & $76^{b l}$ & & 2664.06 & $\mathrm{He} \mathrm{I}$ & $2{ }^{3} S_{1}$ & $11 \mathrm{p}^{3} \mathrm{P}_{2}$ & $2.3 \mathrm{~A}$ & rec & & \\
\hline 2650.16 & 76 & 19 & 2650.26 & $\mathrm{Fe}$ II & $4 \mathrm{~s} \mathrm{~d}^{2} \mathrm{~F}_{5 / 2}$ & $4 \mathrm{pu}^{2} \mathrm{G}_{7 / 2}$ & 2.1 & $\mathrm{fl}$ & & \\
\hline Oth & & & 2644.55 & $\mathrm{Fe}$ II & $4 s^{2} b^{4} G_{5 / 2}$ & $4 \mathrm{px}^{4} \mathrm{H}_{7 / 2}$ & 2.1 & $\mathrm{fl}$ & & \\
\hline \multirow[t]{2}{*}{2639.03} & 85 & 52 & 2639.32 & Fe II & $4 s^{2} b^{4} G_{7 / 2}$ & $4 p u^{2} G_{9 / 2}$ & 2.1 & $\mathrm{fl}$ & & \\
\hline & & & 9.01 & $\mathrm{Fe}$ II & $4 s^{2} b^{4} G_{9 / 2}$ & $4 \mathrm{px}^{4} \mathrm{H}_{11 / 2}$ & 2.1 & fl & & \\
\hline \multirow[t]{3}{*}{2631.94} & 174 & 75 & 2632.11 & $\mathrm{Fe}$ II & $4 \mathrm{~s} \mathrm{a}^{6} \mathrm{D}_{5 / 2}$ & $4 \mathrm{pz}^{6} \mathrm{D}_{7 / 2}$ & $2.3 \mathrm{G}$ & col & & \\
\hline & & & 1.83 & $\mathrm{Fe}$ II & $4 s a^{6} D_{3 / 2}$ & $4 p z^{6} D_{5 / 2}$ & $2.3 \mathrm{G}$ & col & & \\
\hline & & & 1.80 & $\mathrm{Fe}$ II & $4 \mathrm{~s} \mathrm{~b}^{4} \mathrm{~F}_{7 / 2}$ & $4 \mathrm{pz}^{4} \mathrm{G}_{9 / 2}$ & 2.1 & $\mathrm{fl}$ & & \\
\hline 2630.69 & 43 & 15 & 2630.86 & $\mathrm{Fe}$ II & $4 \mathrm{~s} \mathrm{~b}^{4} \mathrm{~F}_{3 / 2}$ & $4 p z^{4} G_{5 / 2}$ & 2.1 & $\mathrm{fl}$ & & \\
\hline 2628.99 & 92 & 30 & 2629.08 & $\mathrm{Fe}$ II & $4 s a^{6} D_{1 / 2}$ & $4 p z^{6} D_{3 / 2}$ & $2.3 \mathrm{G}$ & col & & \\
\hline 2626.35 & 212 & 29 & 2626.45 & $\mathrm{Fe}$ II & $4 s a^{6} D_{7 / 2}$ & $4 p z^{6} D_{9 / 2}$ & $2.3 \mathrm{G}$ & col & & \\
\hline 2622.41 & 90 & 22 & 2622.45 & Fe II & $4 \mathrm{~s} \mathrm{a}^{6} \mathrm{D}_{1 / 2}$ & $4 p z^{6} D_{1 / 2}$ & $2.3 \mathrm{G}$ & col & & \\
\hline 2621.11 & 125 & 34 & 2621.19 & $\mathrm{Fe}$ II & $4 s a^{6} D_{3 / 2}$ & $4 p z^{6} D_{3 / 2}$ & $2.3 \mathrm{G}$ & col & & \\
\hline 2619.82 & $134^{b l}$ & 56 & 2619.86 & $\mathrm{Fe} I \mathrm{II}$ & $4 \mathrm{~s} \mathrm{~b}^{4} \mathrm{~F}_{9 / 2}$ & $4 p z^{4} G_{9 / 2}$ & 2.1 & $\mathrm{fl}$ & & \\
\hline 2618.30 & $160^{b l}$ & 46 & 2618.40 & Fe II & $4 \mathrm{~s} \mathrm{a}^{6} \mathrm{D}_{5 / 2}$ & $4 \mathrm{p} \mathrm{z}^{6} \mathrm{D}_{5 / 2}$ & $2.3 \mathrm{G}$ & col & & \\
\hline 2617.62 & 228 & 26 & & & & & & & & \\
\hline 2614.60 & $82^{b l}$ & 69 & 2614.61 & $\mathrm{Fe}$ II & $4 \mathrm{~s} \mathrm{a}^{6} \mathrm{D}_{3 / 2}$ & $4 p z^{6} D_{1 / 2}$ & $2.3 \mathrm{G}$ & col & & \\
\hline 2612.56 & 173 & 29 & 2612.65 & $\mathrm{Fe}$ II & $4 s a^{6} D_{7 / 2}$ & $4 p z^{6} D_{7 / 2}$ & $2.3 \mathrm{G}$ & col & & \\
\hline 2611.83 & 80 & 34 & 2611.85 & $\mathrm{Fe}$ II & $4 \mathrm{~s} \mathrm{a}{ }^{4} D_{3 / 2}$ & $4 \mathrm{p} \mathrm{z}^{4} \mathrm{P}_{5 / 2}$ & $2.3 \mathrm{G}$ & col & & \\
\hline 2610.79 & 54 & 22 & 2610.81 & $\mathrm{Ne}$ III & $2 \mathrm{p}^{3}\left({ }^{2} \mathrm{D}\right) 3 \mathrm{~s}^{3} \mathrm{D}_{3}$ & $2 p^{3}\left({ }^{2} D\right) 3 p^{3} F_{4}$ & $3.2 \mathrm{~F}$ & rec & & \\
\hline 2607.76 & 105 & 29 & 2607.87 & $\mathrm{Fe}$ II & $4 \mathrm{~s} \mathrm{a}^{6} \mathrm{D}_{5 / 2}$ & $4 p z^{6} D_{3 / 2}$ & $2.3 \mathrm{G}$ & col & & \\
\hline 2607.13 & 87 & 20 & & & & & & & & \\
\hline 2605.68 & 208 & 25 & 2605.82 & $\mathrm{Fe}$ II & $4 \mathrm{~s} \mathrm{c}^{2} \mathrm{~F}_{5 / 2}$ & $4 p v^{2} G_{7 / 2}$ & 2.1 & fl & & \\
\hline 2599.05 & $68^{b l}$ & 50 & 2599.15 & Fe II & $4 \mathrm{~s} \mathrm{a}^{6} \mathrm{D}_{7 / 2}$ & $4 p z^{6} D_{5 / 2}$ & $2.3 \mathrm{G}$ & col & & \\
\hline 2596.34 & 470 & 27 & & & & & & & & \\
\hline 2592.28 & $72^{b l}$ & 35 & 2592.32 & Fe II & $4 \mathrm{~s} \mathrm{a}^{4} \mathrm{D}_{5 / 2}$ & $4 p z^{4} \mathrm{P}_{5 / 2}$ & $2.3 \mathrm{G}$ & col & & \\
\hline 2591.21 & $67^{b l}$ & 39 & 2591.33 & $\mathrm{Fe}$ II & $4 \mathrm{~s} \mathrm{~b}^{4} \mathrm{P}_{3 / 2}$ & $4 p y^{4} P_{5 / 2}$ & 2.1 & $\mathrm{fl}$ & & \\
\hline \multirow[t]{2}{*}{2588.68} & 44 & 79 & 2588.95 & O III] & $2 \mathrm{p} 3 \mathrm{p}^{1} \mathrm{P}_{1}$ & $2 \mathrm{p} 3 \mathrm{~d}^{3} \mathrm{P}_{1}$ & 3 & $\mathrm{fl}$ & & \\
\hline & & & 8.72 & Fe II & $4 \mathrm{~s} \mathrm{c}^{2} \mathrm{G}_{7 / 2}$ & $4 \mathrm{px}^{2} \mathrm{H}_{9 / 2}$ & 2.1 & $\mathrm{fl}$ & & \\
\hline Oth & & & 2583.36 & $\mathrm{Fe}$ II & $4 \mathrm{~s} \mathrm{a}^{4} \mathrm{D}_{3 / 2}$ & $4 \mathrm{p} \mathrm{z}^{4} \mathrm{P}_{3 / 2}$ & $2.3 \mathrm{G}$ & col & & \\
\hline Oth & & & 2581.94 & $\mathrm{Fe}$ II & $4 \mathrm{pz}^{2} \mathrm{D}_{5 / 2}$ & $5 \mathrm{~s} \mathrm{f}^{4} \mathrm{~F}_{5 / 2}$ & 2.1 & $\mathrm{fl}$ & & \\
\hline
\end{tabular}


Table 13. continued.

\begin{tabular}{|c|c|c|c|c|c|c|c|c|c|c|}
\hline$\lambda_{\mathrm{obs}}(\AA)$ & $I^{a}$ & $w^{b}$ & $\lambda_{\text {id }}(\AA)$ & spec. & Lower level & Upper level & $\mathrm{Sec}^{c}$ & $\operatorname{Exc}^{f}$ & $I_{\mathrm{ghrs}}^{d}$ & $w_{\mathrm{ghrs}}^{e}$ \\
\hline 2567.13 & 63 & 33 & 2567.26 & O III] & $2 \mathrm{p} 3 \mathrm{~s}^{3} \mathrm{P}_{2}$ & $2 p 3 p^{1} D_{2}$ & $2.3 \mathrm{~F}$ & unk & & \\
\hline 2564.68 & 105 & 28 & 2564.80 & Co II & $4 \mathrm{sb}^{3} \mathrm{~F}_{3}$ & $4 p z^{3} F_{4}$ & & unk & & \\
\hline 2564.23 & $42^{b l}$ & & 2564.25 & $\mathrm{Fe}$ II & $4 s a^{4} D_{5 / 2}$ & $4 p z^{4} P_{3 / 2}$ & $2.3 \mathrm{G}$ & col & & \\
\hline 2563.17 & 90 & 20 & 2563.30 & $\mathrm{Fe} I I$ & $4 \mathrm{~s} \mathrm{a}^{4} \mathrm{D}_{7 / 2}$ & $4 p z^{4} P_{5 / 2}$ & $2.3 \mathrm{G}$ & col & & \\
\hline \multirow[t]{3}{*}{2558.00} & 58 & 70 & 2558.27 & $\mathrm{Fe} I I$ & $4 s b^{4} F_{9 / 2}$ & $4 \mathrm{p} \mathrm{y}^{4} \mathrm{D}_{7 / 2}$ & & $\mathrm{fl}$ & & \\
\hline & & & 7.92 & $\mathrm{Fe} I I$ & $4 \mathrm{~s} \mathrm{~b}^{4} \mathrm{~F}_{3 / 2}$ & $4 \mathrm{p} \mathrm{z}^{2} \mathrm{D}_{3 / 2}$ & & unk & & \\
\hline & & & 7.85 & $\mathrm{Fe} I I$ & $4 \mathrm{~s} \mathrm{a}^{4} \mathrm{H}_{7 / 2}$ & $4 p z^{4} G_{9 / 2}$ & 2.1 & fl & & \\
\hline 2550.49 & 102 & 20 & 2550.54 & $\mathrm{Fe}$ II & $4 \mathrm{~s} \mathrm{a}^{2} \mathrm{~F}_{7 / 2}$ & $4 p x^{4} F_{5 / 2}$ & 2.1 & $\mathrm{fl}$ & & \\
\hline Oth & & & 2549.69 & $\mathrm{Fe} I I$ & $4 \mathrm{~s} \mathrm{a}^{2} \mathrm{I}_{11 / 2}$ & $4 \mathrm{p} \mathrm{x}^{2} \mathrm{H}_{9 / 2}$ & 2.1 & fl & & \\
\hline 2549.26 & 111 & 25 & 2549.36 & $\mathrm{Fe} I I$ & $4 \mathrm{~s} \mathrm{a}^{4} \mathrm{H}_{9 / 2}$ & $4 \mathrm{p} \mathrm{z}^{4} \mathrm{G}_{9 / 2}$ & 2.1 & fl & & \\
\hline \multirow[t]{2}{*}{2542.50} & 126 & 20 & 2542.60 & $\mathrm{Fe} I I$ & $4 \mathrm{~s} \mathrm{a}^{4} \mathrm{H}_{7 / 2}$ & $4 \mathrm{p} \mathrm{z}^{4} \mathrm{G}_{5 / 2}$ & 2.1 & fl & & \\
\hline & & & 2.58 & Si III & $3 p^{1} \mathrm{P}_{1}$ & $3 \mathrm{p}^{21} \mathrm{D}_{2}$ & & unk & & \\
\hline 2539.40 & 122 & 20 & 2539.56 & $\mathrm{Fe} I I$ & $4 s a^{4} H_{11 / 2}$ & $4 p z^{4} G_{9 / 2}$ & 2.1 & fl & & \\
\hline Oth & & & 2539.35 & $\mathrm{Fe}$ II & $4 s a^{2} F_{5 / 2}$ & $4 p y^{2} D_{5 / 2}$ & 2.1 & $\mathrm{fl}$ & & \\
\hline \multirow[t]{2}{*}{2538.03} & 76 & 31 & 2538.13 & $\mathrm{Fe}$ II & $3 d^{7} a^{4} F_{5 / 2}$ & $4 p z^{6} F_{7 / 2}$ & $2.3 \mathrm{G}$ & col & & \\
\hline & & & 7.90 & $\mathrm{Fe} I I$ & $4 p z^{6} D_{9 / 2}$ & $5 \mathrm{~s} \mathrm{e}^{6} \mathrm{D}_{9 / 2}$ & 2.1 & $\mathrm{fl}$ & & \\
\hline \multirow[t]{2}{*}{2537.43} & 64 & 30 & 2537.61 & $\mathrm{Fe} I I$ & $4 s a^{4} H_{11 / 2}$ & $4 p z^{4} H_{13 / 2}$ & & unk & & \\
\hline & & & 7.57 & $\mathrm{Fe}$ II & $4 \mathrm{~s} \mathrm{a}^{4} \mathrm{H}_{9 / 2}$ & $4 \mathrm{p} \mathrm{z}^{4} \mathrm{H}_{9 / 2}$ & & unk & & \\
\hline 2534.49 & 241 & 26 & & & & & & & & \\
\hline 2531.75 & 89 & 27 & 2531.85 & $\mathrm{Fe}$ II & $3 d^{7} a^{4} F_{5 / 2}$ & $4 p z^{6} F_{5 / 2}$ & $2.3 \mathrm{G}$ & col & & \\
\hline 2530.94 & 111 & 24 & & & & & & & & \\
\hline \multicolumn{11}{|l|}{ Oth } \\
\hline Oth & & & 2527.06 & $\mathrm{Fe}$ II & $4 \mathrm{~s} \mathrm{~b}^{4} \mathrm{P}_{5 / 2}$ & $4 \mathrm{p} \mathrm{y}^{4} \mathrm{P}_{5 / 2}$ & 2.1 & $\mathrm{fl}$ & & \\
\hline 2526.60 & 133 & 15 & 2526.68 & $\mathrm{Fe}$ II & $4 p z^{6} D_{7 / 2}$ & $5 \mathrm{~s} \mathrm{e}^{6} \mathrm{D}_{7 / 2}$ & 2.1 & $\mathrm{fl}$ & & \\
\hline 2525.87 & $48^{b l}$ & 38 & 2526.15 & $\mathrm{Fe}$ II & $4 s a^{4} H_{13 / 2}$ & $4 p z^{4} H_{13 / 2}$ & & unk & & \\
\hline 2524.87 & 120 & 20 & 2524.87 & Si I & $3 \mathrm{p}^{2}{ }^{3} \mathrm{P}_{1}$ & $3 \mathrm{p} 4 \mathrm{~s}^{3} \mathrm{P}_{0}$ & $2.3 \mathrm{E}$ & unk & & \\
\hline \multirow[t]{3}{*}{2519.70} & 77 & 33 & 2519.96 & Si I & $3 \mathrm{p}^{2}{ }^{3} \mathrm{P}_{1}$ & $3 \mathrm{p} 4 \mathrm{~s}^{3} \mathrm{P}_{1}$ & $2.3 \mathrm{E}$ & unk & & \\
\hline & & & 9.86 & $\mathrm{Fe}$ II & $3 d^{7} a^{4} F_{7 / 2}$ & $4 p z^{6} F_{9 / 2}$ & $2.3 \mathrm{G}$ & col & & \\
\hline & & & 9.81 & $\mathrm{Fe} I I$ & $4 s a^{2} F_{7 / 2}$ & $4 p y^{2} D_{5 / 2}$ & 2.1 & fl & & \\
\hline \multirow[t]{2}{*}{2516.79} & 133 & 38 & 2516.87 & Si I & $3 \mathrm{p}^{2}{ }^{3} \mathrm{P}_{2}$ & $3 p 4 s{ }^{3} P_{2}$ & $2.3 \mathrm{E}$ & unk & & \\
\hline & & & 6.75 & $\mathrm{Fe}$ II & $3 d^{7} a^{2} D_{3 / 2}$ & $4 p z^{4} G_{5 / 2}$ & 2.1 & fl & & \\
\hline 2513.96 & $101^{b l}$ & 36 & 2513.91 & $\mathrm{Fe} I I$ & $4 p z^{6} D_{9 / 2}$ & $5 \mathrm{~s} \mathrm{e}^{6} \mathrm{D}_{7 / 2}$ & 2.1 & fl & & \\
\hline 2512.57 & $73^{b l}$ & & 2512.81 & C II & $2 \mathrm{~s} 2 \mathrm{p}^{2}{ }^{2} \mathrm{P}_{3 / 2}$ & $2 \mathrm{p}^{32} \mathrm{D}_{5 / 2}$ & $2.3 \mathrm{D}$ & unk & & \\
\hline 2511.89 & 529 & 61 & 2511.96 & He II & $n=3$ & $n=7$ & 1 & rec & & \\
\hline 2509.77 & $32^{b l}$ & & 2509.88 & C II & $2 \mathrm{~s} 2 \mathrm{p}^{2}{ }^{2} \mathrm{P}_{3 / 2}$ & $2 \mathrm{p}^{3}{ }^{2} \mathrm{D}_{3 / 2}$ & $2.3 \mathrm{D}$ & unk & & \\
\hline 2509.02 & 843 & 23 & 2509.10 & $\mathrm{Fe}$ II & $4 \mathrm{~s} \mathrm{c}^{4} \mathrm{~F}_{7 / 2}$ & $\left({ }^{3} F\right) 4 p{ }^{4} G_{9 / 2}$ & 2.1 & $\mathrm{fl}$ & & \\
\hline \multirow[t]{2}{*}{2507.46} & 336 & & 2507.65 & Si I & $3 \mathrm{p}^{2}{ }^{3} \mathrm{P}_{1}$ & $3 \mathrm{p} 4 \mathrm{~s}{ }^{3} \mathrm{P}_{2}$ & $2.3 \mathrm{E}$ & unk & & \\
\hline & & & 2507.55 & $\mathrm{Fe}$ II & $4 \mathrm{~s} \mathrm{~b}^{4} \mathrm{~F}_{7 / 2}$ & $\left({ }^{5} \mathrm{D}\right) 5 \mathrm{p}{ }^{6} \mathrm{~F}_{9 / 2}$ & 2.1 & $\mathrm{fl}$ & & \\
\hline 2507.13 & $192^{b l}$ & & 2507.19 & $\mathrm{Fe}$ II & $4 \mathrm{~s} \mathrm{c}^{4} \mathrm{~F}_{9 / 2}$ & $\left({ }^{3} F\right) 4 p{ }^{4} G_{9 / 2}$ & 2.1 & $\mathrm{fl}$ & & \\
\hline 2506.70 & 62 & 23 & 2506.85 & Fe II & $4 \mathrm{~s} \mathrm{a}^{4} \mathrm{G}_{9 / 2}$ & $4 \mathrm{p} \mathrm{x}^{4} \mathrm{G}_{9 / 2}$ & & unk & & \\
\hline 2505.94 & 56 & 30 & 2505.97 & $\mathrm{Fe}$ II & $3 d^{7} a^{4} F_{7 / 2}$ & $4 p z^{6} F_{5 / 2}$ & $2.3 \mathrm{G}$ & col & & \\
\hline 2498.55 & 134 & 16 & 2498.57 & $\mathrm{Fe}$ II & $4 \mathrm{~s} \mathrm{a}^{4} \mathrm{G}_{5 / 2}$ & $4 p x^{4} G_{5 / 2}$ & & unk & & \\
\hline \multirow[t]{4}{*}{2493.94} & 106 & 49 & 2494.05 & $\mathrm{Fe}$ II & $3 d^{7} a^{4} F_{9 / 2}$ & $4 p z^{6} F_{11 / 2}$ & $2.3 \mathrm{G}$ & col & & \\
\hline & & & 4.02 & $\mathrm{Fe} I I$ & $4 s a^{4} H_{13 / 2}$ & $4 \mathrm{p} \mathrm{z}^{4} \mathrm{I}_{15 / 2}$ & & unk & & \\
\hline & & & 3.98 & $\mathrm{Fe}$ II & $4 \mathrm{~s} \mathrm{a}^{4} \mathrm{G}_{7 / 2}$ & $4 \mathrm{p} \mathrm{x}^{4} \mathrm{G}_{5 / 2}$ & & unk & & \\
\hline & & & 3.94 & $\mathrm{Fe}$ II & $4 \mathrm{~s} \mathrm{a}^{4} \mathrm{H}_{11 / 2}$ & $4 p z^{4} I_{13 / 2}$ & & unk & & \\
\hline 2493.02 & 675 & 34 & 2493.10 & $\mathrm{Fe} I I$ & $4 s b^{2} \mathrm{H}_{9 / 2}$ & $4 p y^{4} H_{11 / 2}$ & 2.1 & $\mathrm{fl}$ & & \\
\hline 2484.91 & $143^{b l}$ & 35 & 2484.95 & $\mathrm{Fe}$ II & $3 d^{7} a^{4} F_{9 / 2}$ & $4 p z^{6} F_{9 / 2}$ & $2.3 \mathrm{G}$ & col & & \\
\hline 2484.39 & 80 & 28 & 2484.47 & $\mathrm{Fe}$ II & $4 \mathrm{~s} \mathrm{c}^{2} \mathrm{G}_{7 / 2}$ & $4 \mathrm{pw}^{2} \mathrm{H}_{9 / 2}$ & & unk & & \\
\hline
\end{tabular}


Table 13. continued.

\begin{tabular}{|c|c|c|c|c|c|c|c|c|c|c|}
\hline$\lambda_{\text {obs }}(\AA)$ & $I^{a}$ & $w^{b}$ & $\lambda_{\mathrm{id}}(\AA)$ & spec. & Lower level & Upper level & $\mathrm{Sec}^{c}$ & $\operatorname{Exc}^{f}$ & $I_{\text {ghrs }}^{d}$ & $w_{\text {ghrs }}^{e}$ \\
\hline 2483.74 & 73 & 21 & & & & & & & & \\
\hline 2482.98 & 579 & 29 & 2483.08 & $\mathrm{Fe}$ II & $4 \mathrm{~s} \mathrm{c}^{2} \mathrm{D}_{3 / 2}$ & $4 p w^{2} D_{3 / 2}$ & 2.1 & $\mathrm{fl}$ & & \\
\hline 2481.70 & 628 & 23 & 2481.80 & $\mathrm{Fe}$ II & $4 \mathrm{~s} \mathrm{~b}^{2} \mathrm{H}_{11 / 2}$ & $4 p y^{4} \mathrm{H}_{11 / 2}$ & 2.1 & $\mathrm{fl}$ & & \\
\hline 2479.90 & 366 & 23 & 2479.98 & Fe II & $4 \mathrm{sc}^{2} \mathrm{D}_{5 / 2}$ & $4 \mathrm{pw}^{2} \mathrm{D}_{3 / 2}$ & 2.1 & $\mathrm{fl}$ & & \\
\hline 2476.96 & 50 & 25 & 2477.01 & $\mathrm{Fe}$ II & $4 \mathrm{~s} \mathrm{a}^{4} \mathrm{H}_{7 / 2}$ & $4 \mathrm{p} \mathrm{z}^{2} \mathrm{G}_{9 / 2}$ & 2.1 & $\mathrm{fl}$ & & \\
\hline 2474.06 & $61^{b l}$ & 39 & 2474.20 & $\mathrm{Fe}$ II & $4 \mathrm{~s} \mathrm{c}^{4} \mathrm{P}_{5 / 2}$ & $\left(b^{3} P\right) 4 p^{4} S_{3 / 2}$ & 2.1 & $\mathrm{fl}$ & & \\
\hline 2473.53 & $101^{b l}$ & 34 & 2473.66 & Fe II & $4 \mathrm{~s} \mathrm{c}^{4} \mathrm{P}_{5 / 2}$ & $\left({ }^{5} \mathrm{D}\right) 5 \mathrm{p}^{4} \mathrm{D}_{5 / 2}$ & 2.1 & $\mathrm{fl}$ & & \\
\hline 2471.06 & 119 & 16 & 2471.15 & $\mathrm{Fe}$ II & $3 d^{7} a^{2} \mathrm{H}_{11 / 2}$ & $4 \mathrm{pz}^{4} \mathrm{G}_{9 / 2}$ & 2.1 & $\mathrm{fl}$ & & \\
\hline 2470.23 & $57^{b l}$ & 47 & 2470.26 & Fe II & $4 \mathrm{~s} \mathrm{~b}^{4} \mathrm{D}_{7 / 2}$ & $\left({ }^{3} \mathrm{D}\right) 4 \mathrm{p}^{4} \mathrm{P}_{5 / 2}$ & & unk & & \\
\hline Oth & & & 2464.76 & $\mathrm{Fe}$ II & $4 \mathrm{~s} \mathrm{a}^{4} \mathrm{G}_{9 / 2}$ & $4 \mathrm{px}^{4} \mathrm{~F}_{7 / 2}$ & 2.1 & $\mathrm{fl}$ & & \\
\hline 2459.65 & 87 & & 2459.72 & Fe II & $4 \mathrm{~s} \mathrm{~b}^{4} \mathrm{D}_{5 / 2}$ & $\left({ }^{3} \mathrm{D}\right) 4 \mathrm{p}^{4} \mathrm{P}_{3 / 2}$ & 2.1 & $\mathrm{fl}$ & & \\
\hline 2459.46 & 721 & 28 & 2459.53 & $\mathrm{Fe}$ II & $4 \mathrm{~s} \mathrm{a}^{4} \mathrm{G}_{9 / 2}$ & $4 \mathrm{p} \mathrm{y}^{4} \mathrm{H}_{11 / 2}$ & 2.1 & $\mathrm{fl}$ & & \\
\hline 2458.23 & 121 & 26 & 2458.30 & $\mathrm{Fe}$ II & $4 \mathrm{~s} \mathrm{~b}^{4} \mathrm{D}_{3 / 2}$ & $\left({ }^{3} \mathrm{D}\right) 4 \mathrm{p}{ }^{4} \mathrm{P}_{3 / 2}$ & 2.1 & $\mathrm{fl}$ & & \\
\hline 2457.68 & 111 & 29 & 2457.71 & $\mathrm{Fe}$ II & $4 \mathrm{~s} \mathrm{c}^{4} \mathrm{P}_{5 / 2}$ & $\left({ }^{5} \mathrm{D}\right) 5 \mathrm{p}{ }^{4} \mathrm{P}_{5 / 2}$ & 2.1 & $\mathrm{fl}$ & & \\
\hline Oth & & & 2455.71 & O III & $2 \mathrm{p} 3 \mathrm{~s}{ }^{1} \mathrm{P}_{1}$ & $2 \mathrm{p} 3 \mathrm{p}^{1} \mathrm{~S}_{0}$ & $2.3 \mathrm{~F}$ & rec & & \\
\hline 2448.43 & 140 & 23 & 2448.50 & Fe II & $4 \mathrm{~s} \mathrm{a}^{2} \mathrm{I}_{11 / 2}$ & $4 \mathrm{p} \mathrm{w}^{2} \mathrm{H}_{9 / 2}$ & & unk & & \\
\hline Oth & & & 2437.94 & $\mathrm{Fe}$ II & $4 \mathrm{~s} \mathrm{a}^{4} \mathrm{G}_{7 / 2}$ & $4 p y^{2} D_{5 / 2}$ & 2.1 & $\mathrm{fl}$ & & \\
\hline 2436.89 & 582 & 21 & 2436.96 & $\mathrm{Fe}$ II & $4 \mathrm{~s} \mathrm{a}^{4} \mathrm{G}_{11 / 2}$ & $4 \mathrm{p} \mathrm{y}^{4} \mathrm{H}_{11 / 2}$ & 2.1 & $\mathrm{fl}$ & & \\
\hline \multirow[t]{2}{*}{ Oth } & & & 2435.69 & $\mathrm{Fe}$ II & $4 \mathrm{~s} \mathrm{~b}^{4} \mathrm{~F}_{3 / 2}$ & $4 \mathrm{p} \mathrm{y}^{4} \mathrm{G}_{5 / 2}$ & 2.1 & $\mathrm{fl}$ & & \\
\hline & & & 5.66 & Ne III & $2 \mathrm{p}^{3}\left({ }^{2} \mathrm{D}\right) 3 \mathrm{~s}{ }^{1} \mathrm{D}_{2}$ & $2 p^{3}\left({ }^{2} D\right) 3 p{ }^{3} P_{2}$ & $2.3 \mathrm{~F}$ & rec & & \\
\hline Oth & & & 2429.98 & $\mathrm{Ne}$ III & $2 \mathrm{p}^{3}\left({ }^{2} \mathrm{D}\right) 3 \mathrm{~s}{ }^{1} \mathrm{D}_{2}$ & $2 p^{3}\left({ }^{2} \mathrm{D}\right) 3 \mathrm{p}{ }^{3} \mathrm{P}_{1}$ & $2.3 \mathrm{~F}$ & rec & & \\
\hline 2427.85 & $64^{b l}$ & 32 & 2427.93 & Fe II & $3 d^{7} a^{2} H_{11 / 2}$ & $4 p z^{4} I_{13 / 2}$ & & unk & & \\
\hline Oth & & & 2426.42 & Fe II & $4 \mathrm{~s} \mathrm{~b}^{2} \mathrm{P}_{3 / 2}$ & $4 \mathrm{p} \mathrm{y}^{2} \mathrm{D}_{5 / 2}$ & 2.1 & $\mathrm{fl}$ & & \\
\hline Oth & & & 2425.23 & [Ne IV] & $2 p^{3}{ }^{4} S_{3 / 2}$ & $2 \mathrm{p}^{3}{ }^{2} \mathrm{D}_{5 / 2}$ & 2.2 & col & & \\
\hline Oth & & & 2422.60 & [Ne IV] & $2 p^{3}{ }^{4} S_{3 / 2}$ & $2 \mathrm{p}^{3}{ }^{2} \mathrm{D}_{3 / 2}$ & 2.2 & col & & \\
\hline 2417.36 & 159 & 19 & & & & & & & & \\
\hline \multirow[t]{2}{*}{ Oth } & & & 2413.67 & $\mathrm{Ne}$ III & $2 p^{3}\left({ }^{4} S\right) 3 p^{3} P_{1}$ & $2 p^{3}\left({ }^{4} S\right) 3 d^{3} D_{2}$ & $2.3 \mathrm{~F}$ & rec & & \\
\hline & & & 3.47 & $\mathrm{Ne}$ III & $2 p^{3}\left({ }^{4} S\right) 3 p^{3} P_{2}$ & $2 p^{3}\left({ }^{4} S\right) 3 d^{3} D_{3}$ & $2.3 \mathrm{~F}$ & rec & & \\
\hline 2411.36 & 84 & 40 & 2411.25 & Fe II & $4 s a^{6} D_{3 / 2}$ & $4 p z^{6} F_{5 / 2}$ & $2.3 \mathrm{G}$ & col & & \\
\hline 2407.85 & 220 & 17 & 2407.96 & $\mathrm{Fe}$ II & $4 \mathrm{~s} \mathrm{c}^{4} \mathrm{P}_{1 / 2}$ & $\left({ }^{3} \mathrm{P}\right) 4 \mathrm{p}^{4} \mathrm{~S}_{3 / 2}$ & 2.1 & $\mathrm{fl}$ & & \\
\hline \multirow[t]{2}{*}{2399.87} & 166 & 16 & 2399.97 & $\mathrm{Fe} I I$ & $4 \mathrm{~s} \mathrm{a}^{6} \mathrm{D}_{5 / 2}$ & $4 \mathrm{p} \mathrm{z}^{6} \mathrm{~F}_{5 / 2}$ & $2.3 \mathrm{G}$ & col & & \\
\hline & & & 2399.96 & $\mathrm{Fe}$ II & $3 d^{7} a^{4} F_{3 / 2}$ & $4 \mathrm{p} \mathrm{z}^{4} \mathrm{D}_{5 / 2}$ & $2.3 \mathrm{G}$ & col & & \\
\hline 2396.28 & 172 & 20 & 2396.36 & $\mathrm{Fe}$ II & $4 \mathrm{~s} \mathrm{a}^{6} \mathrm{D}_{7 / 2}$ & $4 p z^{6} F_{9 / 2}$ & $2.3 \mathrm{G}$ & col & & \\
\hline 2395.47 & 94 & 38 & 2395.62 & Fe II & $3 d^{7} a^{2} \mathrm{H}_{11 / 2}$ & $4 \mathrm{p} \mathrm{z}^{2} \mathrm{G}_{9 / 2}$ & 2.1 & $\mathrm{fl}$ & & \\
\hline 2392.19 & 134 & 28 & 2392.21 & $\mathrm{Fe}$ II & $3 d^{7} a^{4} F_{7 / 2}$ & $4 \mathrm{pz}^{4} \mathrm{~F}_{9 / 2}$ & $2.3 \mathrm{G}$ & col & & \\
\hline 2389.34 & 73 & & 2389.36 & $\mathrm{Fe}$ II & $4 \mathrm{~s} \mathrm{a}^{6} \mathrm{D}_{7 / 2}$ & $4 p z^{6} F_{7 / 2}$ & $2.3 \mathrm{G}$ & col & & \\
\hline 2386.08 & 332 & 49 & 2386.13 & He II & $n=3$ & $n=8$ & 1 & rec & & \\
\hline 2383.96 & 90 & 24 & 2383.97 & $\mathrm{Fe}$ II & $3 d^{7} a^{4} F_{5 / 2}$ & $4 \mathrm{p} \mathrm{z}^{4} \mathrm{D}_{5 / 2}$ & $2.3 \mathrm{G}$ & col & & \\
\hline 2379.91 & $68^{b l}$ & 62 & 2380.00 & Fe II & $3 d^{7} a^{4} F_{7 / 2}$ & $4 \mathrm{p} \mathrm{z}^{4} \mathrm{D}_{7 / 2}$ & $2.3 \mathrm{G}$ & $\mathrm{col}$ & & \\
\hline 2362.18 & 130 & 28 & 2362.24 & Co II & $4 \mathrm{~s} \mathrm{a}^{5} \mathrm{~F}_{1}$ & $4 \mathrm{pz}^{5} \mathrm{D}_{2}$ & & unk & & \\
\hline 2360.66 & 96 & 15 & 2360.68 & $\mathrm{Fe}$ II & $4 \mathrm{~s} \mathrm{~b}^{2} \mathrm{D}_{3 / 2}$ & $4 \mathrm{pw}^{2} \mathrm{D}_{3 / 2}$ & 2.1 & $\mathrm{fl}$ & & \\
\hline 2359.66 & $131^{b l}$ & 27 & 2359.83 & $\mathrm{Fe} I I$ & $4 \mathrm{~s} \mathrm{a}^{6} \mathrm{D}_{3 / 2}$ & $4 p z^{6} \mathrm{P}_{5 / 2}$ & $2.3 \mathrm{G}$ & $\mathrm{col}$ & & \\
\hline 2350.86 & 137 & 29 & 2350.89 & $\mathrm{Si}$ II] & $3 p^{2} \mathrm{P}_{3 / 2}$ & $3 \mathrm{p}^{2}{ }^{4} \mathrm{P}_{1 / 2}$ & $2.3 \mathrm{D}$ & col & & \\
\hline 2348.93 & 116 & 24 & 2349.02 & $\mathrm{Fe}$ II & $4 \mathrm{~s} \mathrm{a}^{6} \mathrm{D}_{5 / 2}$ & $4 p z^{6} P_{5 / 2}$ & $2.3 \mathrm{G}$ & col & & \\
\hline \multirow[t]{2}{*}{2347.98} & 224 & 56 & 2348.12 & Co II & $4 \mathrm{~s} \mathrm{a}^{5} \mathrm{~F}_{2}$ & $4 \mathrm{pz}^{5} \mathrm{D}_{2}$ & & unk & & \\
\hline & & & 7.92 & $\mathrm{Fe}$ II & $3 d^{7} d^{2} D 1_{5 / 2}$ & $\left(b^{3} P\right) 4 p{ }^{4} S_{3 / 2}$ & 2.1 & $\mathrm{fl}$ & & \\
\hline 2344.94 & 188 & 24 & 2345.00 & Fe II & $4 \mathrm{~s} \mathrm{a}^{6} \mathrm{D}_{1 / 2}$ & $4 \mathrm{p} \mathrm{z}^{6} \mathrm{P}_{3 / 2}$ & $2.3 \mathrm{G}$ & $\mathrm{col}$ & & \\
\hline 2335.15 & 410 & 19 & 2335.12 & $\mathrm{Si}$ II] & $3 p^{2} \mathrm{P}_{1 / 2}$ & $3 \mathrm{p}^{2}{ }^{4} \mathrm{P}_{1 / 2}$ & 2.3D & col & & \\
\hline 2333.49 & $109^{b l}$ & 33 & 2333.52 & $\mathrm{Fe}$ II & $4 \mathrm{~s} \mathrm{a}^{6} \mathrm{D}_{7 / 2}$ & $4 p z^{6} \mathrm{P}_{5 / 2}$ & $2.3 \mathrm{G}$ & $\mathrm{col}$ & & \\
\hline
\end{tabular}


Table 13. continued.

\begin{tabular}{|c|c|c|c|c|c|c|c|c|c|c|}
\hline$\lambda_{\mathrm{obs}}(\AA)$ & $I^{a}$ & $w^{b}$ & $\lambda_{\text {id }}(\AA)$ & spec. & Lower level & Upper level & $\mathrm{Sec}^{c}$ & $\operatorname{Exc}^{f}$ & $I_{\mathrm{ghrs}}^{d}$ & $w_{\text {ghrs }}^{e}$ \\
\hline 2326.77 & 463 & 25 & 2326.84 & Co II & $4 \mathrm{~s} \mathrm{a}^{5} \mathrm{~F}_{3}$ & $4 p z^{5} D_{2}$ & & unk & & \\
\hline 2326.04 & 173 & 27 & & & & & & & & \\
\hline Oth & & & 2321.66 & [O III] & $2 \mathrm{p}^{2}{ }^{3} \mathrm{P}_{1}$ & $2 \mathrm{p}^{2}{ }^{1} \mathrm{~S}_{0}$ & 2.2 & col & & \\
\hline Oth & & & 2316.46 & Co II & $4 \mathrm{~s} \mathrm{c}^{3} \mathrm{~F}_{4}$ & $4 p v^{3} D_{3}$ & 2.1 & $\mathrm{fl}$ & & \\
\hline 2315.57 & 141 & 25 & 2315.58 & $\mathrm{Fe}$ II & $4 \mathrm{~s} \mathrm{c}^{4} \mathrm{~F}_{5 / 2}$ & $4 p u^{4} F_{3 / 2}$ & 2.1 & $\mathrm{fl}$ & & \\
\hline 2311.97 & 282 & 25 & 2312.00 & $\mathrm{Fe}$ II & $4 \mathrm{~s} \mathrm{c}^{4} \mathrm{~F}_{3 / 2}$ & $4 p u^{4} F_{3 / 2}$ & 2.1 & $\mathrm{fl}$ & & \\
\hline 2306.85 & 355 & 49 & 2306.91 & $\mathrm{He}$ II & $n=3$ & $n=9$ & 1 & $\mathrm{rec}$ & & \\
\hline 2297.49 & 512 & 25 & 2297.58 & C III & $2 \mathrm{~s} 2 \mathrm{p}^{1} \mathrm{P}_{1}$ & $2 \mathrm{p}^{2}{ }^{1} \mathrm{D}_{2}$ & & unk & & \\
\hline 2281.60 & 128 & 22 & 2281.73 & $\mathrm{Fe}$ II & $4 \mathrm{~s} \mathrm{~b}^{4} \mathrm{~F}_{9 / 2}$ & $4 p y^{4} H_{11 / 2}$ & 2.1 & $\mathrm{fl}$ & & \\
\hline 2280.55 & 248 & 22 & 2280.62 & $\mathrm{Fe}$ II & $4 \mathrm{~s} \mathrm{a}^{6} \mathrm{D}_{7 / 2}$ & $4 p z^{4} F_{9 / 2}$ & $2.3 \mathrm{G}$ & col & & \\
\hline Oth & & & 2253.83 & $\mathrm{Fe}$ II & $4 \mathrm{~s} \mathrm{a}^{6} \mathrm{D}_{7 / 2}$ & $4 \mathrm{p} \mathrm{z}^{4} \mathrm{~F}_{7 / 2}$ & $2.3 \mathrm{G}$ & col & & \\
\hline 2253.34 & 388 & 29 & 2253.34 & $\mathrm{He}$ II & $n=3$ & $n=10$ & 1 & $\mathrm{rec}$ & & \\
\hline 2228.01 & 270 & 20 & 2228.07 & $\mathrm{Fe}$ II & $4 \mathrm{~s} \mathrm{a}^{4} \mathrm{H}_{9 / 2}$ & $4 p y^{4} H_{11 / 2}$ & 2.1 & $\mathrm{fl}$ & & \\
\hline 2220.51 & 487 & 28 & 2220.59 & $\mathrm{Fe}$ II & $4 s a^{4} H_{11 / 2}$ & $4 \mathrm{p} \mathrm{y}^{4} \mathrm{H}_{11 / 2}$ & 2.1 & $\mathrm{fl}$ & & \\
\hline 2215.31 & 150 & 39 & 2215.36 & He II & $n=3$ & $n=11$ & 1 & rec & & \\
\hline Oth & & & 2211.81 & $\mathrm{Fe}$ II & $4 s a^{4} H_{13 / 2}$ & $4 p y^{4} \mathrm{H}_{11 / 2}$ & 2.1 & $\mathrm{fl}$ & & \\
\hline 2187.30 & 251 & 46 & 2187.29 & He II & $n=3$ & $n=12$ & 1 & rec & & \\
\hline \multicolumn{11}{|l|}{ Oth } \\
\hline 2168.04 & 296 & 19 & 2168.11 & $\mathrm{Fe}$ II & $3 d^{7} a^{2} H_{11 / 2}$ & $4 p y^{4} H_{11 / 2}$ & 2.1 & $\mathrm{fl}$ & & \\
\hline 2165.93 & 180 & & 2165.93 & He II & $n=3$ & $n=13$ & 1 & rec & & \\
\hline \multicolumn{11}{|l|}{ Oth } \\
\hline Oth & & & 2149.28 & $\mathrm{He}$ II & $n=3$ & $n=14$ & 1 & rec & & \\
\hline 2142.43 & 237 & 25 & 2142.46 & $\mathrm{Fe}$ II & $4 \mathrm{sb}^{2} \mathrm{~F}_{5 / 2}$ & $4 p w^{2} D_{3 / 2}$ & 2.1 & $\mathrm{fl}$ & & \\
\hline Oth & & & 2136.03 & He II & $n=3$ & $n=15$ & 1 & rec & & \\
\hline \multicolumn{11}{|l|}{ Oth } \\
\hline Oth & & & 2125.31 & $\mathrm{He}$ II & $n=3$ & $n=16$ & 1 & rec & & \\
\hline Oth & & & 2122.12 & $\mathrm{Fe}$ II & $4 \mathrm{~s} \mathrm{~b}^{4} \mathrm{D}_{3 / 2}$ & $4 p w^{2} D_{3 / 2}$ & 2.1 & $\mathrm{fl}$ & & \\
\hline Oth & & & 2038.11 & $\mathrm{Fe}$ II & $4 \mathrm{sc}^{2} \mathrm{P}_{3 / 2}$ & $\left({ }^{4} \mathrm{P}\right) 4 \mathrm{sp}{ }^{2} \mathrm{~S}_{1 / 2}$ & 2.1 & $\mathrm{fl}$ & & \\
\hline Oth & & & 2003.85 & $\mathrm{Fe}$ II & $4 \mathrm{~s} \mathrm{c}^{2} \mathrm{P}_{1 / 2}$ & $\left({ }^{4} \mathrm{P}\right) 4 \mathrm{sp}{ }^{2} \mathrm{~S}_{1 / 2}$ & 2.1 & $\mathrm{fl}$ & & \\
\hline \multicolumn{11}{|l|}{ Oth } \\
\hline 1979.04 & 43 & 29 & & & & & & & & \\
\hline 1978.60 & 43 & 24 & & & & & & & & \\
\hline 1978.29 & 71 & 17 & 1978.51 & $\mathrm{Fe}$ II & $4 s^{2} b^{4} G_{9 / 2}$ & $\left({ }^{2} \mathrm{I}\right) 4 \mathrm{sp}{ }^{4} \mathrm{H}_{11 / 2}$ & 2.1 & $\mathrm{fl}$ & & \\
\hline 1975.36 & $129^{b l}$ & 35 & 1975.55 & Fe II & $3 d^{7} a^{2} G_{9 / 2}$ & $4 p y^{4} H_{11 / 2}$ & 2.1 & $\mathrm{fl}$ & & \\
\hline Oth & & & 1975.07 & $\mathrm{Fe}$ II & $3 d^{7} a^{2} G_{7 / 2}$ & $4 p y^{2} D_{5 / 2}$ & 2.1 & $\mathrm{fl}$ & & \\
\hline 1974.53 & $29^{b l}$ & 33 & 1974.83 & Fe II & $4 s^{2} d^{4} P_{3 / 2}$ & $\left({ }^{4} \mathrm{~F}\right) 4 \mathrm{sp}{ }^{6} \mathrm{D}_{5 / 2}$ & 2.1 & $\mathrm{fl}$ & & \\
\hline Oth & & & 1973.78 & $\mathrm{Fe}$ II & $4 s^{2} b^{4} G_{9 / 2}$ & $\left({ }^{2} \mathrm{I}\right) 4 \mathrm{sp}{ }^{4} \mathrm{H}_{9 / 2}$ & 2.1 & $\mathrm{fl}$ & & \\
\hline 1973.32 & 18 & 20 & & & & & & & & \\
\hline Oth & & & 1972.16 & $\mathrm{Fe}$ II & $4 s^{2} b^{4} G_{11 / 2}$ & $\left({ }^{2} \mathrm{I}\right) 4 \mathrm{sp}{ }^{4} \mathrm{H}_{9 / 2}$ & 2.1 & $\mathrm{fl}$ & & \\
\hline 1971.49 & $25^{b l}$ & 33 & 1971.63 & $\mathrm{Fe}$ II & $4 s^{2} d^{4} P_{5 / 2}$ & $\left({ }^{4} \mathrm{~F}\right) 4 \mathrm{sp}{ }^{6} \mathrm{D}_{5 / 2}$ & 2.1 & $\mathrm{fl}$ & & \\
\hline 1970.83 & 15 & 20 & 1971.03 & $\mathrm{Fe}$ II & $3 d^{7} a^{2} D_{3 / 2}$ & $\left({ }^{3} \mathrm{D}\right) 4 \mathrm{p}{ }^{4} \mathrm{P}_{3 / 2}$ & 2.1 & $\mathrm{fl}$ & & \\
\hline 1970.58 & 17 & 17 & & & & & & & & \\
\hline 1970.02 & 24 & 18 & 1970.36 & $\mathrm{Fe}$ II & $3 d^{7} a^{4} P_{3 / 2}$ & $4 \mathrm{p} \mathrm{z}^{2} \mathrm{~F}_{5 / 2}$ & & $\mathrm{fl}$ & & \\
\hline 1965.73 & 136 & 29 & 1965.92 & $\mathrm{Fe} I I$ & $4 \mathrm{~s} \mathrm{a}^{2} \mathrm{~F}_{5 / 2}$ & $4 p w^{2} D_{3 / 2}$ & 2.1 & $\mathrm{fl}$ & & \\
\hline 1963.99 & 30 & 20 & & & & & & & & \\
\hline Oth & & & 1957.28 & {$[\mathrm{Fe} \mathrm{VI}]$} & $3 d^{3}{ }^{2} G_{7 / 2}$ & $3 d^{32} \mathrm{D} 1_{5 / 2}$ & 2.2 & col & & \\
\hline \multicolumn{11}{|l|}{ Oth } \\
\hline \multicolumn{11}{|l|}{ Oth } \\
\hline Oth & & & & & & & & & & \\
\hline
\end{tabular}


Table 13. continued.

\begin{tabular}{|c|c|c|c|c|c|c|c|c|c|c|}
\hline$\lambda_{\text {obs }}(\AA)$ & $I^{a}$ & $w^{b}$ & $\lambda_{\mathrm{id}}(\AA)$ & spec. & Lower level & Upper level & $\mathrm{Sec}^{c}$ & $\operatorname{Exc}^{f}$ & $I_{\mathrm{ghrs}}^{d}$ & $w_{\text {ghrs }}^{e}$ \\
\hline 1947.41 & 46 & 14 & 1947.64 & $\mathrm{Fe}$ II & $4 \mathrm{~s} \mathrm{~d}^{2} \mathrm{G}_{9 / 2}$ & $\left({ }^{3} \mathrm{H}\right) 5 \mathrm{p}{ }^{4} \mathrm{G}_{7 / 2}$ & 2.1 & $\mathrm{fl}$ & & \\
\hline 1946.77 & 20 & & 1947.00 & $\mathrm{Fe}$ II & $4 \mathrm{~s} \mathrm{c}^{4} \mathrm{P}_{5 / 2}$ & $\left({ }^{4} \mathrm{D}\right) 4 \mathrm{sp}{ }^{4} \mathrm{P}_{3 / 2}$ & 2.1 & $\mathrm{fl}$ & & \\
\hline 1944.19 & 20 & 20 & 1944.30 & [Fe VI] & $3 d^{32} G_{7 / 2}$ & $3 \mathrm{~d}^{32} \mathrm{D} 1_{3 / 2}$ & 2.2 & col & & \\
\hline 1943.33 & 19 & 17 & 1943.48 & Fe III & $\left({ }^{4} G\right) 4 s^{5} G_{2}$ & $\left({ }^{4} \mathrm{G}\right) 4 \mathrm{p}^{5} \mathrm{H}_{3}$ & & unk & & \\
\hline \multirow[t]{2}{*}{1941.86} & 26 & 20 & 1942.00 & $\mathrm{Fe}$ II & $3 d^{7} b^{2} F_{5 / 2}$ & $4 p v^{2} G_{7 / 2}$ & 2.1 & $\mathrm{fl}$ & & \\
\hline & & & 1.90 & Fe II & $4 \mathrm{~s} \mathrm{c}^{2} \mathrm{P}_{3 / 2}$ & $\left({ }^{4} \mathrm{~F}\right) 4 \mathrm{sp}{ }^{6} \mathrm{~F}_{3 / 2}$ & 2.1 & $\mathrm{fl}$ & & \\
\hline 1940.55 & 20 & 22 & 1940.70 & $\mathrm{Fe}$ II & $4 \mathrm{~s} \mathrm{~d}^{2} \mathrm{~F}_{5 / 2}$ & $\left({ }^{4} \mathrm{~F}\right) 4 \mathrm{sp}{ }^{6} \mathrm{~F}_{3 / 2}$ & 2.1 & $\mathrm{fl}$ & & \\
\hline 1938.51 & $57^{b l}$ & 46 & 1938.77 & $\mathrm{Fe}$ II & $4 \mathrm{~s} \mathrm{c}^{2} \mathrm{P}_{3 / 2}$ & $\left({ }^{4} \mathrm{D}\right) 4 \mathrm{sp}^{2} \mathrm{P}_{3 / 2}$ & & unk & & \\
\hline \multicolumn{11}{|l|}{1934.30} \\
\hline 1928.58 & 63 & 33 & & & & & & & & \\
\hline 1928.01 & 38 & 26 & 1928.09 & Fe III & $\left({ }^{4} \mathrm{G}\right) 4 \mathrm{~s}^{5} \mathrm{G}_{6}$ & $\left({ }^{4} \mathrm{G}\right) 4 \mathrm{p}^{5} \mathrm{H}_{5}$ & & unk & & \\
\hline 1926.07 & 57 & 23 & 1926.24 & $\mathrm{Fe}$ II & $4 \mathrm{~s} \mathrm{a}^{6} \mathrm{D}_{7 / 2}$ & $4 \operatorname{sp~z}{ }^{8} \mathrm{P}_{5 / 2}$ & $2.3 \mathrm{H}$ & $\mathrm{rec}$ & & \\
\hline \multicolumn{11}{|l|}{ Oth } \\
\hline \multirow[t]{4}{*}{1922.91} & 123 & 80 & 1923.34 & C III & $2 \mathrm{~s} 3 \mathrm{~d}^{3} \mathrm{D}_{1}$ & $2 \mathrm{~s} 4 \mathrm{f}^{3} \mathrm{~F}_{2}$ & $2.3 \mathrm{~F}$ & rec & & \\
\hline & & & 3.16 & C III & $2 \mathrm{~s} 3 \mathrm{~d}^{3} \mathrm{D}_{2}$ & $2 \mathrm{~s} 4 \mathrm{f}^{3} \mathrm{~F}_{3}$ & $2.3 \mathrm{~F}$ & rec & & \\
\hline & & & 2.96 & C III & $2 \mathrm{~s} 3 \mathrm{~d}^{3} \mathrm{D}_{3}$ & $2 \mathrm{~s} 4 \mathrm{f}^{3} \mathrm{~F}_{4}$ & $2.3 \mathrm{~F}$ & $\mathrm{rec}$ & & \\
\hline & & & 2.79 & Fe III & $\left({ }^{4} \mathrm{G}\right) 4 \mathrm{~s}^{5} \mathrm{G}_{5}$ & $\left({ }^{4} \mathrm{G}\right) 4 \mathrm{p}^{5} \mathrm{H}_{6}$ & & unk & & \\
\hline \multicolumn{11}{|l|}{ Oth } \\
\hline 1919.96 & 19 & 30 & 1920.02 & O III & $2 p 3 p{ }^{1} D_{2}$ & $2 \mathrm{p} 4 \mathrm{~s}^{1} \mathrm{P}_{1}$ & $2.3 \mathrm{~F}$ & $\mathrm{rec}$ & & \\
\hline \multicolumn{11}{|l|}{ Oth } \\
\hline 1915.62 & 28 & 17 & 1915.79 & $\mathrm{Fe}$ II & $4 \mathrm{~s} \mathrm{a}^{6} \mathrm{D}_{7 / 2}$ & $4 \operatorname{sp~z}{ }^{8} \mathrm{P}_{7 / 2}$ & $2.3 \mathrm{H}$ & rec & & \\
\hline 1913.89 & 207 & 33 & 1914.06 & Fe III & $\left({ }^{6} \mathrm{~S}\right) 4 \mathrm{~s}{ }^{7} \mathrm{~S}_{3}$ & $\left({ }^{6} \mathrm{~S}\right) 4 \mathrm{p}{ }^{7} \mathrm{P}_{3}$ & 2.1 & $\mathrm{fl}$ & & \\
\hline 1912.72 & 22 & 27 & & & & & & & & \\
\hline 1911.66 & 16 & 16 & 1911.72 & $\mathrm{Fe}$ II & $4 s^{2} b^{4} G_{7 / 2}$ & $\left({ }^{4} \mathrm{~F}\right) 4 \mathrm{sp}{ }^{6} \mathrm{~F}_{5 / 2}$ & 2.1 & $\mathrm{fl}$ & & \\
\hline 1911.37 & 30 & 16 & 1911.44 & $\mathrm{Fe}$ II & $4 s^{2} b^{4} G_{5 / 2}$ & $\left({ }^{4} \mathrm{~F}\right) 4 \mathrm{sp}{ }^{6} \mathrm{~F}_{5 / 2}$ & 2.1 & $\mathrm{fl}$ & & \\
\hline 1910.34 & $25^{b l}$ & 53 & 1910.77 & $\mathrm{Fe}$ II & $4 \mathrm{~s} \mathrm{c}^{2} \mathrm{P}_{1 / 2}$ & $\left({ }^{4} \mathrm{~F}\right) 4 \mathrm{sp}^{6} \mathrm{~F}_{3 / 2}$ & 2.1 & $\mathrm{fl}$ & & \\
\hline Oth & & & 1909.91 & Fe II & $4 \mathrm{sb}^{4} \mathrm{P}_{5 / 2}$ & $4 \mathrm{p} \mathrm{y}^{2} \mathrm{P}_{3 / 2}$ & & unk & & \\
\hline 1908.57 & oe & & 1908.73 & C III] & $2 \mathrm{~s}^{2}{ }^{1} \mathrm{~S}_{0}$ & $2 \mathrm{~s} 2 \mathrm{p}^{3} \mathrm{P}_{1}$ & $2.3 \mathrm{C}$ & col & & \\
\hline 1907.03 & $41^{b l}$ & 31 & 1907.24 & $\mathrm{Fe}$ II & $4 \mathrm{~s} \mathrm{a}^{4} \mathrm{G}_{5 / 2}$ & $4 \mathrm{pw}^{2} \mathrm{D}_{3 / 2}$ & 2.1 & $\mathrm{fl}$ & & \\
\hline \multirow[t]{2}{*}{1906.67} & 19 & 30 & 1906.72 & $\mathrm{Mg}$ IV & $\left({ }^{3} \mathrm{P}\right) 3 \mathrm{~s}{ }^{4} \mathrm{P}_{3 / 2}$ & $\left({ }^{3} \mathrm{P}\right) 3 \mathrm{p}{ }^{4} \mathrm{P}_{1 / 2}$ & $2.3 \mathrm{~F}$ & rec & & \\
\hline & & & 6.68 & C III] & $2 \mathrm{~s}^{2}{ }^{1} \mathrm{~S}_{0}$ & $2 \mathrm{~s} 2 \mathrm{p}^{3} \mathrm{P}_{2}$ & $2.3 \mathrm{C}$ & col & & \\
\hline 1905.58 & 22 & & 1905.68 & $\mathrm{Fe}$ II & $4 \mathrm{~s} \mathrm{c}^{2} \mathrm{D}_{5 / 2}$ & $\left({ }^{5} \mathrm{D}\right) 5 \mathrm{p}^{4} \mathrm{D}_{5 / 2}$ & 2.1 & $\mathrm{fl}$ & & \\
\hline 1900.15 & 58 & 27 & 1900.29 & S I] & $3 p^{4}{ }^{3} \mathrm{P}_{2}$ & $4 s^{5} S_{2}$ & $2.3 \mathrm{E}$ & col & & \\
\hline \multirow[t]{2}{*}{1897.32} & 27 & 24 & 1897.55 & $\mathrm{Fe}$ II & $4 \mathrm{sb}^{2} \mathrm{P}_{3 / 2}$ & $4 \mathrm{pw}^{2} \mathrm{D}_{3 / 2}$ & 2.1 & $\mathrm{fl}$ & & \\
\hline & & & 7.48 & $\mathrm{Fe}$ II & $4 \mathrm{~s} \mathrm{a}^{4} \mathrm{D}_{5 / 2}$ & $4 \mathrm{p} \mathrm{z}^{2} \mathrm{D}_{5 / 2}$ & & unk & & \\
\hline 1895.31 & 87 & 35 & 1895.46 & Fe III & $\left({ }^{6} \mathrm{~S}\right) 4 \mathrm{~s}{ }^{7} \mathrm{~S}_{3}$ & $\left({ }^{6} \mathrm{~S}\right) 4 \mathrm{p}{ }^{7} \mathrm{P}_{4}$ & 2.1 & $\mathrm{fl}$ & & \\
\hline Oth & & & 1894.29 & C III & $2 \mathrm{~s} 3 \mathrm{p}^{1} \mathrm{P}_{1}$ & $2 \mathrm{~s} 4 \mathrm{~s}{ }^{1} \mathrm{~S}_{0}$ & $2.3 \mathrm{~F}$ & rec & & \\
\hline Oth & & & 1893.89 & Mg IV & $\left({ }^{3} \mathrm{P}\right) 3 \mathrm{~s}{ }^{4} \mathrm{P}_{5 / 2}$ & $\left({ }^{3} \mathrm{P}\right) 3 \mathrm{p}{ }^{4} \mathrm{P}_{5 / 2}$ & $2.3 \mathrm{~F}$ & $\mathrm{rec}$ & & \\
\hline 1891.90 & oe & & 1892.03 & Si III] & $3 \mathrm{~s}^{2}{ }^{1} \mathrm{~S}_{0}$ & $3 p^{3} \mathrm{P}_{1}$ & $2.3 \mathrm{C}$ & col & & \\
\hline 1890.49 & 88 & 40 & 1890.66 & $\mathrm{Fe}$ III & $\left({ }^{4} \mathrm{G}\right) 4 \mathrm{~s}{ }^{5} \mathrm{G}_{6}$ & $\left({ }^{4} \mathrm{G}\right) 4 \mathrm{p}^{5} \mathrm{~F}_{5}$ & & unk & & \\
\hline 1889.34 & 26 & 25 & 1889.45 & Fe III & $\left({ }^{4} \mathrm{G}\right) 4 s^{5} \mathrm{G}_{3}$ & $\left({ }^{4} \mathrm{P}\right) 4 \mathrm{p}^{5} \mathrm{D}_{2}$ & & unk & & \\
\hline 1888.40 & 26 & 25 & 1888.52 & P IV & $3 s 3 p{ }^{1} \mathrm{P}_{1}$ & $3 \mathrm{p}^{2}{ }^{1} \mathrm{D}_{2}$ & & unk & & \\
\hline 1887.83 & 29 & 21 & 1888.01 & $\mathrm{Fe}$ II & $4 \mathrm{~s} \mathrm{a}^{6} \mathrm{D}_{9 / 2}$ & $4 \mathrm{sp} z^{8} \mathrm{P}_{9 / 2}$ & $2.3 \mathrm{H}$ & rec & & \\
\hline 1887.28 & $38^{b l}$ & & 1887.45 & Fe III & $\left({ }^{4} \mathrm{G}\right) 4 \mathrm{~s}^{5} \mathrm{G}_{3}$ & $\left({ }^{4} \mathrm{G}\right) 4 p{ }^{5} \mathrm{~F}_{3}$ & & unk & & \\
\hline 1887.05 & $29^{b l}$ & & 1887.20 & Fe III & $\left({ }^{4} \mathrm{G}\right) 4 \mathrm{~s}{ }^{5} \mathrm{G}_{4}$ & $\left({ }^{4} \mathrm{G}\right) 4 \mathrm{p}^{5} \mathrm{~F}_{3}$ & & unk & & \\
\hline 1886.57 & 44 & 22 & 1886.76 & Fe III & $\left({ }^{4} \mathrm{G}\right) 4 \mathrm{~s}^{5} \mathrm{G}_{5}$ & $\left({ }^{4} \mathrm{G}\right) 4 \mathrm{p}^{5} \mathrm{~F}_{4}$ & & unk & & \\
\hline \multirow[t]{3}{*}{1884.94} & 110 & 56 & 1885.22 & N III & $3 d^{2} D_{5 / 2}$ & $4 f^{2} F_{7 / 2}$ & $2.3 \mathrm{~F}$ & rec & & \\
\hline & & & 5.09 & $\mathrm{Fe}$ II & $3 d^{7} a^{4} P_{5 / 2}$ & $4 p x^{4} F_{5 / 2}$ & 2.1 & $\mathrm{fl}$ & & \\
\hline & & & 5.06 & N III & $3 d^{2} D_{3 / 2}$ & $4 f^{2} F_{5 / 2}$ & $2.3 \mathrm{~F}$ & rec & & \\
\hline
\end{tabular}


Table 13. continued.

\begin{tabular}{|c|c|c|c|c|c|c|c|c|c|c|}
\hline$\lambda_{\mathrm{obs}}(\AA)$ & $I^{a}$ & $w^{b}$ & $\lambda_{\mathrm{id}}(\AA)$ & spec. & Lower level & Upper level & $\mathrm{Sec}^{c}$ & $\operatorname{Exc}^{f}$ & $I_{\mathrm{ghrs}}^{d}$ & $w_{\mathrm{ghrs}}^{e}$ \\
\hline 1883.95 & 60 & 21 & 1884.12 & $\mathrm{Fe}$ II & $4 s^{2} d^{4} P_{3 / 2}$ & $\left({ }^{3} F\right) 5 p^{4} D_{5 / 2}$ & 2.1 & fl & & \\
\hline Oth & & & 1883.72 & $\mathrm{Fe}$ II & $4 \mathrm{~s} \mathrm{a}^{4} \mathrm{D}_{7 / 2}$ & $4 \mathrm{pz}^{4} \mathrm{G}_{5 / 2}$ & 2.1 & $\mathrm{fl}$ & & \\
\hline 1882.02 & 35 & 24 & & & & & & & & \\
\hline Oth & & & 1881.89 & $\mathrm{Fe}$ II & $4 s \mathrm{a}^{4} \mathrm{D}_{7 / 2}$ & $4 p z^{2} D_{5 / 2}$ & & unk & & \\
\hline Oth & & & 1881.25 & $\mathrm{Fe}$ II & $3 d^{7} a^{2} P_{1 / 2}$ & $\left({ }^{3} \mathrm{D}\right) 4 \mathrm{p}^{4} \mathrm{P}_{3 / 2}$ & 2.1 & $\mathrm{fl}$ & & \\
\hline 1879.16 & 97 & 21 & & & & & & & & \\
\hline \multicolumn{11}{|l|}{ Oth } \\
\hline Oth & & & 1877.02 & $\mathrm{Fe}$ II & $4 \mathrm{~s} \mathrm{a}^{4} \mathrm{G}_{5 / 2}$ & $4 \operatorname{sp~} x^{6} P_{7 / 2}$ & 2.1 & $\mathrm{fl}$ & & \\
\hline 1874.82 & $32^{b l}$ & & 1874.97 & $\mathrm{Fe}$ II & $4 s a^{4} D_{5 / 2}$ & $4 p y^{4} D_{7 / 2}$ & & $\mathrm{fl}$ & & \\
\hline 1874.55 & $33^{b l}$ & & 1874.58 & Mg IV & $\left({ }^{3} \mathrm{P}\right) 3 \mathrm{~s}{ }^{4} \mathrm{P}_{5 / 2}$ & $\left({ }^{3} \mathrm{P}\right) 3 \mathrm{p}{ }^{4} \mathrm{P}_{3 / 2}$ & $2.3 \mathrm{~F}$ & rec & & \\
\hline \multirow[t]{2}{*}{1872.44} & 99 & 48 & 1872.64 & $\mathrm{Fe}$ II & $4 s^{2} b^{4} G_{9 / 2}$ & $\left({ }^{2} \mathrm{~F}\right) 4 \mathrm{sp}{ }^{4} \mathrm{G}_{9 / 2}$ & 2.1 & $\mathrm{fl}$ & & \\
\hline & & & 1872.57 & $\mathrm{Fe}$ II & $4 \mathrm{~s} \mathrm{a}^{2} \mathrm{~S}_{1 / 2}$ & $\left({ }^{3} \mathrm{P}\right) 4 \mathrm{p}{ }^{4} \mathrm{~S}_{3 / 2}$ & 2.1 & fl & & \\
\hline 1870.93 & 19 & 29 & 1871.08 & $\mathrm{Fe}$ II & $4 \mathrm{~s} \mathrm{a}^{4} \mathrm{D}_{3 / 2}$ & $4 \mathrm{p} \mathrm{z}^{2} \mathrm{D}_{3 / 2}$ & & unk & & \\
\hline \multirow[t]{2}{*}{1869.51} & 92 & 56 & 1869.82 & $\mathrm{Fe}$ III & $\left({ }^{4} \mathrm{G}\right) 4 \mathrm{~s}^{5} \mathrm{G}_{3}$ & $\left({ }^{4} \mathrm{G}\right) 4 \mathrm{p}{ }^{5} \mathrm{~F}_{2}$ & & unk & & \\
\hline & & & 9.55 & $\mathrm{Fe} I I$ & $4 s^{2} b^{4} G_{11 / 2}$ & $\left({ }^{2} \mathrm{~F}\right) 4 \mathrm{sp}{ }^{4} \mathrm{G}_{11 / 2}$ & 2.1 & $\mathrm{fl}$ & & \\
\hline \multirow[t]{2}{*}{1862.59} & 248 & 45 & 1862.81 & $\mathrm{Fe}$ II & $3 d^{7} a^{2} P_{3 / 2}$ & $\left({ }^{3} \mathrm{D}\right) 4 \mathrm{p}{ }^{4} \mathrm{P}_{3 / 2}$ & 2.1 & $\mathrm{fl}$ & & \\
\hline & & & 2.79 & Al III & $3 \mathrm{~s}^{2} \mathrm{~S}_{1 / 2}$ & $3 \mathrm{p}^{2} \mathrm{P}_{1 / 2}$ & $2.3 \mathrm{~B}$ & $\mathrm{col}$ & & \\
\hline 1856.63 & 48 & 23 & & & & & & & & \\
\hline 1854.53 & 338 & 55 & 1854.72 & Al III & $3 \mathrm{~s}^{2} \mathrm{~S}_{1 / 2}$ & $3 p^{2} \mathrm{P}_{3 / 2}$ & $2.3 \mathrm{~B}$ & col & & \\
\hline Oth & & & 1853.73 & Co II & $4 s^{2} a^{5} D_{2}$ & $\left({ }^{4} F\right) 5 p{ }^{5} D_{3}$ & 2.1 & $\mathrm{fl}$ & & \\
\hline 1851.65 & 35 & 26 & & & & & & & & \\
\hline 1851.33 & 30 & 18 & 1851.53 & Fe II & $4 s a^{4} D_{3 / 2}$ & $4 p y^{4} D_{5 / 2}$ & & $\mathrm{fl}$ & & \\
\hline \multicolumn{11}{|l|}{ Oth } \\
\hline Oth & & & 1850.20 & $\mathrm{Fe}$ III & $\left({ }^{4} \mathrm{~F}\right) 4 \mathrm{~s}{ }^{5} \mathrm{~F}_{4}$ & $\left({ }^{4} F\right) 4 p{ }^{5} D_{4}$ & & unk & & \\
\hline Oth & & & 1849.40 & Fe III & $\left({ }^{4} F\right) 4 s{ }^{5} F_{5}$ & $\left({ }^{4} F\right) 4 p{ }^{5} D_{4}$ & & unk & & \\
\hline 1847.32 & 37 & 21 & 1847.48 & $\mathrm{Fe}$ II & $4 \mathrm{~s} \mathrm{a}^{4} \mathrm{D}_{7 / 2}$ & $4 p z^{2} G_{9 / 2}$ & 2.1 & $\mathrm{fl}$ & & \\
\hline 1843.10 & 47 & 21 & 1843.26 & $\mathrm{Fe}$ II & $4 s^{2} b^{4} G_{11 / 2}$ & $\left({ }^{4} G\right) 4 s p{ }^{4} G_{11 / 2}$ & 2.1 & $\mathrm{fl}$ & & \\
\hline \multirow[t]{3}{*}{1840.04} & 37 & 38 & 1840.25 & Co II & $4 s^{2} a^{5} D_{4}$ & $\left({ }^{4} F\right) 5 p{ }^{5} D_{4}$ & & unk & & \\
\hline & & & 0.06 & $\mathrm{Fe}$ II & $4 s^{2} b^{4} G_{7 / 2}$ & $\left({ }^{4} \mathrm{G}\right) 4 \mathrm{sp}{ }^{4} \mathrm{G}_{5 / 2}$ & 2.1 & $\mathrm{fl}$ & & \\
\hline & & & 0.00 & $\mathrm{Fe}$ II & $4 s^{2} b^{4} G_{7 / 2}$ & $\left({ }^{4} G\right) 4 s p{ }^{4} G_{7 / 2}$ & 2.1 & $\mathrm{fl}$ & & \\
\hline \multirow[t]{2}{*}{1839.63} & 54 & 41 & 1839.80 & $\mathrm{Fe}$ II & $4 s^{2} b^{4} G_{5 / 2}$ & $\left({ }^{4} G\right) 4 s p{ }^{4} G_{5 / 2}$ & 2.1 & $\mathrm{fl}$ & & \\
\hline & & & 9.74 & $\mathrm{Fe}$ II & $4 s^{2} b^{4} G_{5 / 2}$ & $\left({ }^{4} \mathrm{G}\right) 4 \mathrm{sp}^{4} \mathrm{G}_{7 / 2}$ & 2.1 & fl & & \\
\hline 1839.21 & 25 & 21 & 1839.27 & Co II & $4 s^{2} a^{5} D_{3}$ & $\left({ }^{4} \mathrm{~F}\right) 4 \mathrm{p}^{5} \mathrm{D}_{3}$ & 2.1 & $\mathrm{fl}$ & & \\
\hline \multirow[t]{2}{*}{ Oth } & & & 1836.72 & $\mathrm{~N} \mathrm{I}]$ & $2 \mathrm{p}^{3}{ }^{2} \mathrm{P}_{3 / 2}$ & $3 s^{4} P_{1 / 2}$ & $2.3 \mathrm{E}$ & col & & \\
\hline & & & 6.71 & $\mathrm{~N} \mathrm{I}]$ & $2 \mathrm{p}^{3}{ }^{2} \mathrm{P}_{1 / 2}$ & $3 \mathrm{~s}{ }^{4} \mathrm{P}_{1 / 2}$ & $2.3 \mathrm{E}$ & col & & \\
\hline Oth & & & 1835.57 & $\mathrm{~N} \mathrm{I}]$ & $2 \mathrm{p}^{3}{ }^{2} \mathrm{P}_{1 / 2}$ & $3 \mathrm{~s}{ }^{4} \mathrm{P}_{3 / 2}$ & $2.3 \mathrm{E}$ & col & & \\
\hline Oth & & & 1834.01 & $\mathrm{~N} \mathrm{I}]$ & $2 \mathrm{p}^{3}{ }^{2} \mathrm{P}_{1 / 2}$ & $3 \mathrm{~s}{ }^{4} \mathrm{P}_{3 / 2}$ & $2.3 \mathrm{E}$ & col & & \\
\hline 1831.80 & 171 & 25 & 1836.98 & $\mathrm{Fe}$ II & $4 s^{2} b^{4} G_{7 / 2}$ & $\left({ }^{4} \mathrm{G}\right) 4 \mathrm{sp}{ }^{4} \mathrm{H}_{9 / 2}$ & 2.1 & $\mathrm{fl}$ & & \\
\hline 1831.50 & $35^{b l}$ & & 1831.66 & $\mathrm{Fe}$ II & $4 s^{2} b^{4} G_{9 / 2}$ & $\left({ }^{4} \mathrm{G}\right) 4 \mathrm{sp}{ }^{4} \mathrm{H}_{9 / 2}$ & 2.1 & $\mathrm{fl}$ & & \\
\hline 1829.85 & 34 & 26 & 1829.95 & $\mathrm{Fe} \mathrm{V}$ & $\left({ }^{4} \mathrm{P}\right) 4 \mathrm{~s}{ }^{5} \mathrm{P}_{1}$ & $\left({ }^{4} F\right) 4 p{ }^{5} F_{2}$ & $2.3 \mathrm{~F}$ & rec & & \\
\hline 1826.10 & 48 & 38 & 1826.25 & S I & $3 p^{4} g^{3} P_{0}$ & $4 s^{3} S_{1}$ & $2.3 \mathrm{E}$ & col & & \\
\hline 1823.39 & 118 & 18 & & & & & & & & \\
\hline 1820.18 & $28^{b l}$ & & 1820.34 & S I & $3 p^{4} g^{3} P_{1}$ & $4 s^{3} S_{1}$ & $2.3 \mathrm{E}$ & col & & \\
\hline 1817.22 & 191 & 31 & 1817.45 & Si II & $3 p^{2} \mathrm{P}_{3 / 2}$ & $3 \mathrm{p}^{2}{ }^{2} \mathrm{D}_{3 / 2}$ & $2.3 \mathrm{D}$ & col & & \\
\hline 1816.75 & 962 & 31 & 1816.93 & $\mathrm{Si}$ II & $3 \mathrm{p}^{2} \mathrm{P}_{3 / 2}$ & $3 \mathrm{p}^{2}{ }^{2} \mathrm{D}_{5 / 2}$ & $2.3 \mathrm{D}$ & col & & \\
\hline Oth & & & 1814.63 & {$[\mathrm{Ne} \mathrm{III]}$} & $2 \mathrm{p}^{4}{ }^{3} \mathrm{P}_{1}$ & $2 \mathrm{p}^{4}{ }^{1} \mathrm{~S}_{0}$ & 2.2 & col & & \\
\hline \multicolumn{11}{|l|}{ Oth } \\
\hline 1810.15 & 30 & 20 & 1810.23 & P II] & $2 \mathrm{p}^{2}{ }^{1} \mathrm{~S}_{0}$ & $2 \mathrm{~s} 2 \mathrm{p}^{3}{ }^{3} \mathrm{P}_{1}$ & $2.3 \mathrm{D}$ & $\mathrm{col}$ & & \\
\hline Oth & & & & & & & & & & \\
\hline
\end{tabular}


Table 13. continued.

\begin{tabular}{|c|c|c|c|c|c|c|c|c|c|c|}
\hline$\lambda_{\text {obs }}(\AA)$ & $I^{a}$ & $w^{b}$ & $\lambda_{\text {id }}(\AA)$ & spec. & Lower level & Upper level & $\mathrm{Sec}^{c}$ & $\operatorname{Exc}^{f}$ & $I_{\mathrm{ghrs}}^{d}$ & $w_{\text {ghrs }}^{e}$ \\
\hline 1808.20 & 71 & 48 & & & & & & & & \\
\hline 1807.76 & 92 & 27 & 1808.01 & Si II & $3 p^{2} \mathrm{P}_{1 / 2}$ & $3 \mathrm{p}^{2}{ }^{2} \mathrm{D}_{3 / 2}$ & $2.3 \mathrm{D}$ & col & & \\
\hline 1807.07 & 26 & 15 & 1807.31 & S I & $3 p^{4} g^{3} P_{2}$ & $4 s^{3} S_{1}$ & $2.3 \mathrm{E}$ & col & & \\
\hline 1805.44 & 46 & 32 & 1805.67 & N III & $3 p^{2} \mathrm{P}_{3 / 2}$ & $4 s^{2} S_{1 / 2}$ & $2.3 \mathrm{~F}$ & rec & & \\
\hline 1803.54 & 77 & 22 & 1803.82 & S II] & $3 \mathrm{p}^{3}{ }^{2} \mathrm{P}_{1 / 2}$ & $3 p^{4}{ }^{4} \mathrm{P}_{1 / 2}$ & $2.3 \mathrm{D}$ & col & & \\
\hline \multirow[t]{3}{*}{ Oth } & & & 1795.57 & $\mathrm{Fe}$ II & $4 s^{2} b^{4} G_{7 / 2}$ & $\left({ }^{3} \mathrm{H}\right) 5 \mathrm{p}{ }^{4} \mathrm{G}_{7 / 2}$ & 2.1 & $\mathrm{fl}$ & & \\
\hline & & & 5.33 & Fe II & $4 s^{2} b^{4} G_{5 / 2}$ & $\left({ }^{3} \mathrm{H}\right) 5 \mathrm{p}^{4} \mathrm{G}_{7 / 2}$ & 2.1 & $\mathrm{fl}$ & & \\
\hline & & & 5.27 & $\mathrm{Fe}$ II & $4 s^{2} b^{4} G_{9 / 2}$ & $\left({ }^{3} \mathrm{H}\right) 5 \mathrm{p}{ }^{4} \mathrm{G}_{7 / 2}$ & 2.1 & $\mathrm{fl}$ & & \\
\hline Oth & & & 1788.00 & $\mathrm{Fe}$ II & $4 s^{2} a^{6} S_{5 / 2}$ & $4 \operatorname{sp~} x^{6} P_{3 / 2}$ & 2.1 & $\mathrm{fl}$ & & \\
\hline \multirow[t]{2}{*}{1786.58} & 67 & 40 & 1786.82 & Si II & $3 d^{2} D_{3 / 2}$ & $3 \mathrm{p}^{32} \mathrm{D}_{3 / 2}$ & $2.3 \mathrm{D}$ & unk & & \\
\hline & & & 6.75 & Fe II & $4 s^{2} a^{6} S_{5 / 2}$ & $4 \operatorname{sp~} x^{6} \mathrm{P}_{5 / 2}$ & & $\mathrm{fl}$ & & \\
\hline 1785.12 & $108^{b l}$ & 55 & 1785.27 & Fe II & $4 s^{2} a^{6} S_{5 / 2}$ & $4 \operatorname{sp~} x^{6} \mathrm{P}_{7 / 2}$ & 2.1 & $\mathrm{fl}$ & & \\
\hline Oth & & & 1783.98 & Fe II & $4 \mathrm{~s} \mathrm{~b}^{4} \mathrm{D}_{7 / 2}$ & $4 \mathrm{sp} \mathrm{y}{ }^{6} \mathrm{~F}_{7 / 2}$ & 2.1 & $\mathrm{fl}$ & & \\
\hline \multicolumn{11}{|l|}{ Oth } \\
\hline 1781.45 & 47 & 24 & 1781.51 & $\mathrm{Fe}$ II & $4 s a^{4} D_{7 / 2}$ & $4 p y^{4} G_{5 / 2}$ & 2.1 & $\mathrm{fl}$ & & \\
\hline 1780.87 & $74^{b l}$ & 45 & 1780.95 & $\mathrm{Fe}$ II & $4 \mathrm{~s} \mathrm{~b}^{4} \mathrm{D}_{5 / 2}$ & $4 \operatorname{sp~y}{ }^{6} \mathrm{~F}_{7 / 2}$ & 2.1 & $\mathrm{fl}$ & & \\
\hline 1779.65 & 51 & & 1779.82 & Fe II & $4 \mathrm{~s} \mathrm{c}^{4} \mathrm{P}_{5 / 2}$ & $\left({ }^{4} \mathrm{~F}\right) 4 \mathrm{sp}{ }^{6} \mathrm{~F}_{3 / 2}$ & 2.1 & $\mathrm{fl}$ & & \\
\hline 1768.15 & 264 & 17 & & & & & & & & \\
\hline Oth & & & 1760.82 & C II & $2 \mathrm{~s} 2 \mathrm{p}^{2}{ }^{2} \mathrm{D}_{3 / 2}$ & $3 p^{2} \mathrm{P}_{1 / 2}$ & & col & & \\
\hline \multirow[t]{2}{*}{ Oth } & & & 1760.47 & C II & $2 \mathrm{~s} 2 \mathrm{p}^{2}{ }^{2} \mathrm{D}_{3 / 2}$ & $3 \mathrm{p}^{2} \mathrm{P}_{3 / 2}$ & & col & & \\
\hline & & & 0.40 & C II & $2 \mathrm{~s} 2 \mathrm{p}^{2}{ }^{2} \mathrm{D}_{5 / 2}$ & $3 p^{2} \mathrm{P}_{3 / 2}$ & & col & & \\
\hline Oth & & & 1757.74 & $\mathrm{Fe}$ II & $4 \mathrm{~s} \mathrm{c}^{4} \mathrm{P}_{3 / 2}$ & $\left({ }^{4} \mathrm{~F}\right) 4 \mathrm{sp}{ }^{6} \mathrm{~F}_{3 / 2}$ & 2.1 & $\mathrm{fl}$ & & \\
\hline 1753.80 & 1482 & 19 & 1754.00 & N III] & $2 p^{2} \mathrm{P}_{3 / 2}$ & $2 \mathrm{~s} 2 \mathrm{p}^{2}{ }^{4} \mathrm{P}_{1 / 2}$ & $2.3 \mathrm{D}$ & col & & \\
\hline 1753.32 & 79 & 36 & 1753.47 & Mg II & $3 p^{2} \mathrm{P}_{3 / 2}$ & $5 s^{2} S_{1 / 2}$ & & unk & & \\
\hline 1752.03 & $515^{b l}$ & 41 & 1752.16 & N III] & $2 \mathrm{p}^{2} \mathrm{P}_{3 / 2}$ & $2 \mathrm{~s} 2 \mathrm{p}^{2}{ }^{4} \mathrm{P}_{3 / 2}$ & $2.3 \mathrm{D}$ & $\mathrm{col}$ & & \\
\hline Oth & & & 1751.66 & N III & $2 \mathrm{~s} 2 \mathrm{p}^{2}{ }^{2} \mathrm{P}_{3 / 2}$ & $2 \mathrm{p}^{32} \mathrm{D}_{5 / 2}$ & $2.3 \mathrm{D}$ & unk & & \\
\hline Oth & & & 1750.66 & Mg II & $3 p^{2} \mathrm{P}_{1 / 2}$ & $5 \mathrm{~s}^{2} \mathrm{~S}_{1 / 2}$ & & unk & & \\
\hline 1749.49 & oe & & 1749.67 & N III] & $2 \mathrm{p}^{2} \mathrm{P}_{3 / 2}$ & $2 \mathrm{~s} 2 \mathrm{p}^{2}{ }^{4} \mathrm{P}_{5 / 2}$ & $2.3 \mathrm{D}$ & $\mathrm{col}$ & & \\
\hline 1748.51 & 960 & 24 & 1748.64 & N III] & $2 p^{2} \mathrm{P}_{1 / 2}$ & $2 \mathrm{~s} 2 \mathrm{p}^{2}{ }^{4} \mathrm{P}_{1 / 2}$ & $2.3 \mathrm{D}$ & col & & \\
\hline Oth & & & 1747.85 & N III & $2 \mathrm{~s} 2 \mathrm{p}^{2}{ }^{2} \mathrm{P}_{1 / 2}$ & $2 \mathrm{p}^{32} \mathrm{D}_{3 / 2}$ & $2.3 \mathrm{D}$ & unk & & \\
\hline 1746.61 & $64^{b l}$ & 45 & 1746.82 & N III] & $2 \mathrm{p}^{2} \mathrm{P}_{1 / 2}$ & $2 \mathrm{~s} 2 \mathrm{p}^{2}{ }^{4} \mathrm{P}_{3 / 2}$ & $2.3 \mathrm{D}$ & col & & \\
\hline 1745.08 & 136 & 36 & 1745.25 & N I & $2 \mathrm{p}^{32} \mathrm{P}_{3 / 2}$ & $3 \mathrm{~s}^{2} \mathrm{P}_{1 / 2}$ & $2.3 \mathrm{E}$ & unk & & \\
\hline 1742.60 & 39 & 34 & 1742.73 & N I & $2 \mathrm{p}^{3}{ }^{2} \mathrm{P}_{3 / 2}$ & $3 \mathrm{~s}^{2} \mathrm{P}_{3 / 2}$ & $2.3 \mathrm{E}$ & unk & & \\
\hline \multirow[t]{2}{*}{1737.40} & 63 & 50 & 1737.62 & Mg II & $3 \mathrm{p}^{2} \mathrm{P}_{3 / 2}$ & $4 d^{2} D_{5 / 2}$ & & unk & & \\
\hline & & & 7.33 & Co II & $4 \mathrm{~s} \mathrm{a}^{3} \mathrm{D}_{3}$ & $4 \mathrm{sp} \mathrm{y}^{5} \mathrm{P}_{3}$ & 2.1 & $\mathrm{fl}$ & & \\
\hline 1728.79 & $157^{b l}$ & 33 & 1728.85 & Fe II & $4 \mathrm{~s} \mathrm{a}^{4} \mathrm{D}_{3 / 2}$ & $4 p x^{4} F_{5 / 2}$ & 2.1 & $\mathrm{fl}$ & 37 & 34 \\
\hline 1727.17 & 53 & 31 & 1727.38 & Si IV & $3 d^{2} D_{3 / 2}$ & $4 p^{2} \mathrm{P}_{1 / 2}$ & & unk & & \\
\hline Oth & & & 1725.98 & Fe II & $3 d^{7} a^{2} D_{3 / 2}$ & $4 \operatorname{sp~} x^{6} \mathrm{P}_{3 / 2}$ & & $\mathrm{fl}$ & & \\
\hline \multirow[t]{3}{*}{1725.13} & 86 & 104 & 1725.36 & Fe II & $4 \mathrm{~s} \mathrm{~b}^{2} \mathrm{D}_{5 / 2}$ & $\left({ }^{4} \mathrm{P}\right) 4 \mathrm{sp}{ }^{4} \mathrm{P}_{5 / 2}$ & 2.1 & $\mathrm{fl}$ & & \\
\hline & & & 5.02 & Fe II & $3 d^{7} a^{2} D 2_{5 / 2}$ & $4 \mathrm{pw}^{2} \mathrm{D}_{3 / 2}$ & 2.1 & $\mathrm{fl}$ & & \\
\hline & & & 4.96 & Fe II & $3 d^{7} a^{4} F_{7 / 2}$ & $4 \mathrm{p} \mathrm{y}^{4} \mathrm{P}_{5 / 2}$ & 2.1 & $\mathrm{fl}$ & & \\
\hline \multirow[t]{2}{*}{1722.41} & 94 & 56 & 1722.56 & $\mathrm{Si}$ IV & $3 d^{2} D_{3 / 2}$ & $4 p^{2} \mathrm{P}_{3 / 2}$ & & unk & & \\
\hline & & & 2.53 & $\mathrm{Si} I V$ & $3 d^{2} D_{5 / 2}$ & $4 p^{2} \mathrm{P}_{3 / 2}$ & & unk & & \\
\hline Oth & & & 1721.68 & C II & $2 \mathrm{~s} 2 \mathrm{p}^{2}{ }^{2} \mathrm{P}_{3 / 2}$ & $2 \mathrm{p}^{32} \mathrm{P}_{3 / 2}$ & $2.3 \mathrm{D}$ & col & & \\
\hline 1720.96 & $39^{b l}$ & 40 & 1721.01 & C II & $2 \mathrm{~s} 2 \mathrm{p}^{2}{ }^{2} \mathrm{P}_{1 / 2}$ & $2 \mathrm{p}^{32} \mathrm{P}_{1 / 2}$ & $2.3 \mathrm{D}$ & col & & \\
\hline 1720.64 & 33 & 19 & 1720.85 & $\mathrm{Ne}$ V] & $2 \mathrm{p}^{2}{ }^{1} \mathrm{D}_{2}$ & $2 \mathrm{~s} 2 \mathrm{p}^{3}{ }^{5} \mathrm{~S}_{2}$ & $2.3 \mathrm{D}$ & col & & \\
\hline \multirow[t]{2}{*}{1718.34} & 214 & 145 & 1718.55 & N IV & $2 \mathrm{p}^{1} \mathrm{P}_{1}$ & $2 \mathrm{p}^{21} \mathrm{D}_{2}$ & 1 & rec & 107 & 145 \\
\hline & & & 8.10 & Fe II & $3 d^{7} a^{4} F_{5 / 2}$ & $4 p z^{4} G_{5 / 2}$ & 2.1 & $\mathrm{fl}$ & & \\
\hline Oth & & & 1713.00 & $\mathrm{Fe}$ II & $3 d^{7} a^{4} F_{7 / 2}$ & $4 \mathrm{pz}^{4} \mathrm{G}_{9 / 2}$ & 2.1 & $\mathrm{fl}$ & & \\
\hline
\end{tabular}


Table 13. continued.

\begin{tabular}{|c|c|c|c|c|c|c|c|c|c|c|}
\hline$\lambda_{\mathrm{obs}}(\AA)$ & $I^{a}$ & $w^{b}$ & $\lambda_{\text {id }}(\AA)$ & spec. & Lower level & Upper level & $\mathrm{Sec}^{c}$ & $\operatorname{Exc}^{f}$ & $I_{\mathrm{ghrs}}^{d}$ & $w_{\mathrm{ghrs}}^{e}$ \\
\hline Oth & & & 1706.83 & $\mathrm{Fe} \mathrm{II}$ & $4 \mathrm{~s} \mathrm{c}^{2} \mathrm{G}_{7 / 2}$ & $4 \operatorname{sp~x}{ }^{4} \mathrm{H}_{7 / 2}$ & 2.1 & $\mathrm{fl}$ & & \\
\hline 1698.63 & 50 & 12 & 1698.78 & Mg IV & $\left({ }^{3} \mathrm{P}\right) 3 \mathrm{~s}{ }^{4} \mathrm{P}_{3 / 2}$ & $\left({ }^{3} \mathrm{P}\right) 3 \mathrm{p}{ }^{4} \mathrm{D}_{5 / 2}$ & $2.3 \mathrm{~F}$ & rec & & \\
\hline 1696.47 & $153^{b l}$ & 34 & 1696.79 & $\mathrm{Fe}$ II & $3 d^{7} a^{4} F_{9 / 2}$ & $4 \mathrm{p} \mathrm{z}^{4} \mathrm{G}_{9 / 2}$ & 2.1 & $\mathrm{fl}$ & & \\
\hline 1682.79 & 45 & 32 & 1683.00 & Mg IV & $\left({ }^{3} \mathrm{P}\right) 3 \mathrm{~s}{ }^{4} \mathrm{P}_{5 / 2}$ & $\left({ }^{3} \mathrm{P}\right) 3 \mathrm{p}{ }^{4} \mathrm{D}_{7 / 2}$ & $2.3 \mathrm{~F}$ & rec & & \\
\hline 1682.30 & 114 & 27 & 1682.37 & $\mathrm{Fe}$ II & $4 \mathrm{p} \mathrm{z}^{4} \mathrm{P}_{1 / 2}$ & $\left({ }^{3} \mathrm{~F}\right) 4 \mathrm{~d}^{4} \mathrm{P}_{3 / 2}$ & 2.1 & $\mathrm{fl}$ & & \\
\hline 1679.95 & 42 & 30 & 1679.96 & Mg IV & $\left({ }^{3} \mathrm{P}\right) 3 \mathrm{~s}{ }^{4} \mathrm{P}_{3 / 2}$ & $\left({ }^{3} \mathrm{P}\right) 3 \mathrm{p}^{4} \mathrm{D}_{3 / 2}$ & $2.3 \mathrm{~F}$ & rec & & \\
\hline 1677.67 & 115 & 18 & 1677.84 & $\mathrm{Fe}$ II & $3 d^{7} a^{2} P_{1 / 2}$ & $4 \mathrm{pw}^{2} \mathrm{D}_{3 / 2}$ & 2.1 & $\mathrm{fl}$ & & \\
\hline 1675.48 & 63 & 29 & 1675.71 & $\mathrm{Fe}$ II & $4 p z^{4} P_{3 / 2}$ & $\left({ }^{3} F\right) 4 d{ }^{4} P_{3 / 2}$ & 2.1 & $\mathrm{fl}$ & & \\
\hline 1671.35 & 53 & 25 & 1671.42 & $\mathrm{Fe}$ II & $4 p z^{4} P_{5 / 2}$ & $\left({ }^{3} F\right) 4 d{ }^{4} P_{5 / 2}$ & 2.1 & $\mathrm{fl}$ & & \\
\hline 1669.47 & 68 & 23 & 1669.57 & Mg IV & $\left({ }^{3} \mathrm{P}\right) 3 \mathrm{~s}{ }^{4} \mathrm{P}_{3 / 2}$ & $\left({ }^{3} \mathrm{P}\right) 3 \mathrm{p}{ }^{4} \mathrm{D}_{1 / 2}$ & $2.3 \mathrm{~F}$ & rec & & \\
\hline 1666.81 & 158 & 18 & 1666.69 & S I & $3 p^{4}{ }^{1} D_{2}$ & $\left({ }^{2} \mathrm{D}\right) 4 \mathrm{~s}{ }^{1} \mathrm{D}_{2}$ & $2.3 \mathrm{E}$ & unk & & \\
\hline 1666.01 & oe & & 1666.15 & O III] & $2 p^{2}{ }^{3} P_{2}$ & $2 \mathrm{~s} 2 \mathrm{p}^{3}{ }^{5} \mathrm{~S}_{2}$ & $2.3 \mathrm{D}$ & col & & \\
\hline 1665.14 & 131 & 31 & & & & & & & & \\
\hline 1660.61 & oe & & 1660.81 & O III] & $2 \mathrm{p}^{2}{ }^{3} \mathrm{P}_{1}$ & $2 \mathrm{~s} 2 \mathrm{p}^{3}{ }^{5} \mathrm{~S}_{2}$ & $2.3 \mathrm{D}$ & col & & \\
\hline 1640.07 & oe & & 1640.35 & He II & $n=2$ & $n=3$ & 1 & rec & 8700 & 82 \\
\hline 1625.45 & $97^{b l}$ & 35 & 1625.58 & $\mathrm{Fe}$ II & $4 \mathrm{sb}^{2} \mathrm{~F}_{5 / 2}$ & $4 p u^{4} F_{3 / 2}$ & 2.1 & $\mathrm{fl}$ & & \\
\hline 1613.83 & 63 & 39 & 1613.94 & $\mathrm{Fe}$ II & $4 s b^{4} D_{1 / 2}$ & $4 p u^{4} F_{3 / 2}$ & 2.1 & $\mathrm{fl}$ & & \\
\hline & & & 3.84 & $\mathrm{Fe}$ II & $4 \mathrm{~s} \mathrm{~b}^{4} \mathrm{D}_{3 / 2}$ & $4 p u^{4} F_{3 / 2}$ & 2.1 & $\mathrm{fl}$ & & \\
\hline 1601.51 & 60 & 45 & 1601.67 & [Ne IV] & $2 \mathrm{p}^{3}{ }^{4} \mathrm{~S}_{3 / 2}$ & $2 \mathrm{p}^{3}{ }^{2} \mathrm{P}_{1 / 2}$ & 2.2 & col & & \\
\hline & & & 1.50 & [Ne IV] & $2 \mathrm{p}^{3}{ }^{4} \mathrm{~S}_{3 / 2}$ & $2 \mathrm{p}^{3}{ }^{2} \mathrm{P}_{3 / 2}$ & 2.2 & col & & \\
\hline 1601.18 & 71 & & & & & & & & & \\
\hline 1599.85 & 55 & 23 & 1600.01 & Fe II & $3 d^{7} a^{2} H_{9 / 2}$ & $4 p v^{2} G_{7 / 2}$ & 2.1 & $\mathrm{fl}$ & & \\
\hline 1589.91 & 79 & 26 & & & & & & & & \\
\hline Oth & & & 1588.29 & $\mathrm{Fe} I I$ & $3 d^{7} a^{4} F_{3 / 2}$ & $4 \mathrm{px}^{4} \mathrm{G}_{5 / 2}$ & 2.1 & fl & & \\
\hline 1579.06 & 90 & 36 & & & & & & & & \\
\hline 1577.84 & $125^{b l}$ & 49 & 1577.88 & C III & $2 \mathrm{~s} 3 \mathrm{~d}^{3} \mathrm{D}_{1}$ & $2 \mathrm{p} 3 \mathrm{~d}^{3} \mathrm{~F}_{2}$ & $2.3 \mathrm{~F}$ & rec & & \\
\hline 1577.13 & 129 & 23 & 1577.30 & C III & $2 \mathrm{~s} 3 \mathrm{~d}^{3} \mathrm{D}_{2}$ & $2 \mathrm{p} 3 \mathrm{~d}^{3} \mathrm{~F}_{3}$ & $2.3 \mathrm{~F}$ & rec & & \\
\hline 1576.37 & $153^{b l}$ & 48 & 1576.48 & C III & $2 \mathrm{~s} 3 \mathrm{~d}^{3} \mathrm{D}_{3}$ & $2 \mathrm{p} 3 \mathrm{~d}^{3} \mathrm{~F}_{4}$ & $2.3 \mathrm{~F}$ & rec & & \\
\hline 1574.53 & 258 & 84 & 1575.18 & {$[\mathrm{Ne} \mathrm{V}]$} & $2 \mathrm{p}^{2}{ }^{3} \mathrm{P}_{1}$ & $2 \mathrm{p}^{2}{ }^{1} \mathrm{~S}_{0}$ & 2.2 & col & & \\
\hline 1565.72 & 118 & 35 & & & & & & & & \\
\hline 1560.02 & 242 & 27 & 1560.25 & $\mathrm{Fe}$ II & $3 d^{7} a^{4} F_{7 / 2}$ & $4 \mathrm{px}^{4} \mathrm{~F}_{5 / 2}$ & 2.1 & $\mathrm{fl}$ & & \\
\hline 1553.32 & 225 & 33 & & & & & & & 137 & 21 \\
\hline 1550.65 & oe & & 1550.77 & C IV & $2 \mathrm{~s}^{2} \mathrm{~S}_{1 / 2}$ & $2 \mathrm{p}^{2} \mathrm{P}_{1 / 2}$ & 1 & col & 7570 & 48 \\
\hline 1548.11 & oe & & 1548.19 & C IV & $2 s^{2} S_{1 / 2}$ & $2 p^{2} P_{3 / 2}$ & 1 & col & 11650 & 46 \\
\hline Oth & & & 1538.63 & $\mathrm{Fe}$ II & $4 \mathrm{~s} \mathrm{a}^{4} \mathrm{G}_{5 / 2}$ & $\left({ }^{5} \mathrm{D}\right) 5 \mathrm{p}{ }^{4} \mathrm{D}_{3 / 2}$ & 2.1 & $\mathrm{fl}$ & & \\
\hline 1538.13 & 98 & 27 & 1538.16 & Fe II & $3 d^{7} a^{4} P_{5 / 2}$ & $4 \mathrm{pw}^{2} \mathrm{D}_{3 / 2}$ & 2.1 & $\mathrm{fl}$ & & \\
\hline \multirow[t]{2}{*}{1537.10} & 324 & 37 & 1537.37 & $\mathrm{Fe}$ II & $4 \mathrm{sc}^{2} \mathrm{~F}_{5 / 2}$ & $\left({ }^{3} \mathrm{H}\right) 5 \mathrm{p}{ }^{4} \mathrm{G}_{7 / 2}$ & 2.1 & $\mathrm{fl}$ & 129 & 25 \\
\hline & & & 7.03 & Fe II & $4 \mathrm{~s} \mathrm{c}^{2} \mathrm{~F}_{7 / 2}$ & $\left({ }^{3} \mathrm{H}\right) 5 \mathrm{p}{ }^{4} \mathrm{G}_{7 / 2}$ & 2.1 & $\mathrm{fl}$ & & \\
\hline Oth & & & 1534.05 & $\mathrm{OV}$ & $2 p 3 p{ }^{1} \mathrm{P}_{1}$ & $2 \mathrm{~s} 4 \mathrm{p}{ }^{1} \mathrm{P}_{1}$ & $2.3 \mathrm{~F}$ & rec & & \\
\hline 1533.25 & 390 & 35 & 1533.43 & Si II & $3 p^{2} \mathrm{P}_{3 / 2}$ & $4 s^{2} S_{1 / 2}$ & & unk & & \\
\hline \multicolumn{11}{|l|}{ Oth } \\
\hline 1515.01 & 44 & 30 & 1515.23 & $\mathrm{Fe}$ II & $4 \mathrm{~s} \mathrm{~b}^{2} \mathrm{H}_{11 / 2}$ & $4 \operatorname{sp~} x^{4} H_{11 / 2}$ & 2.1 & $\mathrm{fl}$ & & \\
\hline 1514.20 & 135 & 30 & 1514.38 & Fe II & $4 s a^{4} G_{5 / 2}$ & $4 \operatorname{sp~x}{ }^{4} \mathrm{H}_{7 / 2}$ & 2.1 & $\mathrm{fl}$ & & \\
\hline 1512.55 & 235 & 32 & 1512.69 & $\mathrm{Fe}$ II & $4 \mathrm{~s} \mathrm{a}^{4} \mathrm{G}_{7 / 2}$ & $4 \operatorname{sp~} x^{4} H_{7 / 2}$ & 2.1 & fl & & \\
\hline 1506.75 & 144 & 52 & 1506.76 & $\mathrm{OV}$ & $2 \mathrm{~s} 4 \mathrm{~d}^{3} \mathrm{D}_{3}$ & $2 s 5 f^{3} F_{4}$ & $2.3 \mathrm{~F}$ & rec & & \\
\hline 1502.55 & 79 & 26 & 1502.69 & Fe II & $4 s a^{4} G_{5 / 2}$ & $4 \mathrm{pu}^{2} \mathrm{G}_{7 / 2}$ & 2.1 & $\mathrm{fl}$ & & \\
\hline Oth & & & 1501.76 & S V & $3 \mathrm{~s} 3 \mathrm{p}^{1} \mathrm{P}_{1}$ & $3 \mathrm{p}^{2}{ }^{1} \mathrm{D}_{2}$ & 1 & unk & & \\
\hline 1492.10 & $144^{b l}$ & 32 & 1492.26 & Co II & $4 s a^{5} P_{2}$ & $4 \operatorname{sp~} y^{5} \mathrm{P}_{3}$ & 2.1 & $\mathrm{fl}$ & 125 & 24 \\
\hline 1488.36 & 139 & 32 & 1438.38 & Si I & $3 \mathrm{p}^{2}{ }^{1} \mathrm{~S}_{0}$ & $3 \mathrm{~s} 3 \mathrm{p}^{3}{ }^{1} \mathrm{P}_{1}$ & $2.3 \mathrm{E}$ & unk & & \\
\hline
\end{tabular}


Table 13. continued.

\begin{tabular}{|c|c|c|c|c|c|c|c|c|c|c|}
\hline$\lambda_{\text {obs }}(\AA)$ & $I^{a}$ & $w^{b}$ & $\lambda_{\text {id }}(\AA)$ & spec. & Lower level & Upper level & $\mathrm{Sec}^{c}$ & $\operatorname{Exc}^{f}$ & $I_{\mathrm{ghrs}}^{d}$ & $w_{\text {ghrs }}^{e}$ \\
\hline 1486.42 & oe & & 1486.50 & N IV] & $2 \mathrm{~s}^{2}{ }^{1} \mathrm{~S}_{0}$ & $2 p^{3} \mathrm{P}_{1}$ & 1 & col & 8290 & 38 \\
\hline 1483.26 & 139 & 160 & 1483.32 & [N IV] & $2 \mathrm{~s}^{2}{ }^{1} \mathrm{~S}_{0}$ & $2 p^{3} \mathrm{P}_{2}$ & $2.3 \mathrm{C}$ & col & 73 & 301 \\
\hline 1471.93 & 95 & 26 & 1471.94 & $\mathrm{Fe}$ II & $4 p z^{6} D_{5 / 2}$ & $\left({ }^{3} \mathrm{~F}\right) 4 \mathrm{~d}^{4} \mathrm{P}_{5 / 2}$ & 2.1 & $\mathrm{fl}$ & & \\
\hline \multicolumn{11}{|l|}{ Oth } \\
\hline 1467.25 & 134 & 33 & 1467.43 & P IV] & $3 \mathrm{~s}^{2}{ }^{1} \mathrm{~S}_{0}$ & $3 p^{3} \mathrm{P}_{1}$ & $2.3 \mathrm{C}$ & col & & \\
\hline 1464.68 & 84 & 29 & & & & & & & & \\
\hline 1459.73 & 98 & 31 & & & & & & & & \\
\hline Oth & & & 1457.76 & Fe II & $4 s^{2} a^{6} S_{5 / 2}$ & $\left({ }^{4} \mathrm{D}\right) 4 \mathrm{sp}{ }^{6} \mathrm{~F}_{3 / 2}$ & 2.1 & $\mathrm{fl}$ & & \\
\hline 1445.59 & $82^{b l}$ & 62 & 1445.69 & $\mathrm{Fe}$ II & $4 \mathrm{~s} \mathrm{a}^{2} \mathrm{~S}_{1 / 2}$ & $\left({ }^{4} \mathrm{~F}\right) 4 \mathrm{sp}{ }^{6} \mathrm{~F}_{3 / 2}$ & 2.1 & $\mathrm{fl}$ & & \\
\hline 1423.71 & 433 & 32 & 1423.79 & S IV] & $3 p^{2} \mathrm{P}_{3 / 2}$ & $3 \mathrm{p}^{2}{ }^{4} \mathrm{P}_{1 / 2}$ & $2.3 \mathrm{D}$ & col & & \\
\hline 1422.37 & 137 & 25 & 1422.53 & $\mathrm{Fe}$ II & $4 \mathrm{~s} \mathrm{~b}^{4} \mathrm{D}_{3 / 2}$ & $4 p u^{4} F_{3 / 2}$ & 2.1 & $\mathrm{fl}$ & & \\
\hline 1416.77 & 582 & 40 & 1416.98 & S IV] & $3 \mathrm{p}^{2} \mathrm{P}_{3 / 2}$ & $3 p^{2}{ }^{4} \mathrm{P}_{3 / 2}$ & $2.3 \mathrm{D}$ & col & 235 & 36 \\
\hline 1413.57 & 130 & 23 & 1413.70 & $\mathrm{Fe}$ II & $4 \mathrm{~s} \mathrm{a}^{4} \mathrm{H}_{11 / 2}$ & $4 \operatorname{sp~} x^{4} \mathrm{H}_{11 / 2}$ & 2.1 & fl & 61 & 23 \\
\hline 1411.77 & 1182 & 36 & 1411.94 & $\mathrm{~N} \mathrm{I}$ & $2 \mathrm{p}^{3}{ }^{2} \mathrm{P}_{3 / 2}$ & $3 \mathrm{~s}^{2} \mathrm{D}_{5 / 2}$ & 2.1 & fl & 301 & 49 \\
\hline \multirow[t]{2}{*}{1409.15} & 106 & 92 & 1409.34 & S I & $3 p^{4}{ }^{3} \mathrm{P}_{1}$ & $\left({ }^{4} S\right) 5 s{ }^{3} S_{1}$ & 2.1 & $\mathrm{fl}$ & 60 & 51 \\
\hline & & & 9.33 & Co II & $3 \mathrm{~d}^{8} \mathrm{a}^{3} \mathrm{P}_{2}$ & $4 \mathrm{pv}^{3} \mathrm{D}_{3}$ & & unk & & \\
\hline 1407.24 & 1630 & 51 & 1407.38 & O IV] & $2 \mathrm{p}^{2} \mathrm{P}_{3 / 2}$ & $2 \mathrm{~s} 2 \mathrm{p}^{2}{ }^{4} \mathrm{P}_{1 / 2}$ & $2.3 \mathrm{D}$ & col & 854 & 42 \\
\hline 1406.54 & 67 & 41 & & & & & & & & \\
\hline 1405.90 & 1214 & 36 & 1406.08 & S IV] & $3 p^{2} \mathrm{P}_{3 / 2}$ & $3 p^{2}{ }^{4} P_{5 / 2}$ & $2.3 \mathrm{D}$ & col & 384 & 38 \\
\hline \multirow[t]{2}{*}{1404.65} & oe & & 1404.80 & O IV] & $2 \mathrm{p}^{2} \mathrm{P}_{3 / 2}$ & $2 \mathrm{~s} 2 \mathrm{p}^{2}{ }^{4} \mathrm{P}_{3 / 2}$ & $2.3 \mathrm{D}$ & col & 1350 & 41 \\
\hline & & & 4.77 & S IV] & $3 p^{2} \mathrm{P}_{1 / 2}$ & $3 \mathrm{p}^{2}{ }^{4} \mathrm{P}_{1 / 2}$ & $2.3 \mathrm{D}$ & col & & \\
\hline 1402.65 & oe & & 1402.77 & Si IV & $3 \mathrm{~s}^{2} \mathrm{~S}_{1 / 2}$ & $3 p^{2} \mathrm{P}_{1 / 2}$ & 1 & col & 579 & 49 \\
\hline 1401.04 & oe & & 1401.16 & O IV] & $2 \mathrm{p}^{2} \mathrm{P}_{3 / 2}$ & $2 \mathrm{~s} 2 \mathrm{p}^{2}{ }^{4} \mathrm{P}_{5 / 2}$ & $2.3 \mathrm{D}$ & col & 3870 & 41 \\
\hline 1399.61 & 1723 & 47 & 1399.78 & O IV] & $2 \mathrm{p}^{2} \mathrm{P}_{1 / 2}$ & $2 \mathrm{~s} 2 \mathrm{p}^{2}{ }^{4} \mathrm{P}_{1 / 2}$ & $2.3 \mathrm{D}$ & col & 1030 & 41 \\
\hline 1397.96 & 58 & & 1398.13 & S IV] & $3 \mathrm{p}^{2} \mathrm{P}_{1 / 2}$ & $3 \mathrm{p}^{2}{ }^{4} \mathrm{P}_{3 / 2}$ & $2.3 \mathrm{D}$ & col & & \\
\hline 1397.08 & 385 & 34 & 1397.23 & O IV] & $2 p^{2} P_{1 / 2}$ & $2 \mathrm{~s} 2 \mathrm{p}^{2}{ }^{4} \mathrm{P}_{3 / 2}$ & $2.3 \mathrm{D}$ & col & 185 & 56 \\
\hline 1393.67 & oe & & 1393.76 & Si IV & $3 \mathrm{~s}^{2} \mathrm{~S}_{1 / 2}$ & $3 \mathrm{p}^{2} \mathrm{P}_{3 / 2}$ & 1 & col & 1080 & 54 \\
\hline Oth & & & 1393.21 & $\mathrm{Fe}$ II & $3 d^{7} a^{2} \mathrm{H}_{11 / 2}$ & $4 \operatorname{sp~x}{ }^{4} H_{9 / 2}$ & 2.1 & $\mathrm{fl}$ & & \\
\hline \multirow[t]{2}{*}{1387.10} & 214 & 80 & 1387.38 & N III & $3 p^{2} \mathrm{P}_{3 / 2}$ & $4 d^{2} D_{5 / 2}$ & $2.3 \mathrm{~F}$ & rec & & \\
\hline & & & 7.26 & N III & $2 \mathrm{~s} 2 \mathrm{p}^{2}{ }^{2} \mathrm{~S}_{1 / 2}$ & $2 \mathrm{p}^{3}{ }^{2} \mathrm{D}_{3 / 2}$ & $2.3 \mathrm{D}$ & unk & & \\
\hline 1385.64 & 129 & 35 & 1385.78 & $\mathrm{Fe}$ II & $3 d^{7} a^{2} P_{1 / 2}$ & $\left({ }^{5} \mathrm{D}\right) 5 \mathrm{p}{ }^{4} \mathrm{D}_{3 / 2}$ & 2.1 & $\mathrm{fl}$ & & \\
\hline 1383.41 & 117 & 22 & 1383.54 & Fe II & $3 d^{7} a^{2} P_{3 / 2}$ & $\left({ }^{5} \mathrm{D}\right) 5 \mathrm{p}{ }^{4} \mathrm{D}_{5 / 2}$ & 2.1 & $\mathrm{fl}$ & & \\
\hline 1381.08 & 193 & 30 & 1381.22 & Fe II & $4 \mathrm{~s} \mathrm{~b}^{4} \mathrm{P}_{3 / 2}$ & $\left({ }^{4} \mathrm{P}\right) 4 \mathrm{sp}{ }^{4} \mathrm{P}_{5 / 2}$ & 2.1 & $\mathrm{fl}$ & & \\
\hline 1376.26 & 67 & & 1376.34 & $\mathrm{Fe} \mathrm{V}$ & $\left({ }^{4} \mathrm{~F}\right) 4 \mathrm{~s}^{5} \mathrm{~F}_{5}$ & $\left({ }^{4} \mathrm{~F}\right) 4 \mathrm{p}^{5} \mathrm{~F}_{5}$ & $2.3 \mathrm{~F}$ & rec & & \\
\hline 1375.56 & 164 & 33 & 1375.75 & Fe II & $3 d^{7} a^{2} P_{3 / 2}$ & $\left({ }^{5} \mathrm{D}\right) 5 \mathrm{p}{ }^{4} \mathrm{D}_{3 / 2}$ & 2.1 & $\mathrm{fl}$ & 110 & 24 \\
\hline 1373.44 & 69 & 22 & 1373.59 & $\mathrm{Fe} \mathrm{V}$ & $\left({ }^{4} \mathrm{~F}\right) 4 \mathrm{~s}{ }^{5} \mathrm{~F}_{4}$ & $\left({ }^{4} \mathrm{~F}\right) 4 \mathrm{p}^{5} \mathrm{~F}_{4}$ & $2.3 \mathrm{~F}$ & rec & & \\
\hline 1372.93 & 209 & 28 & & & & & & & & \\
\hline \multirow[t]{2}{*}{1371.18} & 473 & 83 & 1371.30 & $\mathrm{OV}$ & $2 \mathrm{~s} 2 \mathrm{p}{ }^{1} \mathrm{P}_{1}$ & $2 \mathrm{p}^{21} \mathrm{D}_{2}$ & 1 & unk & 214 & 126 \\
\hline & & & 0.94 & $\mathrm{Fe} \mathrm{V}$ & $\left({ }^{4} \mathrm{~F}\right) 4 \mathrm{~s}^{5} \mathrm{~F}_{1}$ & $\left({ }^{4} \mathrm{~F}\right) 4 \mathrm{p}^{5} \mathrm{~F}_{2}$ & $2.3 \mathrm{~F}$ & rec & & \\
\hline 1367.80 & 89 & 22 & & & & & & & & \\
\hline 1362.60 & 161 & 22 & 1362.78 & Fe II & $4 \mathrm{~s} \mathrm{~b}^{4} \mathrm{P}_{5 / 2}$ & $\left({ }^{4} \mathrm{P}\right) 4 \mathrm{sp}{ }^{4} \mathrm{P}_{5 / 2}$ & 2.1 & fl & & \\
\hline 1360.05 & 184 & 40 & 1360.30 & O III] & $2 \mathrm{~s} 2 \mathrm{p}^{3}{ }^{1} \mathrm{P}_{1}$ & $2 \mathrm{p}^{4}{ }^{3} \mathrm{P}_{1}$ & $2.3 \mathrm{D}$ & unk & & \\
\hline \multirow[t]{2}{*}{1358.35} & 298 & 31 & 1358.51 & O III] & $2 \mathrm{~s} 2 \mathrm{p}^{3}{ }^{1} \mathrm{P}_{1}$ & $2 \mathrm{p}^{4}{ }^{3} \mathrm{P}_{0}$ & $2.3 \mathrm{D}$ & unk & 107 & 24 \\
\hline & & & 1358.51 & $\mathrm{O}$ I] & $2 p^{4}{ }^{3} \mathrm{P}_{1}$ & $3 \mathrm{~s}^{5} \mathrm{~S}_{2}$ & $2.3 \mathrm{E}$ & unk & & \\
\hline 1355.43 & 406 & 31 & 1355.60 & $\mathrm{OI}]$ & $2 \mathrm{p}^{4}{ }^{3} \mathrm{P}_{2}$ & $3 \mathrm{~s}{ }^{5} \mathrm{~S}_{2}$ & $2.3 \mathrm{E}$ & unk & 121 & 24 \\
\hline 1345.54 & 99 & 31 & & & & & & & & \\
\hline 1344.80 & 115 & 45 & 1344.85 & P III & $3 p^{2} \mathrm{P}_{3 / 2}$ & $3 \mathrm{p}^{2}{ }^{2} \mathrm{D}_{3 / 2}$ & $2.3 \mathrm{D}$ & col & & \\
\hline 1344.29 & 85 & & 1344.33 & P III & $3 p^{2} \mathrm{P}_{3 / 2}$ & $3 \mathrm{p}^{2}{ }^{2} \mathrm{D}_{5 / 2}$ & $2.3 \mathrm{D}$ & col & & \\
\hline 1343.41 & 253 & 34 & 1343.51 & O IV & $2 \mathrm{~s} 2 \mathrm{p}^{2}{ }^{2} \mathrm{P}_{3 / 2}$ & $2 \mathrm{p}^{32} \mathrm{D}_{5 / 2}$ & $2.3 \mathrm{D}$ & unk & & \\
\hline
\end{tabular}


Table 13. continued.

\begin{tabular}{|c|c|c|c|c|c|c|c|c|c|c|}
\hline$\lambda_{\text {obs }}(\AA)$ & $I^{a}$ & $w^{b}$ & $\lambda_{\mathrm{id}}(\AA)$ & spec. & Lower level & Upper level & $\mathrm{Sec}^{c}$ & $\operatorname{Exc}^{f}$ & $I_{\mathrm{ghrs}}^{d}$ & $w_{\text {ghrs }}^{e}$ \\
\hline 1338.47 & 85 & 38 & 1338.62 & O IV & $2 \mathrm{~s} 2 \mathrm{p}^{2}{ }^{2} \mathrm{P}_{1 / 2}$ & $2 p^{32} D_{3 / 2}$ & $2.3 \mathrm{D}$ & unk & & \\
\hline 1336.71 & 119 & 63 & & & & & & & & \\
\hline 1335.55 & 315 & 25 & 1335.71 & C II & $2 p^{2} \mathrm{P}_{3 / 2}$ & $2 \mathrm{~s} 2 \mathrm{p}^{2}{ }^{2} \mathrm{D}_{5 / 2}$ & $2.3 \mathrm{D}$ & $\mathrm{col}$ & & \\
\hline 1324.25 & 115 & 20 & 1324.45 & [Mg V] & $2 p^{4}{ }^{3} \mathrm{P}_{1}$ & $2 \mathrm{p}^{4}{ }^{1} \mathrm{~S}_{0}$ & 2.2 & col & & \\
\hline 1323.15 & 63 & 20 & & & & & & & & \\
\hline Oth & & & 1312.49 & $\mathrm{Fe}$ II & $4 \mathrm{~s} \mathrm{~b}^{4} \mathrm{D}_{7 / 2}$ & $\left({ }^{2} \mathrm{~F}\right) 4 \mathrm{sp}{ }^{4} \mathrm{G}_{9 / 2}$ & 2.1 & $\mathrm{fl}$ & & \\
\hline 1310.92 & 58 & 27 & 1310.95 & N I & $2 \mathrm{p}^{3}{ }^{2} \mathrm{P}_{1 / 2}$ & $3 d^{2} D_{3 / 2}$ & $2.3 \mathrm{E}$ & unk & & \\
\hline \multirow[t]{2}{*}{1310.47} & 60 & 46 & 1310.70 & P II & $3 \mathrm{p}^{2}{ }^{3} \mathrm{P}_{2}$ & $3 \mathrm{p}^{3}{ }^{3} \mathrm{P}_{2}$ & $2.3 \mathrm{D}$ & col & & \\
\hline & & & 0.54 & N I & $2 \mathrm{p}^{32} \mathrm{P}_{3 / 2}$ & $3 d^{2} D_{5 / 2}$ & $2.3 \mathrm{E}$ & unk & & \\
\hline Oth & & & 1310.15 & $\mathrm{Fe}$ II & $3 d^{7} a^{2} G_{9 / 2}$ & $4 \mathrm{pu}^{2} \mathrm{G}_{9 / 2}$ & 2.1 & $\mathrm{fl}$ & & \\
\hline 1309.69 & $74^{b l}$ & & 1309.87 & P II & $3 p^{2}{ }^{3} \mathrm{P}_{2}$ & $3 p^{3}{ }^{3} \mathrm{P}_{1}$ & $2.3 \mathrm{D}$ & col & & \\
\hline 1308.63 & 41 & & 1308.71 & C III & $2 \mathrm{p}^{2}{ }^{1} \mathrm{~S}_{0}$ & $2 \mathrm{~s} 3 \mathrm{p}^{1} \mathrm{P}_{1}$ & $2.3 \mathrm{~F}$ & rec & & \\
\hline 1305.90 & 2566 & 46 & 1306.03 & O I & $2 \mathrm{p}^{4}{ }^{3} \mathrm{P}_{0}$ & $3 \mathrm{~s}^{3} \mathrm{~S}_{1}$ & $2.3 \mathrm{E}$ & $\mathrm{col}$ & & \\
\hline 1304.73 & 2345 & 46 & 1304.86 & O I & $2 p^{4}{ }^{3} \mathrm{P}_{1}$ & $3 \mathrm{~s}^{3} \mathrm{~S}_{1}$ & $2.3 \mathrm{E}$ & col & & \\
\hline 1301.86 & 83 & 16 & 1301.87 & P II & $3 \mathrm{p}^{2}{ }^{3} \mathrm{P}_{0}$ & $3 \mathrm{p}^{3}{ }^{3} \mathrm{P}_{1}$ & $2.3 \mathrm{D}$ & col & & \\
\hline 1301.03 & $96^{b l}$ & & 1301.15 & Si III & $3 p^{3} \mathrm{P}_{1}$ & $3 \mathrm{p}^{2}{ }^{3} \mathrm{P}_{0}$ & $2.3 \mathrm{D}$ & unk & & \\
\hline Oth & & & 1300.86 & O III] & $2 \mathrm{p}^{2}{ }^{1} \mathrm{~S}_{0}$ & $2 \mathrm{~s} 2 \mathrm{p}^{3}{ }^{3} \mathrm{D}_{1}$ & $2.3 \mathrm{D}$ & col & & \\
\hline Oth & & & 1298.89 & Si III & $3 \mathrm{p}^{3} \mathrm{P}_{1}$ & $3 p^{2}{ }^{3} \mathrm{P}_{1}$ & $2.3 \mathrm{D}$ & unk & & \\
\hline Oth & & & 1296.73 & Si III & $3 \mathrm{p}^{3} \mathrm{P}_{0}$ & $3 \mathrm{p}^{2}{ }^{3} \mathrm{P}_{1}$ & $2.3 \mathrm{D}$ & unk & & \\
\hline Oth & & & & & & & 1 & & & \\
\hline Oth & & & & & & & 1 & & & \\
\hline Oth & & & & & & & 1 & & & \\
\hline 1252.48 & 149 & 26 & & & & & & & & \\
\hline \multirow[t]{2}{*}{1250.01} & 197 & 108 & 1250.43 & Si II & $3 \mathrm{p}^{2}{ }^{2} \mathrm{D}_{5 / 2}$ & $3 \mathrm{p}^{3}{ }^{2} \mathrm{D}_{5 / 2}$ & $2.3 \mathrm{D}$ & unk & & \\
\hline & & & 0.09 & Si II & $3 \mathrm{p}^{2}{ }^{2} \mathrm{D}_{3 / 2}$ & $3 \mathrm{p}^{32} \mathrm{D}_{3 / 2}$ & $2.3 \mathrm{D}$ & unk & & \\
\hline 1248.20 & $130^{b l}$ & 50 & 1248.43 & Si II & $3 \mathrm{p}^{2}{ }^{4} \mathrm{P}_{3 / 2}$ & $3 \mathrm{p}^{3}{ }^{4} \mathrm{~S}_{3 / 2}$ & $2.3 \mathrm{D}$ & unk & & \\
\hline 1247.25 & 236 & 29 & 1247.38 & C III & $2 \mathrm{~s} 2 \mathrm{p}^{1} \mathrm{P}_{1}$ & $2 \mathrm{p}^{2}{ }^{1} \mathrm{~S}_{0}$ & & unk & & \\
\hline 1242.73 & oe & & 1242.78 & $\mathrm{~N} \mathrm{~V}$ & $2 \mathrm{~s}^{2} \mathrm{~S}_{1 / 2}$ & $2 \mathrm{p}^{2} \mathrm{P}_{1 / 2}$ & 1 & col & 6080 & 67 \\
\hline 1238.74 & oe & & 1238.80 & $\mathrm{~N} \mathrm{~V}$ & $2 s^{2} S_{1 / 2}$ & $2 \mathrm{p}^{2} \mathrm{P}_{3 / 2}$ & 1 & col & 9990 & 67 \\
\hline 1227.70 & 283 & 73 & & & & & & & & \\
\hline 1218.26 & 2237 & 71 & 1218.34 & $\mathrm{O}$ V] & $2 s^{2}{ }^{1} S_{0}$ & $2 p^{3} \mathrm{P}_{1}$ & $2.3 \mathrm{~F}$ & unk & & \\
\hline 1215.65 & 936 & 106 & 1215.67 & H I & $n=1$ & $n=2$ & & rec & & \\
\hline 1199.04 & 1066 & 40 & 1199.13 & S V] & $3 \mathrm{~s}^{2}{ }^{1} \mathrm{~S}_{0}$ & $3 p^{3} \mathrm{P}_{1}$ & 1 & unk & & \\
\hline 1184.43 & 180 & 28 & 1184.51 & N III & $2 \mathrm{~s} 2 \mathrm{p}^{2}{ }^{2} \mathrm{P}_{3 / 2}$ & $2 \mathrm{p}^{32} \mathrm{P}_{3 / 2}$ & $2.3 \mathrm{D}$ & unk & & \\
\hline Oth & & & 1174.93 & C III & $2 \mathrm{~s} 2 \mathrm{p}^{3} \mathrm{P}_{1}$ & $2 \mathrm{p}^{2}{ }^{3} \mathrm{P}_{2}$ & & unk & & \\
\hline 1151.04 & 65 & & 1151.15 & $\mathrm{Fe}$ II & $4 \mathrm{~s} \mathrm{a}^{6} \mathrm{D}_{5 / 2}$ & $4 s 4 p y^{6} F_{7 / 2}$ & 2.1 & $\mathrm{fl}$ & & \\
\hline 1147.27 & 71 & & 1147.41 & $\mathrm{Fe}$ II & $4 \mathrm{~s} \mathrm{a}^{6} \mathrm{D}_{7 / 2}$ & $4 s 4 p y^{6} F_{7 / 2}$ & 2.1 & $\mathrm{fl}$ & & \\
\hline 1145.38 & 1014 & 58 & 1145.58 & $\mathrm{Ne}$ V] & $2 \mathrm{p}^{2}{ }^{3} \mathrm{P}_{2}$ & $2 \mathrm{~s} 2 \mathrm{p}^{35} \mathrm{~S}_{2}$ & $2.3 \mathrm{D}$ & col & & \\
\hline 1141.22 & 94 & & & & & & & & & \\
\hline 1136.38 & 492 & 60 & 1136.49 & $\mathrm{Ne}$ V] & $2 \mathrm{p}^{2}{ }^{3} \mathrm{P}_{1}$ & $2 \mathrm{~s} 2 \mathrm{p}^{3}{ }^{5} \mathrm{~S}_{2}$ & $2.3 \mathrm{D}$ & col & & \\
\hline \multirow[t]{2}{*}{1128.21} & 96 & 90 & 1128.35 & Si IV & $3 p^{2} \mathrm{P}_{3 / 2}$ & $3 d^{2} D_{5 / 2}$ & & unk & & \\
\hline & & & 8.33 & Si IV & $3 p^{2} \mathrm{P}_{3 / 2}$ & $3 \mathrm{~d}^{2} \mathrm{D}_{3 / 2}$ & & unk & & \\
\hline 1124 & $115^{p c}$ & 700 & & & & & & & & \\
\hline 1084.7 & 1940 & 63 & 1084.9 & He II & $n=2$ & $n=5$ & $2.3 \mathrm{~F}$ & rec & & \\
\hline 1067.62 & 227 & & & & & & & & & \\
\hline 1037.62 & 4140 & 116 & 1037.61 & O VI & $2 s^{2} S_{1 / 2}$ & $2 \mathrm{p}^{2} \mathrm{P}_{1 / 2}$ & 1 & col & & \\
\hline 1031.92 & 7970 & 120 & 1031.92 & O VI & $2 \mathrm{~s}^{2} \mathrm{~S}_{1 / 2}$ & $2 \mathrm{p}^{2} \mathrm{P}_{3 / 2}$ & 1 & col & & \\
\hline 974 & $359^{p c}$ & 700 & & & & & & & & \\
\hline 967 & $212^{p c}$ & 700 & & & & & & & & \\
\hline
\end{tabular}


M. Eriksson et al.: Emission lines in symbiotic stars, Online Material p 16

Table 13. continued.

\begin{tabular}{lrlllllllll}
\hline \hline$\lambda_{\text {obs }}(\AA)$ & $I^{a}$ & $w^{b}$ & $\lambda_{\text {id }}(\AA)$ & spec. & Lower level & Upper level & $\operatorname{Sec}^{c}$ & $\operatorname{Exc}^{f}$ & $I_{\text {ghrs }}^{d}$ & $w_{\text {ghrs }}^{e}$ \\
\hline 958.51 & 351 & & & & & & & \\
\hline
\end{tabular}

${ }^{a}$ Peak intensity measured in $10^{13} \mathrm{erg} \mathrm{cm}^{-2} \mathrm{~s}^{-1} \AA^{-1}$.

${ }^{b}$ Gaussian widths measured in $\mathrm{km} \mathrm{s}^{-1}$.

${ }^{c}$ Reference to the section in the paper the mechanism responsible for the line is discussed.

${ }^{d}$ Intensity measured with GHRS.

${ }^{e}$ width measured with GHRS.

${ }^{f}$ Excitation mechanism, $\mathrm{fl}=$ fluorescence, $\mathrm{rec}=$ recombination, $\mathrm{col}=$ collision and unk=unknown excitation mechanism 
M. Eriksson et al.: Emission lines in symbiotic stars, Online Material p 17

Table 14. Intensities of emission lines not detectable with LWP25995 or SWP47715.

\begin{tabular}{|c|c|c|c|c|c|c|c|}
\hline$\overline{\lambda_{\mathrm{obs}}}$ & $\overline{I^{a}}$ & $w^{b}$ & $\overline{\lambda_{\text {id }}}$ & spec. & Lower level & Upper level & spectra \\
\hline 3300.29 & 234 & 45 & 3300.34 & O III & $2 \mathrm{p} 3 \mathrm{~s}{ }^{3} \mathrm{P}_{0}$ & $2 \mathrm{p} 3 \mathrm{p}{ }^{3} \mathrm{~S}_{1}$ & LWP19253 \\
\hline 3049.78 & 58 & 18 & 3049.88 & $\mathrm{Fe}$ II & $4 \mathrm{p} \mathrm{z}^{4} \mathrm{P}_{3 / 2}$ & $5 \mathrm{~s} \mathrm{e}^{4} \mathrm{D}_{3 / 2}$ & LWP25565 \\
\hline 2831.45 & 57 & 22 & 2831.76 & $\mathrm{Fe}$ II & $4 \mathrm{~s} \mathrm{~b}^{2} \mathrm{G}_{7 / 2}$ & $4 \mathrm{px}^{4} \mathrm{G}_{5 / 2}$ & LWR06398 \\
\hline 2817.11 & 52 & 20 & & & & & LWP19253 \\
\hline 2644.61 & 76 & 32 & 2644.55 & $\mathrm{Fe}$ II & $4 s^{2} b^{4} G_{5 / 2}$ & $4 \mathrm{px}^{4} \mathrm{H}_{7 / 2}$ & LWP09698 \\
\hline 2583.28 & 144 & 17 & 2583.36 & $\mathrm{Fe}$ II & $4 \mathrm{~s} \mathrm{a}^{4} \mathrm{D}_{3 / 2}$ & $4 p z^{4} P_{3 / 2}$ & LWP09698 \\
\hline 2581.81 & 79 & 20 & 2581.94 & $\mathrm{Fe}$ II & $4 \mathrm{p} \mathrm{z}^{2} \mathrm{D}_{5 / 2}$ & $5 \mathrm{~s} \mathrm{f}^{4} \mathrm{~F}_{5 / 2}$ & LWP25565 \\
\hline 2549.69 & 61 & & 2549.69 & $\mathrm{Fe}$ II & $4 \mathrm{~s} \mathrm{a}^{2} \mathrm{I}_{11 / 2}$ & $4 \mathrm{p} \mathrm{x}^{2} \mathrm{H}_{9 / 2}$ & LWP09698 \\
\hline 2539.19 & 91 & & 2539.35 & $\mathrm{Fe}$ II & $4 \mathrm{~s} \mathrm{a}^{2} \mathrm{~F}_{5 / 2}$ & $4 p y^{2} D_{5 / 2}$ & LWR06389 \\
\hline 2528.28 & 89 & 23 & & & & & LWR09130 \\
\hline 2527.02 & 32 & & 2527.06 & Fe II & $4 \mathrm{~s} \mathrm{~b}^{4} \mathrm{P}_{5 / 2}$ & $4 p y^{4} P_{5 / 2}$ & LWR09130 \\
\hline 2464.62 & 62 & 30 & 2464.76 & $\mathrm{Fe}$ II & $4 \mathrm{~s} \mathrm{a}^{4} \mathrm{G}_{9 / 2}$ & $4 \mathrm{px}^{4} \mathrm{~F}_{7 / 2}$ & LWR06398 \\
\hline 2455.53 & 47 & & 2455.71 & O III & $2 \mathrm{p} 3 \mathrm{~s}{ }^{1} \mathrm{P}_{1}$ & $2 \mathrm{p} 3 \mathrm{p}^{1} \mathrm{~S}_{0}$ & LWP09698 \\
\hline 2437.89 & 142 & 28 & 2437.94 & $\mathrm{Fe}$ II & $4 \mathrm{~s} \mathrm{a}^{4} \mathrm{G}_{7 / 2}$ & $4 \mathrm{p} \mathrm{y}^{2} \mathrm{D}_{5 / 2}$ & LWP09698 \\
\hline \multirow[t]{2}{*}{2435.70} & 159 & 47 & 2435.69 & $\mathrm{Fe}$ II & $4 \mathrm{~s} \mathrm{~b}^{4} \mathrm{~F}_{3 / 2}$ & $4 \mathrm{p} \mathrm{y}^{4} \mathrm{G}_{5 / 2}$ & LWP09698 \\
\hline & & & 5.66 & $\mathrm{Ne}$ III] & $2 \mathrm{p}^{3}\left({ }^{2} \mathrm{D}\right) 3 \mathrm{~s}^{1} \mathrm{D}_{2}$ & $2 \mathrm{p}^{3}\left({ }^{2} \mathrm{D}\right) 3 \mathrm{p}^{3} \mathrm{P}_{2}$ & \\
\hline 2429.94 & 61 & 16 & 2429.98 & $\mathrm{Ne}$ III] & $2 \mathrm{p}^{3}\left({ }^{2} \mathrm{D}\right) 3 \mathrm{~s}{ }^{1} \mathrm{D}_{2}$ & $2 p^{3}\left({ }^{2} D\right) 3 p^{3} P_{1}$ & LWP09698 \\
\hline 2426.32 & 79 & 16 & 2426.42 & Fe II & $4 \mathrm{~s} \mathrm{~b}^{2} \mathrm{P}_{3 / 2}$ & $4 p y^{2} D_{5 / 2}$ & LWR09130 \\
\hline 2425.28 & 64 & 19 & 2425.23 & [Ne IV] & $2 p^{3}{ }^{4} S_{3 / 2}$ & $2 \mathrm{p}^{3}{ }^{2} \mathrm{D}_{5 / 2}$ & LWP09698 \\
\hline 2422.66 & 108 & 16 & 2422.60 & [Ne IV] & $2 p^{3}{ }^{4} S_{3 / 2}$ & $2 \mathrm{p}^{3}{ }^{2} \mathrm{D}_{3 / 2}$ & LWP09698 \\
\hline \multirow[t]{2}{*}{2413.64} & 85 & & 2413.67 & $\mathrm{Ne}$ III & $2 p^{3}\left({ }^{4} S\right) 3 p^{3} P_{1}$ & $2 p^{3}\left({ }^{4} S\right) 3 d^{3} D_{2}$ & LWP09698 \\
\hline & & & 3.47 & $\mathrm{Ne}$ III & $2 p^{3}\left({ }^{4} S\right) 3 p{ }^{3} P_{2}$ & $2 \mathrm{p}^{3}\left({ }^{4} \mathrm{~S}\right) 3 \mathrm{~d}^{3} \mathrm{D}_{3}$ & \\
\hline 2321.28 & 48 & 25 & 2321.66 & [O III] & $2 \mathrm{p}^{2}{ }^{3} \mathrm{P}_{1}$ & $2 \mathrm{p}^{2}{ }^{1} \mathrm{~S}_{0}$ & LWR09130 \\
\hline 2316.42 & 53 & 26 & 2316.46 & Co II & $4 \mathrm{~s} \mathrm{c}^{3} \mathrm{~F}_{4}$ & $4 p v^{3} D_{3}$ & LWR09130 \\
\hline 2253.78 & 187 & 37 & 2253.83 & Fe II & $4 \mathrm{~s} \mathrm{a}{ }^{6} \mathrm{D}_{7 / 2}$ & $4 \mathrm{pz}^{4} \mathrm{~F}_{7 / 2}$ & LWR09130 \\
\hline 2211.72 & 221 & 23 & 2211.81 & Fe II & $4 \mathrm{~s} \mathrm{a}^{4} \mathrm{H}_{13 / 2}$ & $4 \mathrm{p} \mathrm{y}^{4} \mathrm{H}_{11 / 2}$ & LWP25565 \\
\hline 2179.99 & 619 & 29 & & & & & LWP25565 \\
\hline 2152.70 & 230 & 29 & & & & & LWR06389 \\
\hline 2149.26 & 195 & 45 & 2149.28 & He II & $n=3$ & $n=13$ & LWP09698 \\
\hline 2136.06 & 158 & 35 & 2136.03 & He II & $n=3$ & $n=14$ & LWP09698 \\
\hline 2127.87 & 241 & 24 & & & & & LWR06389 \\
\hline 2125.30 & 113 & & 2125.31 & He II & $n=3$ & $n=15$ & LWR06389 \\
\hline 2121.96 & 62 & & 2122.12 & $\mathrm{Fe}$ II & $4 \mathrm{~s} \mathrm{~b}^{4} \mathrm{D}_{3 / 2}$ & $4 \mathrm{pw}^{2} \mathrm{D}_{3 / 2}$ & LWR09130 \\
\hline 2092.38 & 235 & 19 & & & & & LWR06389 \\
\hline 2037.98 & 299 & 19 & 2038.11 & $\mathrm{Fe}$ II & $4 \mathrm{sc}^{2} \mathrm{P}_{3 / 2}$ & $\left({ }^{4} \mathrm{P}\right) 4 \mathrm{sp}^{2} \mathrm{~S}_{1 / 2}$ & LWR06389 \\
\hline 2003.72 & 242 & 39 & 2003.85 & $\mathrm{Fe}$ II & $4 \mathrm{~s} \mathrm{c}^{2} \mathrm{P}_{1 / 2}$ & $\left({ }^{4} \mathrm{P}\right) 4 \mathrm{sp}{ }^{2} \mathrm{~S}_{1 / 2}$ & LWR06389 \\
\hline 2001.77 & 195 & 28 & & & & & LWR06389 \\
\hline 1974.85 & 32 & 15 & 1975.07 & $\mathrm{Fe}$ II & $3 d^{7} a^{2} G_{7 / 2}$ & $4 p y^{2} D_{5 / 2}$ & SWP15651 \\
\hline 1973.58 & 25 & 20 & 1973.78 & Fe II & $4 s^{2} b^{4} G_{9 / 2}$ & $\left({ }^{2} \mathrm{I}\right) 4 \mathrm{sp}{ }^{4} \mathrm{H}_{9 / 2}$ & SWP37477 \\
\hline 1971.98 & 45 & 21 & 1972.16 & Fe II & $4 s^{2} b^{4} G_{11 / 2}$ & $\left({ }^{2} \mathrm{I}\right) 4 \mathrm{sp}{ }^{4} \mathrm{H}_{9 / 2}$ & SWP15651 \\
\hline 1957.05 & 36 & 44 & 1957.28 & {$[\mathrm{Fe} \mathrm{VI}]$} & $3 \mathrm{~d}^{3}{ }^{2} \mathrm{G}_{7 / 2}$ & $3 d^{32} D 1_{5 / 2}$ & SWP43007 \\
\hline 1956.35 & 77 & 28 & & & & & SWP43007 \\
\hline 1951.69 & 34 & 23 & & & & & SWP43007 \\
\hline 1950.85 & 65 & 28 & & & & & SWP43007 \\
\hline 1925.70 & 137 & 25 & & & & & SWP02334 \\
\hline 1921.14 & 58 & 20 & & & & & SWP15651 \\
\hline 1919.00 & 30 & 30 & & & & & SWP15651 \\
\hline 1909.74 & 89 & 17 & 1909.91 & $\mathrm{Fe}$ II & $4 \mathrm{~s} \mathrm{~b}^{4} \mathrm{P}_{5 / 2}$ & $4 p y^{2} P_{3 / 2}$ & SWP15651 \\
\hline 1894.16 & 40 & 17 & 1894.29 & C III & $2 \mathrm{~s} 3 \mathrm{p}^{1} \mathrm{P}_{1}$ & $2 \mathrm{~s} 4 \mathrm{~s}{ }^{1} \mathrm{~S}_{0}$ & SWP15651 \\
\hline 1893.83 & 61 & 36 & 1893.89 & $\mathrm{Mg}$ IV & $\left({ }^{3} \mathrm{P}\right) 3 \mathrm{~s}{ }^{4} \mathrm{P}_{5 / 2}$ & $\left({ }^{3} \mathrm{P}\right) 3 \mathrm{p}{ }^{4} \mathrm{P}_{5 / 2}$ & SWP15651 \\
\hline 1883.71 & 31 & 19 & 1883.72 & $\mathrm{Fe}$ II & $4 \mathrm{~s} \mathrm{a}^{4} \mathrm{D}_{7 / 2}$ & $4 p z^{4} G_{5 / 2}$ & SWP37477 \\
\hline 1881.75 & 24 & & 1881.89 & Fe II & $4 \mathrm{~s} \mathrm{a}^{4} \mathrm{D}_{7 / 2}$ & $4 \mathrm{p} \mathrm{z}^{2} \mathrm{D}_{5 / 2}$ & SWP29862 \\
\hline 1880.99 & 28 & 19 & 1881.25 & Fe II & $3 d^{7} a^{2} P_{1 / 2}$ & ( $\left.{ }^{3} \mathrm{D}\right) 4 \mathrm{p}^{4} \mathrm{P}_{3 / 2}$ & SWP15651 \\
\hline
\end{tabular}


Table 14. continued.

\begin{tabular}{|c|c|c|c|c|c|c|c|}
\hline$\lambda_{\mathrm{obs}}$ & $I^{a}$ & $w^{b}$ & $\lambda_{\text {id }}$ & spec. & Lower level & Upper level & spectra \\
\hline 1877.66 & 146 & 53 & & & & & SWP15651 \\
\hline 1876.94 & 93 & 16 & 1877.02 & $\mathrm{Fe}$ II & $4 s a^{4} G_{5 / 2}$ & $4 \operatorname{sp~} x^{6} P_{7 / 2}$ & SWP02334 \\
\hline 1853.52 & 53 & 31 & 1853.73 & Co II & $4 s^{2} a^{5} D_{2}$ & $\left({ }^{4} F\right) 4 p{ }^{5} D_{3}$ & SWP15651 \\
\hline 1850.50 & 136 & 26 & & & & & SWP43007 \\
\hline 1850.06 & 53 & 91 & 1850.20 & $\mathrm{Fe}$ III & $\left({ }^{4} \mathrm{~F}\right) 4 \mathrm{~s}^{5} \mathrm{~F}_{4}$ & $\left({ }^{4} \mathrm{~F}\right) 4 \mathrm{p}{ }^{5} \mathrm{D}_{4}$ & SWP43007 \\
\hline 1849.15 & 38 & 24 & 1849.40 & $\mathrm{Fe}$ III & $\left({ }^{4} \mathrm{~F}\right) 4 \mathrm{~s}^{5} \mathrm{~F}_{5}$ & $\left({ }^{4} \mathrm{~F}\right) 4 \mathrm{p}{ }^{5} \mathrm{D}_{4}$ & SWP43007 \\
\hline \multirow[t]{2}{*}{1836.52} & 22 & 34 & 1836.72 & N I & $2 \mathrm{p}^{3}{ }^{2} \mathrm{P}_{3 / 2}$ & $3 \mathrm{~s}{ }^{4} \mathrm{P}_{1 / 2}$ & SWP40149 \\
\hline & & & 6.71 & N I & $2 \mathrm{p}^{3}{ }^{2} \mathrm{P}_{1 / 2}$ & $3 \mathrm{~s}{ }^{4} \mathrm{P}_{1 / 2}$ & \\
\hline 1835.37 & 27 & 21 & 1835.57 & N I & $2 \mathrm{p}^{3}{ }^{2} \mathrm{P}_{3 / 2}$ & $3 \mathrm{~s}{ }^{4} \mathrm{P}_{3 / 2}$ & SWP40149 \\
\hline 1833.83 & 29 & 20 & 1834.01 & N I & $2 \mathrm{p}^{3}{ }^{2} \mathrm{P}_{1 / 2}$ & $3 \mathrm{~s}^{4} \mathrm{P}_{3 / 2}$ & SWP40149 \\
\hline 1814.50 & 51 & 40 & 1814.63 & [Ne III] & $2 p^{4}{ }^{3} \mathrm{P}_{1}$ & $2 \mathrm{p}^{4}{ }^{1} \mathrm{~S}_{0}$ & SWP15651 \\
\hline 1813.85 & 41 & 18 & & & & & SWP43007 \\
\hline 1809.84 & 101 & 22 & & & & & SWP43007 \\
\hline \multirow[t]{3}{*}{1795.30} & 94 & 52 & 1795.57 & $\mathrm{Fe}$ II & $4 s^{2} b^{4} G_{7 / 2}$ & $\left({ }^{3} \mathrm{H}\right) 5 \mathrm{p}{ }^{4} \mathrm{G}_{7 / 2}$ & SWP15651 \\
\hline & & & 5.33 & $\mathrm{Fe}$ II & $4 s^{2} b^{4} G_{5 / 2}$ & $\left({ }^{3} \mathrm{H}\right) 5 \mathrm{p}{ }^{4} \mathrm{G}_{7 / 2}$ & \\
\hline & & & 5.27 & $\mathrm{Fe}$ II & $4 s^{2} b^{4} G_{9 / 2}$ & $\left({ }^{3} \mathrm{H}\right) 5 \mathrm{p}{ }^{4} \mathrm{G}_{7 / 2}$ & \\
\hline 1787.79 & 49 & 22 & 1788.00 & $\mathrm{Fe}$ II & $4 s^{2} a^{6} S_{5 / 2}$ & $4 \operatorname{sp~} x^{6} P_{3 / 2}$ & SWP37477 \\
\hline 1783.88 & 99 & 44 & 1783.98 & $\mathrm{Fe}$ II & $4 s b^{4} D_{7 / 2}$ & $4 \operatorname{sp~} y^{6} F_{7 / 2}$ & SWP10454 \\
\hline 1782.64 & 42 & 49 & & & & & SWP43007 \\
\hline 1760.78 & 40 & 32 & 1760.82 & C II & $2 \mathrm{~s} 2 \mathrm{p}^{2}{ }^{2} \mathrm{D}_{3 / 2}$ & $3 p^{2} \mathrm{P}_{1 / 2}$ & SWP29862 \\
\hline \multirow[t]{2}{*}{1760.26} & 103 & 49 & 1760.47 & C II & $2 \mathrm{~s} 2 \mathrm{p}^{2}{ }^{2} \mathrm{D}_{3 / 2}$ & $3 p^{2} \mathrm{P}_{3 / 2}$ & SWP29862 \\
\hline & & & 0.40 & C II & $2 \mathrm{~s} 2 \mathrm{p}^{2}{ }^{2} \mathrm{D}_{5 / 2}$ & $3 p^{2} \mathrm{P}_{3 / 2}$ & \\
\hline 1757.61 & 46 & 22 & 1757.74 & $\mathrm{Fe}$ II & $4 \mathrm{~s} \mathrm{c}^{4} \mathrm{P}_{3 / 2}$ & $\left({ }^{4} \mathrm{~F}\right) 4 \mathrm{sp}{ }^{6} \mathrm{~F}_{3 / 2}$ & SWP43007 \\
\hline 1751.45 & 47 & 33 & 1751.66 & N III & $2 \mathrm{~s} 2 \mathrm{p}^{2}{ }^{2} \mathrm{P}_{3 / 2}$ & $2 \mathrm{p}^{3}{ }^{2} \mathrm{D}_{5 / 2}$ & SWP15651 \\
\hline 1750.46 & 65 & 41 & 1750.66 & Mg II & $3 p^{2} P_{1 / 2}$ & $5 \mathrm{~s}^{2} \mathrm{~S}_{1 / 2}$ & SWP40149 \\
\hline 1747.64 & 36 & & 1747.85 & N III & $2 \mathrm{~s} 2 \mathrm{p}^{2}{ }^{2} \mathrm{P}_{1 / 2}$ & $2 \mathrm{p}^{3}{ }^{2} \mathrm{D}_{3 / 2}$ & SWP15651 \\
\hline 1725.78 & 141 & 17 & 1725.98 & $\mathrm{Fe}$ II & $3 d^{7} a^{2} D_{3 / 2}$ & $4 \operatorname{sp~} x^{6} P_{3 / 2}$ & SWP15651 \\
\hline 1721.46 & 102 & 23 & 1721.68 & C II & $2 \mathrm{~s} 2 \mathrm{p}^{2}{ }^{2} \mathrm{P}_{3 / 2}$ & $2 \mathrm{p}^{3}{ }^{2} \mathrm{P}_{3 / 2}$ & SWP10454 \\
\hline 1712.99 & 56 & 18 & 1713.00 & Fe II & $3 d^{7} a^{4} F_{7 / 2}$ & $4 \mathrm{p} \mathrm{z}^{4} \mathrm{G}_{9 / 2}$ & SWP43007 \\
\hline 1706.78 & 164 & 19 & 1706.83 & $\mathrm{Fe}$ II & $4 \mathrm{~s} \mathrm{c}^{2} \mathrm{G}_{7 / 2}$ & $4 \operatorname{sp~x}{ }^{4} H_{7 / 2}$ & SWP15651 \\
\hline 1588.07 & 167 & 21 & 1588.29 & Fe II & $3 d^{7} a^{4} F_{3 / 2}$ & $4 \mathrm{p} \mathrm{x}^{4} \mathrm{G}_{5 / 2}$ & SWP06355 \\
\hline 1538.59 & 152 & 18 & 1538.63 & $\mathrm{Fe}$ II & $4 \mathrm{~s} \mathrm{a}^{4} \mathrm{G}_{5 / 2}$ & $\left({ }^{5} D\right) 5 p{ }^{4} D_{3 / 2}$ & SWP29862 \\
\hline 1533.8 & 170 & & 1534.05 & $\mathrm{OV}$ & $2 \mathrm{p} 3 \mathrm{p}^{1} \mathrm{P}_{1}$ & $2 \mathrm{~s} 4 \mathrm{p}^{1} \mathrm{P}_{1}$ & SWP29862 \\
\hline 1531.0 & 232 & 127 & & & & & SWP29862 \\
\hline 1502.0 & 429 & 937 & 1501.76 & S V & $3 s 3 p{ }^{1} P_{1}$ & $3 \mathrm{p}^{2}{ }^{1} \mathrm{D}_{2}$ & SWP02334 \\
\hline 1468.88 & 103 & 49 & & & & & SWP29862 \\
\hline 1457.53 & 163 & 23 & 1457.76 & $\mathrm{Fe}$ II & $4 s^{2} a^{6} S_{5 / 2}$ & $\left({ }^{4} \mathrm{D}\right) 4 \mathrm{sp}{ }^{6} \mathrm{~F}_{3 / 2}$ & SWP15651 \\
\hline 1392.99 & 195 & 24 & 1393.21 & $\mathrm{Fe}$ II & $3 d^{7} a^{2} H_{11 / 2}$ & $4 \mathrm{sp} \mathrm{x}{ }^{4} \mathrm{H}_{9 / 2}$ & SWP02334 \\
\hline 1312.41 & 94 & 16 & 1312.49 & $\mathrm{Fe}$ II & $4 \mathrm{~s} \mathrm{~b}^{4} \mathrm{D}_{7 / 2}$ & $\left({ }^{2} \mathrm{~F}\right) 4 \mathrm{sp}{ }^{4} \mathrm{G}_{9 / 2}$ & SWP29862 \\
\hline 1310.01 & 184 & 27 & 1310.15 & Fe II & $3 d^{7} a^{2} G_{9 / 2}$ & $4 p u^{2} G_{9 / 2}$ & SWP06355 \\
\hline 1300.75 & 145 & 16 & 1300.86 & O III] & $2 \mathrm{p}^{2}{ }^{1} \mathrm{~S}_{0}$ & $2 \mathrm{~s} 2 \mathrm{p}^{3}{ }^{3} \mathrm{D}_{1}$ & SWP15651 \\
\hline 1298.78 & 120 & 30 & 1298.89 & Si III & $3 p^{3} \mathrm{P}_{1}$ & $3 \mathrm{p}^{2}{ }^{3} \mathrm{P}_{1}$ & SWP29862 \\
\hline 1296.58 & 90 & 19 & 1296.73 & Si III & $3 p^{3} \mathrm{P}_{0}$ & $3 \mathrm{p}^{2}{ }^{3} \mathrm{P}_{1}$ & SWP29862 \\
\hline 1265.98 & 858 & 554 & & & & & SWP02334 \\
\hline 1260.40 & 1556 & 699 & & & & & SWP02334 \\
\hline 1253.26 & 1469 & 789 & & & & & SWP02334 \\
\hline 1174.86 & 399 & 41 & 1174.93 & C III & $2 s 2 p^{3} P_{1}$ & $2 \mathrm{p}^{2}{ }^{3} \mathrm{P}_{2}$ & SWP15651 \\
\hline
\end{tabular}

${ }^{a}$ Peak intensity measured in $10^{13} \mathrm{erg} \mathrm{cm}^{-2} \mathrm{~s}^{-1} \AA^{-1}$.

${ }^{b}$ Gaussian widths measured in $\mathrm{km} \mathrm{s}^{-1}$. 
M. Eriksson et al.: Emission lines in symbiotic stars, Online Material p 19

Table 15. Emission lines saturated in LWP25995 or SWP47715.

\begin{tabular}{|c|c|c|c|c|c|c|c|}
\hline$\overline{\lambda_{\mathrm{obs}}}$ & $\overline{I^{a}}$ & $\overline{w^{b}}$ & $\overline{\lambda_{\text {id }}}$ & spec. & Lower level & Upper level & spectra \\
\hline 3133.62 & 3204 & 49 & 3133.70 & O III & $2 p 3 p{ }^{3} S_{1}$ & $2 \mathrm{p} 3 \mathrm{~d}^{3} \mathrm{P}_{2}$ & LWP21635 \\
\hline 3047.86 & 805 & 34 & 3047.99 & O III & $2 \mathrm{p} 3 \mathrm{~s}{ }^{3} \mathrm{P}_{2}$ & $2 p 3 p{ }^{3} P_{2}$ & LWP30936 \\
\hline 2803.5 & 717 & & 2803.53 & $\mathrm{Mg}$ II & $3 \mathrm{~s}^{2} \mathrm{~S}_{1 / 2}$ & $3 \mathrm{p}^{2} \mathrm{P}_{1 / 2}$ & LWP21635 \\
\hline 2796.3 & 828 & & 2796.35 & $\mathrm{Mg}$ II & $3 \mathrm{~s}^{2} \mathrm{~S}_{1 / 2}$ & $3 p^{2} \mathrm{P}_{3 / 2}$ & LWP21635 \\
\hline 2734.00 & 596 & 54 & 2734.10 & He II & $n=3$ & $n=5$ & LWP19253 \\
\hline 1908.65 & 3389 & 36 & 1908.73 & C III & $2 s^{2}{ }^{1} S_{0}$ & $2 \mathrm{~s} 2 \mathrm{p}^{3} \mathrm{P}_{1}$ & SWP55055 \\
\hline 1891.96 & 5239 & 29 & 1892.03 & Si III & $3 s^{2}{ }^{1} S_{0}$ & $3 p{ }^{3} P_{1}$ & SWP55055 \\
\hline 1749.55 & 2077 & 36 & 1749.67 & N III & $2 \mathrm{p}^{2} \mathrm{P}_{3 / 2}$ & $2 \mathrm{~s} 2 \mathrm{p}^{2}{ }^{4} \mathrm{P}_{5 / 2}$ & SWP55055 \\
\hline 1666.06 & 8540 & 38 & 1666.15 & O III] & $2 p^{2}{ }^{3} \mathrm{P}_{2}$ & $2 \mathrm{~s} 2 \mathrm{p}^{3}{ }^{5} \mathrm{~S}_{2}$ & SWP55055 \\
\hline 1660.70 & 3540 & 34 & 1660.81 & O III] & $2 \mathrm{p}^{2}{ }^{3} \mathrm{P}_{1}$ & $2 \mathrm{~s} 2 \mathrm{p}^{3}{ }^{5} \mathrm{~S}_{2}$ & SWP55055 \\
\hline 1640.28 & 22040 & 60 & 1640.35 & He II & $n=2$ & $n=3$ & SWP55055 \\
\hline 1550.79 & 24420 & 45 & 1550.77 & C IV & $2 s^{2} S_{1 / 2}$ & $2 \mathrm{p}^{2} \mathrm{P}_{1 / 2}$ & SWP55055 \\
\hline 1548.21 & 44470 & 37 & 1548.19 & C IV & $2 s^{2} S_{1 / 2}$ & $2 \mathrm{p}^{2} \mathrm{P}_{3 / 2}$ & SWP55055 \\
\hline 1486.42 & 14200 & 32 & 1486.50 & N IV & $2 s^{2}{ }^{1} S_{0}$ & $2 \mathrm{p}^{3} \mathrm{P}_{1}$ & SWP55055 \\
\hline \multirow[t]{2}{*}{1404.74} & 2389 & 26 & 1404.80 & O IV] & $2 \mathrm{p}^{2} \mathrm{P}_{3 / 2}$ & $2 \mathrm{~s} 2 \mathrm{p}^{2}{ }^{4} \mathrm{P}_{3 / 2}$ & SWP55055 \\
\hline & & & 4.77 & S IV & $3 \mathrm{p}^{2} \mathrm{P}_{1 / 2}$ & $3 \mathrm{p}^{2}{ }^{4} \mathrm{P}_{1 / 2}$ & \\
\hline 1402.78 & 2439 & 36 & 1402.77 & Si IV & $3 s^{2} S_{1 / 2}$ & $3 p^{2} \mathrm{P}_{1 / 2}$ & SWP55055 \\
\hline 1401.07 & 7500 & 43 & 1401.16 & O IV] & $2 \mathrm{p}^{2} \mathrm{P}_{3 / 2}$ & $2 \mathrm{~s} 2 \mathrm{p}^{2}{ }^{4} \mathrm{P}_{5 / 2}$ & SWP55055 \\
\hline 1393.75 & 3796 & 37 & 1393.76 & Si IV & $3 \mathrm{~s}^{2} \mathrm{~S}_{1 / 2}$ & $3 p^{2} P_{3 / 2}$ & SWP55055 \\
\hline 1242.78 & 12570 & 56 & 1242.78 & $\mathrm{~N} \mathrm{~V}$ & $2 s^{2} S_{1 / 2}$ & $2 \mathrm{p}^{2} \mathrm{P}_{1 / 2}$ & SWP55055 \\
\hline 1238.79 & 19560 & 70 & 1238.80 & $\mathrm{~N} \mathrm{~V}$ & $2 s^{2} S_{1 / 2}$ & $2 p^{2} \mathrm{P}_{3 / 2}$ & SWP55055 \\
\hline
\end{tabular}

${ }^{a}$ Peak intensity measured in $10^{13} \mathrm{erg} \mathrm{cm}^{-2} \mathrm{~s}^{-1} \AA^{-1}$.

${ }^{b}$ Gaussian widths measured in $\mathrm{km} \mathrm{s}^{-1}$. 
M. Eriksson et al.: Emission lines in symbiotic stars, Online Material p 20

Table 16. Aborption lines in AG Peg.

\begin{tabular}{|c|c|c|c|c|c|c|c|}
\hline$\lambda_{\mathrm{obs}}$ & $\mathrm{ekv}^{i}$ & $\lambda_{\text {id }}$ & spec. & Lower level & Upper level & shift & rem \\
\hline 2852.92 & 0.21 & 2852.96 & $\mathrm{Mg} \mathrm{I}$ & $3 \mathrm{~s}^{21} \mathrm{~S}_{0}$ & $3 \mathrm{~s} 3 \mathrm{p}^{1} \mathrm{P}_{1}$ & IS & \\
\hline $2606.49^{a}$ & 0.26 & 2606.46 & Mn II & $4 \mathrm{~s} \mathrm{a}^{7} \mathrm{~S}_{3}$ & $4 p z^{7} P_{2}$ & & \\
\hline 2600.13 & 0.20 & 2600.17 & $\mathrm{Fe}$ II & $4 s a^{6} D_{9 / 2}$ & $4 p z^{6} D_{9 / 2}$ & & \\
\hline 2594.51 & 0.17 & 2594.50 & Mn II & $4 \mathrm{~s} \mathrm{a}^{7} \mathrm{~S}_{3}$ & $4 p z^{7} P_{3}$ & & \\
\hline 2586.68 & 0.37 & 2585.65 & $\mathrm{Fe}$ II & $4 s a^{6} D_{9 / 2}$ & $4 \mathrm{pz}^{6} \mathrm{D}_{7 / 2}$ & & \\
\hline 2576.88 & 0.14 & 2576.87 & Mn II & $4 \mathrm{~s} \mathrm{a}^{7} \mathrm{~S}_{3}$ & $4 p z^{7} P_{4}$ & & \\
\hline 2514.83 & 0.21 & 2515.07 & Si I & $2 \mathrm{p}^{2}{ }^{3} \mathrm{P}_{0}$ & $2 \mathrm{p} 3 \mathrm{~s}{ }^{3} \mathrm{P}_{1}$ & & \\
\hline 2382.75 & 0.26 & 2382.77 & $\mathrm{Fe}$ II & $4 s a^{6} D_{9 / 2}$ & $4 p z^{6} F_{11 / 2}$ & & \\
\hline 2374.55 & 0.20 & 2374.46 & $\mathrm{Fe}$ II & $4 s a^{6} D_{9 / 2}$ & $4 p z^{6} F_{9 / 2}$ & & \\
\hline $1969.90^{b}$ & 0.15 & 1970.36 & $\mathrm{Fe}$ II & $3 d^{7} a^{4} P_{3 / 2}$ & $4 \mathrm{p} \mathrm{z}^{2} \mathrm{~F}_{5 / 2}$ & & \\
\hline 1913.26 & 0.15 & 1913.25 & $\mathrm{Fe} \mathrm{I}$ & $4 s^{2} a^{5} D_{3}$ & $\left({ }^{2} \mathrm{D}\right) 4 \mathrm{p}^{3} \mathrm{D}_{2}$ & & \\
\hline 1859.44 & 0.18 & & & & & & \\
\hline $1838.34^{b}$ & 0.21 & & & & & & \\
\hline 1801.49 & 0.15 & & & & & & \\
\hline 1788.61 & 0.21 & & & & & & \\
\hline 1737.82 & 0.13 & & & & & & \\
\hline $1719.41^{b}$ & 0.23 & 1720.03 & $\mathrm{Fe}$ II & $3 d^{7} a^{4} P_{1 / 2}$ & $\left({ }^{3} \mathrm{D}\right) 4 \mathrm{p}{ }^{4} \mathrm{P}_{3 / 2}$ & & \\
\hline \multirow[t]{4}{*}{1670.76} & 0.37 & 1670.99 & $\mathrm{Fe}$ II & $3 d^{7} a^{4} F_{3 / 2}$ & $4 p y^{4} D_{3 / 2}$ & & \\
\hline & & 0.79 & Al II & $2 \mathrm{~s}^{2}{ }^{1} \mathrm{~S}_{0}$ & $3 \mathrm{p}^{1} \mathrm{P}_{1}$ & & \\
\hline & & 0.79 & $\mathrm{Fe} I I$ & $3 d^{7} a^{4} F_{5 / 2}$ & $4 p y^{4} D_{5 / 2}$ & & \\
\hline & & 0.75 & $\mathrm{Fe}$ II & $3 d^{7} a^{4} F_{9 / 2}$ & $4 p y^{4} D_{7 / 2}$ & & \\
\hline 1658.97 & 0.12 & 1659.48 & $\mathrm{Fe}$ II & $3 d^{7} a^{4} F_{7 / 2}$ & $4 \mathrm{p} \mathrm{y}^{4} \mathrm{D}_{5 / 2}$ & & \\
\hline \multirow[t]{2}{*}{1656.82} & 0.21 & 1657.07 & $\mathrm{Fe}$ II & $3 d^{7} a^{4} F_{3 / 2}$ & $4 \mathrm{px}^{4} \mathrm{D}_{3 / 2}$ & & \\
\hline & & 6.93 & C I & $2 \mathrm{p}^{2}{ }^{3} \mathrm{P}_{0}$ & $2 \mathrm{p} 3 \mathrm{~s}{ }^{3} \mathrm{P}_{1}$ & IS & \\
\hline 1642.33 & 0.11 & 1642.37 & $\mathrm{Fe}$ II & $4 s a^{6} D_{9 / 2}$ & $4 \mathrm{p} \mathrm{z}^{4} \mathrm{H}_{11 / 2}$ & & \\
\hline 1608.34 & 0.31 & 1608.45 & Fe II & $4 s a^{6} D_{9 / 2}$ & 4 sp $y^{6} P_{7 / 2}$ & & \\
\hline 1558.97 & 0.23 & 1559.09 & $\mathrm{Fe}$ II & $3 d^{7} a^{4} F_{9 / 2}$ & $4 p x^{4} F_{9 / 2}$ & & \\
\hline 1558.51 & 0.14 & 1558.54 & $\mathrm{Fe}$ II & $3 d^{7} a^{4} F_{5 / 2}$ & $4 \mathrm{p} \mathrm{y}^{2} \mathrm{D}_{5 / 2}$ & & \\
\hline $1548.56^{*}$ & 0.04 & 1548.70 & $\mathrm{Fe}$ II & $3 d^{7} a^{4} F_{7 / 2}$ & $4 \mathrm{p} \mathrm{y}^{2} \mathrm{D}_{5 / 2}$ & & \\
\hline $1548.27^{*}$ & 0.02 & 1548.41 & $\mathrm{Fe}$ II & $3 d^{7} a^{4} P_{1 / 2}$ & $4 p w^{2} D_{3 / 2}$ & & \\
\hline $1548.06^{*}$ & 0.02 & 1548.20 & Fe II & $3 d^{7} a^{4} F_{9 / 2}$ & $4 \mathrm{p} \mathrm{y}^{4} \mathrm{H}_{11 / 2}$ & & \\
\hline 1526.64 & 0.16 & 1526.71 & Si II & $3 \mathrm{p}^{2} \mathrm{P}_{1 / 2}$ & $4{ }^{2} S_{1 / 2}$ & & \\
\hline $1470.35^{c}$ & 0.10 & & & & & & \\
\hline $1470.08^{c}$ & 0.15 & & & & & & \\
\hline 1401.50 & 0.06 & 1401.51 & S I & $3 \mathrm{p}^{4}{ }^{3} \mathrm{P}_{2}$ & $\left({ }^{4} S\right) 5 s{ }^{3} S_{1}$ & & \\
\hline 1334.40 & 0.22 & 1334.53 & C II & $2 p^{2} \mathrm{P}_{1 / 2}$ & $2 \mathrm{~s} 2 \mathrm{p}^{2}{ }^{2} \mathrm{D}_{3 / 2}$ & IS & \\
\hline 1328.71 & 0.15 & 1328.83 & C I & $2 \mathrm{p}^{2}{ }^{3} \mathrm{P}_{0}$ & $2 \mathrm{~s} 2 \mathrm{p}^{3}{ }^{3} \mathrm{P}_{1}$ & IS & \\
\hline 1304.35 & 0.07 & 1304.49 & P II & $3 \mathrm{p}^{2}{ }^{3} \mathrm{P}_{1}$ & $3 \mathrm{p}^{3}{ }^{3} \mathrm{P}_{0}$ & & \\
\hline 1304.19 & 0.09 & 1304.37 & Si II & $3 p^{2} \mathrm{P}_{1 / 2}$ & $3 \mathrm{p}^{2}{ }^{2} \mathrm{~S}_{1 / 2}$ & & \\
\hline 1302.12 & 0.10 & 1302.12 & O I & $2 \mathrm{p}^{4}{ }^{3} \mathrm{P}_{2}$ & $3 \mathrm{~s}^{3} \mathrm{~S}_{1}$ & IS & \\
\hline \multirow[t]{2}{*}{1277.14} & 0.21 & 1277.28 & C I & $2 \mathrm{p}^{2}{ }^{3} \mathrm{P}_{1}$ & $2 \mathrm{p} 3 \mathrm{~d}^{3} \mathrm{D}_{2}$ & IS & \\
\hline & & 7.25 & C I & $2 \mathrm{p}^{2}{ }^{3} \mathrm{P}_{0}$ & $2 \mathrm{p} 3 \mathrm{~d}^{3} \mathrm{D}_{1}$ & IS & \\
\hline \multirow[t]{2}{*}{1260.35} & 0.16 & 1260.53 & $\mathrm{Fe}$ II & $4 s a^{6} D_{9 / 2}$ & $4 \operatorname{sp} x^{6} P_{7 / 2}$ & & \\
\hline & & 1260.42 & Si II & $3 p^{2} \mathrm{P}_{1 / 2}$ & $3 d^{2} D_{3 / 2}$ & & \\
\hline 1259.41 & 0.23 & 1259.52 & S II & $3 p^{3}{ }^{4} S_{3 / 2}$ & $3 \mathrm{p}^{4}{ }^{4} \mathrm{P}_{5 / 2}$ & & \\
\hline 1253.70 & 0.21 & 1253.81 & S II & $3 p^{3}{ }^{4} S_{3 / 2}$ & $3 p^{4}{ }^{4} \mathrm{P}_{3 / 2}$ & & \\
\hline 1250.47 & 0.24 & 1250.58 & S II & $3 p^{3}{ }^{4} S_{3 / 2}$ & $3 p^{4}{ }^{4} \mathrm{P}_{1 / 2}$ & & \\
\hline $1242.63^{*}$ & 0.03 & 1242.74 & $\mathrm{Fe}$ II & $3 d^{7} a^{4} F_{5 / 2}$ & $4 p v^{2} G_{7 / 2}$ & & \\
\hline 1206.39 & 0.10 & 1206.50 & Si III & $3 \mathrm{~s}^{2}{ }^{1} \mathrm{~S}_{0}$ & $3 \mathrm{p}^{1} \mathrm{P}_{1}$ & & \\
\hline $1200.64^{b}$ & 0.14 & 1200.71 & N I & $2 \mathrm{p}^{3}{ }^{4} \mathrm{~S}_{3 / 2}$ & $3 \mathrm{~s}{ }^{4} \mathrm{P}_{5 / 2}$ & IS & \\
\hline $1200.16^{b}$ & 0.18 & 1200.23 & N I & $2 p^{3}{ }^{4} S_{3 / 2}$ & $3 \mathrm{~s}{ }^{4} \mathrm{P}_{3 / 2}$ & IS & \\
\hline $1199.48^{b}$ & 0.13 & 1199.55 & $\mathrm{~N} \mathrm{I}$ & $2 p^{3}{ }^{4} S_{3 / 2}$ & $3 \mathrm{~s}{ }^{4} \mathrm{P}_{1 / 2}$ & IS & \\
\hline 1193.19 & 0.11 & 1193.29 & Si II & $3 p^{2} \mathrm{P}_{1 / 2}$ & $3 \mathrm{p}^{2}{ }^{2} \mathrm{P}_{1 / 2}$ & & \\
\hline
\end{tabular}


M. Eriksson et al.: Emission lines in symbiotic stars, Online Material p 21

Table 16. continued.

\begin{tabular}{|c|c|c|c|c|c|c|c|}
\hline$\lambda_{\text {obs }}$ & $\mathrm{ekv}^{i}$ & $\lambda_{\text {id }}$ & spec. & Lower level & Upper level & shift & rem \\
\hline $1190.29^{b}$ & 0.14 & 1190.42 & Si II & $3 \mathrm{p}^{2} \mathrm{P}_{1 / 2}$ & $3 \mathrm{p}^{2}{ }^{2} \mathrm{P}_{3 / 2}$ & & \\
\hline 1187.42 & 0.05 & 1187.42 & Co II & $3 d^{8} a^{3} F_{4}$ & $4 p v^{3} D_{3}$ & & \\
\hline 1134.96 & 0.18 & 1134.97 & N I & $2 p^{3}{ }^{4} S_{3 / 2}$ & $2 p^{4}{ }^{4} P_{5 / 2}$ & IS & \\
\hline \multirow[t]{2}{*}{1134.28} & 0.45 & 1134.42 & N I & $2 p^{3}{ }^{4} S_{3 / 2}$ & $2 p^{4}{ }^{4} P_{3 / 2}$ & IS & \\
\hline & & 4.17 & N I & $2 p^{3}{ }^{4} S_{3 / 2}$ & $2 p^{4}{ }^{4} P_{1 / 2}$ & IS & \\
\hline 1122.42 & 0.98 & & & & & & \\
\hline 1110.10 & 0.19 & 1110.28 & Fe II & $4 \mathrm{~s} \mathrm{a}^{6} \mathrm{D}_{9 / 2}$ & $\left({ }^{5} \mathrm{D}\right) 5 \mathrm{p}{ }^{6} \mathrm{~F}_{9 / 2}$ & & \\
\hline 1108.45 & 0.66 & 1108.51 & Fe II & $3 d^{7} a^{4} F_{3 / 2}$ & $4 \mathrm{pu}^{4} \mathrm{~F}_{3 / 2}$ & $\mathrm{bl}$ & \\
\hline 1094.06 & 0.28 & 1094.08 & Fe II & $3 d^{7} a^{4} F_{7 / 2}$ & $\left({ }^{4} \mathrm{D}\right) 4 \mathrm{~s} 4 \mathrm{p}{ }^{6} \mathrm{D}_{5 / 2}$ & & \\
\hline 1092.37 & 0.44 & & & & & & \\
\hline 1078.97 & 0.31 & & & & & & \\
\hline 1077.34 & 0.58 & & & & & & \\
\hline 1064.63 & 0.25 & & & & & & \\
\hline 1063.11 & 0.59 & 1063.18 & Fe II & $4 s a^{6} D_{9 / 2}$ & $\left({ }^{4} \mathrm{D}\right) 4 \mathrm{~s} 4 \mathrm{p}{ }^{6} \mathrm{D}_{9 / 2}$ & $\mathrm{bl}$ & \\
\hline 1051.15 & 0.38 & & & & & & \\
\hline 1049.50 & 0.59 & & & & & & \\
\hline 1040.31 & 0.13 & & & & & & \\
\hline 1039.17 & 0.15 & 1039.23 & O I & $2 \mathrm{p}^{4}{ }^{3} \mathrm{P}_{2}$ & $2 p^{3}\left({ }^{4} S\right) 4 s^{3} S_{1}$ & IS & \\
\hline 1038.62 & 0.11 & & & & & & \\
\hline 1038.09 & 0.15 & & & & & & \\
\hline 1014.33 & 0.14 & & & & & & \\
\hline 1012.90 & 0.40 & & & & & & \\
\hline 1009.76 & 0.15 & & & & & & \\
\hline 1008.53 & 0.28 & & & & & & \\
\hline 974.06 & 0.10 & 974.07 & O I & $2 p^{4}{ }^{3} \mathrm{P}_{2}$ & $\left({ }^{2} \mathrm{D}\right) 3 \mathrm{~s}{ }^{1} \mathrm{D}_{2}$ & IS & \\
\hline 973.22 & 0.10 & 973.23 & O I & $2 \mathrm{p}^{4}{ }^{3} \mathrm{P}_{1}$ & $\left({ }^{4} S\right) 4 d^{3} D_{2}$ & & \\
\hline
\end{tabular}

${ }^{i}$ Equivalent width measured in $\AA$. 